九州大学学術情報リポジトリ

Kyushu University Institutional Repository

\title{
Chemische Untersuchungen Ueber Das Glukomannan Aus "Konjak"
}

Nishida, Kitsuji

Forestry Laboratory, Department of Agriculture, Kyusyu Imperial University

Hashima, Hideo

Forestry Laboratory, Department of Agriculture, Kyusyu Imperial University

https://doi.org/10.5109/22557

出版情報 : 九州大学大学院農学研究院紀要. 2 (10)，pp.277-360，1930-05. Kyushu Imperial University

バージョン:

権利関係 : 
Journal of the Iepartment is Agriculture, Kyushu İmererial Üniversity, Vol. 2 , No. Io.

May 20, 19,30 .

\section{CIIEMISCHE UNTERSUCHUNGEN UEBER DAS \\ GLUKOMANNAN AUS "KONJAK"}

Kitsuji Nismoda und Hideo Hashima

INHALTSVERZEICINIS

Einleitung

I KAP'ITEL

Darstellung von Gilukomasmat)

Fxperimentelles

1)arstellung des GInkommmans

Verfaliren - A

Verfahren - 13

II. KAIITFI,

Iydrolyse des Glukomatnans

Fixperimentelles

llydrolyse des (ilukomannans mit hochkomz. Salzsiure

(I) Ifydrolyse mit Salzsäurc yon spez. Gew. 1,2I

(II) 1Iydrolyse mil Salzsäure vom spe\%. Gew, 1,21

(III) IIydrolyse mit Salzsäurc vom spez. (iew. 1,223

(IV) Hydrolyse mit Salzsäure som spez. Gew. 1,23

Ifydrolyse des Glukommans mit verdihnter Salz. urd Schwefelsätuc

(v) Hydrolyse mit ro \% iger Salzsïume

(VI) Ifydrolyse mit $5 \%$ iger Salzsäure

(VII) Hydrolyse nit $2 \%$ iger Salzsïure

(VIII) IIydrolyse nit 10 \% iger Schwefelsäurc

(IX) Hydrolyse unit $5 \%$ iger Schwefelsäurc

(X) Ilydinlyse mit $2 \%$ iger Schwefelsäure

(XI) Hydrolyse mil $2 \%$ iger Silzsäure

(XII) Ifydrolyse nit I \% iger Salzsäure 
(XII) Iydrolyse mit $5 \%$ iger Schwefelsäute

(XIV) Hydrolyse mit $2 \%$ iger Schwefelsäure

(XV) IIydrolyse mit $2 \%$ iger Salzsiure

III. KAI'ITHL

Acetylierung des Glukomannaus

Experimentelles

(I) Acetylierung mit Essignturcanhydrit bej Gegenwart vent l'yridin

(II) Acetylierung mit Fssigsäure:unhydrict bei Gegenwart von Zinnchlorid

(IJI) Acetylierung mit Essigsäureanhydrid bei (jegenwart von Zinkchlorid

(IV) Acetylienıng mit Fssigsäureanhydrid clurch die Verwendung. vom Sulfurylchlorid als Katalysator

IV. KAPITEL

Acetolyse des Glukomannans

Experimentelles.

Acetolyse des Glukomannans

Verseifung des Acetates

(I) Mit 13arytlauge

(II) Mit methylalkoholischem Ammoniak

Iydrolyse der Glukomannotriose

Hydrolyse des Disaccharids (A)

Hydrolyse des Disaccharids (B)

v. KAPITEL

Methylierung des Glukomannans

Experimentelles:

Methylicrung des Glukomatrman:

Spaltung des Methylglukomannans

Verseifung und Oxydation der Fraktionen

$$
\text { vi, KAPITTI. }
$$

Konstitution des Glukomannans

Experimentelles

Spaltung eler Hendekancely]glukomannitriose

Vethylierung der I Jexosencciatc

Verseifung des Sirups

\section{EINLEITLNG}

Mannan findet sich sehr zahlreich in den Pflanzen und zwar meist in gewissen Zellwandungen als Gerüstmannan unci in den Samen, Blättern, Knollen und Wurzeln als Reservemannan. Tollens' und seine Mitarbeiter wiesen Mannan in Picea excelsa Lk., Bertrañ ${ }^{2}$ in 12 Koniferen

I Ber. r. Deutsch. Chem. Ges. 23. 2990 (1890); 7tschr, f. angew. Chem. 5. I55 (16)2); Ann. d. Chem, 267. 349 (1892).

$=$ Comp. Rend. I29. 1027 (189g). 
nach. Wie diese Forscher so fand auch Scnorgen ${ }^{3}$ das Gerüstmannan iu $\mathrm{Holz}$ von 22 verschiedcnen Gymnospermen, aber in keiner von sechs untersuchten Angiospermen. Achnliche Angaben liegen auch von DORE ${ }^{4}$ und anderen Forschern', gegenteilige Befunde aber von KoENia: und Beckke vor. Es findet sich im Johannisbrotsamen, in der Steinnuss aus Phytelephas', in Mehl und in der Kleic von Weizen und Gerste, in der $\mathrm{Hefe}^{\mathrm{io}}$, im Salepschicin ${ }^{11}$, in den Blättern und Knollen des Amorphophallus Konjac C. Koch' (Syn. Conophalhts Konjok Schott.), Cetraria islandicat ${ }^{13}$, Mutterkorn ${ }^{14}$, Penicillizm glaumm ${ }^{15}$, im Samen von Diospyros Kakiri, in Orchideenknollen', und zahlreichen anderen Wur\%elarten ${ }^{18}$ mehr.

3 Ind. Eng. Chem. o. 748 (1917)

4 Elicnda, r2. 473,477 u. 984 (1920).

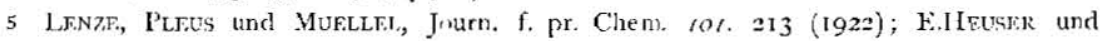
W. Dammer., Cell. 5.45 (I924).

5 Zischr. f. angew. Chem. 32, 155 (1919).

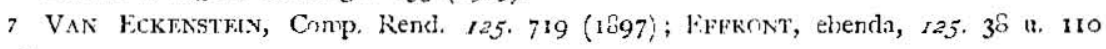
$(1697)$

8 Rriss, Ber. d. Deutsch. Chem. Ges. 22. 609 (1009); Schulze, ebenda 22. Ir9? (1889) und 24. 2277 (I891); Ztschr. f. phisin. Chem. 14. 227(1890); BERTRAxr, Chem. Ztg. 16. 1156 (1892); Lifinand, Comp. Rend. 1.35. 593 (1902); Horton, Ind. Fng. Chem. 1.2. 1040 (I921); Scimint und Gaumann, Tier. d. Deutsch. Chem. Ges. 5\%. I560 (1921); l'attergon, Journ. Clien. Sonc. 123. 1139 (t923).

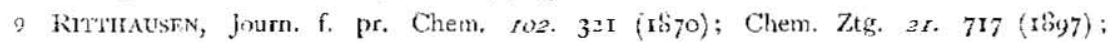
Enfront, Comp. Rend. 125. 38 u. I $10(1 \% 97)$.

so Hrssinlani), Ztschr. Ver. Deutsch. Zuckerind, f2. 671 (1692); Koflis, Zischr. f. phisio. Chem. 29. 429 (Igoo); Wuomijwskr, Journ. f. pr. Chem. (II) 64. 1 (Igor).

11 Gavs und Tolievs, Ber. d. Deutsch. Chem. Ges. 21. $215^{\circ}$ (1886); Ann. d. Chem. 2.p9. 251 (1888); Fiscrite und Hmscmakcik, Ber. d. Deutsch. Chem. Ges. 22. 365 1. 368 (1869);

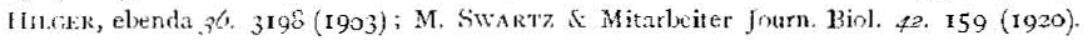

12 Tsujl. Journ. Coll. Agr. 'likyo Imp. Univ. 2. IC4 (1S94-1867); Kinoshrta, ebenda 205 (1894-1897); Tsukamoto, elsenda 2. 406 (1894-1897); M. SAwAmura, elonda 5. 155 и. 453 (1902); Muf. \& M. Gatin, Bull. d. Sei. Pharmacol. $1 \%$. 447 (1905); MAYfdA, Mit. d. med. Ges. 2. Tokyc 25. 12 u. 46 (I911): 2S. $6\left(\mathrm{rg}_{4}\right)$ : 2\%. 57 (I915): 34. 14 u. 20 (1920): Phisis. Lntersuch. von Knnjals-Mannan, Diss. Tokyn (I922); Goro, Journ. Binchem. (Japan) 2. 201 (1922) ; S. MiYake, Journ. Coll. Agr. IInkkaido Imp. Univ. Sapporo 77. 163 (1927).

I3 IIFse, Journ. f. pr. Chem. (II) 9.7. 227 (1916); KAkRFR und Joos, Ztschr. phisin. Chem. I.fI. 3II (1924).

${ }_{4}$ Voswinkta, Ber d. Deutsch. Chem. Ges. 24. 906 (1891); Chcm. Zentralbl. 650 (1894); KRuskal, elenda, $r \cdot 37$ I (1992).

15 Zanotrt, Chem. Zentralbi. r. I 2 Io (1899).

16 I.olw und Isirif, Iand. Versuchsstation $.75 \cdot 435$ (1899).

17 Ireksssty, Comp. Rend. 137. 721 (1902).

18 Chem. Zentralb). (2) 1049) (1894); I155 (1902): Chem. 7tg. 27. 24I (1903). 
Mannane sind als Anhydride oder anhydrige Polymerisationsprodukte der Mannose verbreitet und enthalten häufig auch noch analoge Anhydrick anderer Zuckerarten (Glukose, Galaktose, Pentuse und Methylpentose ?) beigemengt oder chemisch gebuncien.

Mannan. Diese uns bereits etwas bekannten Stoffe liefern bci der Hydrolyse nur Mannose. PATresson ${ }^{19}$ stellte für sein mittels $20 \%$ iger Lauge extrahiertes Mannan von lagua-Palm fest, dass es nur aus Mamnose zusammengesetzt ist. $\left[\mathrm{C}_{6} \mathrm{H}_{\mathrm{ro}} \mathrm{O}_{5}\right]_{x}$, wcisse, amorphe Masse, in schwach alkalischer Lösung starke Rechtsdrehung $[\alpha]_{1 \prime}=(+) 283,7^{\circ}$ bis (+) $287,6^{\circ}$, in Wasser unter Aufquellen etwas löslich, in starkem Alkohol unlöslich, leicht in Alkslien löslich, nicht reduzierend, verbindet sich nicht mit Phenylhydraxin, und gibt bei der Oxyclation d-Manuozuckersäure. Bein Kochen mit Fehlingscher Lösung entsteht ähnlich wie bei Dextran ein Niederschlag, eine in trockenem Zustande grüne Kupferverbindung darstellend $\left[\left(\mathrm{C}_{5} \mathrm{H}_{10} \mathrm{O}_{5}\right)_{2} \mathrm{CuO}+\mathrm{H}_{2} \mathrm{O}\right]_{x}(?)$. Bleiessig fällt aus der alkalischen Lösung dic Verbindung $\left[\left(\mathrm{C}_{6} \mathrm{H}_{10} \mathrm{O}_{5}\right)_{2} \mathrm{l}^{\mathrm{bO}}+\mathrm{H}_{2} \mathrm{O}\right]_{n}$ (?), zcrsetzliche wasserlösliche Masse, aus. Das Trinitrat $\left[\mathrm{C}_{6} \mathrm{H}_{7}\left(\mathrm{NO}_{2}\right)_{3} \mathrm{O}_{5}\right]_{x}$ ist weiss, wasserunlöslich, durch $\mathrm{Kali}$ leicht und unzersetzt verseifbar.

Es liess sich, wenn auch schwierig, in ein Triacetat $\left[\mathrm{C}_{6} \mathrm{I}_{7} \mathrm{O}_{5}\left(\mathrm{COCH}_{3}\right)_{3}\right]_{x}$ überführen. Durch Methylierung des Mannans mit Dimethylsulfat und Alkali entstand ein Produkt, dessen Methoxylgehalt annähernd dem eines Trimethylmannans entsprach $\left(42,6 \% \mathrm{OCH}_{3}\right)$. Damit vorgenommene Molekulargewiclutsbestimmungen lehrten, dass die Verbindung cine recht hochmolekulare oder hoch assozierte scin muss. Dersclbe Schluss dürfte daher auch für das freic Mannan selbst gezogen werden.

Galakto-Maman ${ }^{23}$. Wenig bekannte Stoffe, die durch Hydrolyse in Galaktose und Mannose zerfallen.

Frukto-Mannan ${ }^{22}$. Noch selten dargestelite IIexosane, die durch Hyclrolyse Fruktose and Mannose liefern.

19) Journ. Chem. Sirc. 12.3 .31139 (1923).

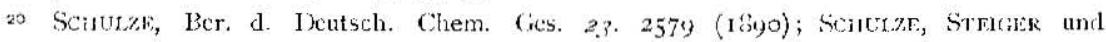

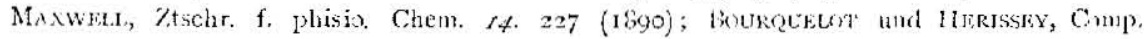

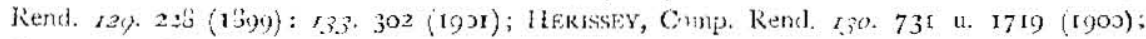

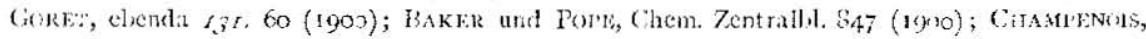

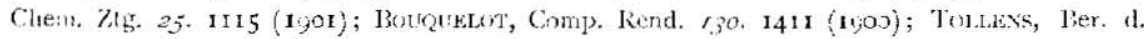
Joufsch. Chen. Ges 30. 2190 (1906) Hrass, Joum. f. pr. Chem. $9 \%$ 227 (I916); l. Karkak und J3. Joos, Ztschr. f. phisio. Chem. 171. 311 (1924).

${ }^{21}$ Journ Chem. Six. 77. 67ó (I900); Mryake, Journ. Coll. Agr. IInkkaido Imp. Univ. Sappono $77 \cdot 163(1927)$. 
Ciluko-Mannan ${ }^{22}$. Fs findet hauptsächlich in den Knollen der japanischen Pflanze, Amorphopluallus Kanjac C. Koch (Syn. Conophallus Konjak Schott.) und in den Samen von Ruscus aculeatus u. a. m.

Das Konjak-Mannan ist neuerdings durch M. MAYEDA ${ }^{23}$ ctwas eingehender untersucht worden. Unter zahlreichen Bakterien liessen sich einige Mesentericusarten (z. B. Bacillns mesentericus oulgatus) finden, die das Mannan verflüssigen. 1)abei hat MAYwoA die Bildung eines Trisaccharids "Iävidlin," festgestellt, das er aber bisher nur amorph crhalten konnte und von dem es ihm nicht gelang die kristallisicrten Derivate darzustellen. MAYEDA fülrte weiter die Ilydrolyse des Mannans durch und fand Mannose und Glukose im Verhältnis von 2:1. Goro\%4 stelite für Konjak-Mannan fest, dass es aus fünf Molekülen Mannose und zwei Molekülen Glukose zusammengeset»t ist. Ueber die Verflüssigung des Kunjak-Mannans (z. B. durch Malzdiastase, Kashiwagidiastase, Takadiastase, Digestin, Excenzym und Indoenzym von Aspergillus niger und durch den Bacillus mesentericus oulgatus) wie sie MAVEDA gelang, liegt auch noch eine andere Arbeit von S. Miyaks:25 vor. Lis wies also Mannose, Glukose und Fruktose in cler mit I \% igrer Salzsäure 2j Standen lang hydrolysierten Mamanlösung nach und behauptete, dass das Konjak-Mannan aus diesen Hexosen in Verhältnis von 3:2:I besteht.

\section{KAPITET.}

\section{IDARSTELLUNG VON GLLKOMANNAN}

Nach den oben wierlergegebenen Mitteilungen liefert also das Konjak-Mannan mach seinen verschiecenen Lutersuchungen bei der Hydrolyse Irei Zuckeraten, Glukose, Mannose und Fruktose in verschiedenen Verhaltnissen, nänlich von $1: 2: 0,2: 5: 0$ und $2: 3:$ I. Dicse Ergcbnisse wurden zur Ursache der Annahme für eine Uneinheitlichkeit in der Zusammensetzung des Mannans. Keiner der verschiecienen Autoren hat bisher rcines Vannan in den Händen gehabt. Dabei ist Mannan, wie wir wissen, von ihnen durch nachfolgendes Verfahren isoliert worlen.

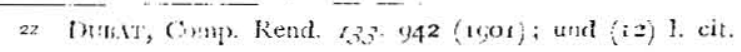

23 Mit. d. med. (ies. z. Tokyo 35.12 u. 46 (1911): 2\$. 6 (19:4): 29. 57 (1915): 37. 14 u. 20 (1920): Phisis. (intersuch. von Konjak Mannan, 1)iss. Tokyo (1922).

24 Journ. Mikcliem. (Japrn) 2. 201 (1922),

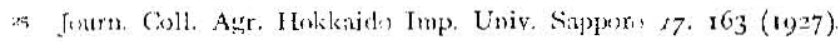


a) Das Maytend'sche Verfahren ${ }^{23}$. MAYEDA wiederholte die Extraktion von Konjakpulver mit warmem Alkohol und zwar so lange bis er das Vorhandensein von Redulitionsprodukten im Extrakt nicht mehr nachweiscn konnte. Dann löste cr das Pulver in Wasser zu kolloidaler Iösung und filtrierte. Dabei kann man ein klares Filtrat gewinnen. Darauf fügte er das gleiche Volumen $95 \%$ igen Alkohols hinzu, liess das Konjak-Mannan niederschlagen und sog ab, dann spülte er den Niederschlag mit $50 \%$ igem Alkohol aus. Das durch dieses dreimal wiederholte Verfahren gewomnene Mannan wurde nit Alkohol und Aether getrocknet und ergab ein weisses Pulver.

b) Das Goro ${ }^{24}-$ MrYake'sche $^{25}$ Verfahren. Konjakpulver wurde mit Wasser gekocht, hierzu Pankreatiniösung und Toluol hinzugefügt und die Lösung auf $35^{\circ} \mathrm{C}$. gehalten. Nach der Verzuckerung wurde die Lösung öfters durch ein Filtrierpapier abfiltriert und zwar so lange, bis eine klare Lösung gewonnen wurde, worauf $1 / 3$ des Volumens an $95 \%$ igem Alkohol hinzugefügt wurde. Das Mannan wurde nochmals in heissem Wasser aufgelöst unel wieder mit Alkohol zum Gerinnen gebracht. Das gewonncne Mannan wurde durch ein Linnenfilter abgesogen und nachher mit $50 \%$ igem, $95 \%$ igem und absolutem Alkohol und Aether gewaschen. Nach dem Trocknen in Vakuum über Schwefelsäure ergab sich ein weisses, amorphes Pulver.

Betrachtet man diese verschiedenen Verfahren, so sind sic doch offensichtlich unbefriedigend: Mannan kann durch kochendes Wasser oder durch Enzyme verflüssigt und durch Alkohol als Aufschlämmung ausgefällt werden, aber es enthält dann noch als Verumreinigungen, z. B. Inulin, Pektinstoffe, Galaktan, Fruktan, Xylan und Araban u. a. m. So hergestelltes Mannan ist durchaus kein reines Produkt, es müsste daher von diesen Begleitstoffen isolicrt werden.

Die Zusammensetzung des Konjakpulvers ist die folgende ${ }^{25}$ :

\begin{tabular}{|c|c|c|c|}
\hline Wasser & $\mathbf{1 7 , 7 6 \%} \%$ & Stickstoffreie Extraktstolfe & $74,36 \%$ \\
\hline Rohle's Eiweiss & $2,56 \%$ & Stärke & 1,49 in \\
\hline Rohics Fett & $0,13 \%$ & Mamnan & $64,7^{8} \%$ \\
\hline Roler Zellstoft & $\mathrm{I}, 43 \%$ & Reduzierender Zucker & $1,61 \%$ \\
\hline Kolie Asche & $3,76 \%$ & & \\
\hline
\end{tabular}


Es ist demnach also vor allen Dingen wichtigs, zur Gewinnung grösserer Mengen von Mannan in reinem Zustande ein Verfahren zu seiner Reinigung auszuarbeiten, insbesondere ein Verfahren des Abbaus durchzuführen und auch in der Frage des Verhältnisses der hydrolysicrten Zuckermenge ordnungsgemäss vorzugehen.

Salkowsk ${ }^{26}$ hat diese Ansicht für Xylan durch cine Reihe von Versuchen zu verbessern gesucht: seine Methode besteht darin, dass man das Stroh mit $6 \%$ iger Natronlauge zum Sieden erhitzt und den Aus\%ug mit Fehlingscher Lösung versetzt, wodurch das Xylan als Kupferxylan abgesclieden wird. Diese Adsorptionsverbindung zerlegt man mit Sal\%säure, filtriert das Xylan ab, wäscht es mit Alkolol und Aether aus und trocknct es vorsichtig auf dem Wasserbade. Hierbei zeigte sich nun, dass nach dieser Methode aus Weizenstrolı dargestelltes Produlst im besten Falle nur so viel Furfurol ergab, ais 80 \% des Ausgangsmaterials an Xylan entspricht, bei cinem Aschenwert von $2,5-4,0,0$.

HEUSER $^{27}$ hat die Strohzcllstoff $A$ blatuge als Ausgangsmaterial mit Alkohol extrahiert und untersuchte weiter auch durch Ausfälen des in Natronlauge wiedergelösten Produktes mit Fehlingscher Lösung und dann durch Behandeln mit Alkohol und Salzsäure den Reinheitsgrad les Xylans wesentlicl zu erhöhen. Die Asche konnte er auf dem langwierigen Wege der Dialyse von $2-3 \%$ auf $0,7 \%$ vermindern. Dabei verwenclete aber auch er an Stelle der wässerigen Salzsäure gasförmigen Chlorwasserstoft zun Zersetzen des Kupferxylans, demgenäss das Produlst nur noch wenig Asche, nämlich im Mittel o,35 \% á enthielt. Sein Xylangehalt betrug $9^{5} \%$, bezogen auf absolut trockne und aschefreic: Substan\%. Er versuchte dan die Fehlingsche Jösung durch eine andere Metallsalzlösungr zu ersetzen, nämlich durch die Anwendung von Ferrosulfat als Fällungsmittel zu arbciten, doch erhielt er ein Rohprodukt, dessen Wort für Xylan hinter dem des ersten Produktes um einige P'rozente zurückblieb.

KARKFR ${ }^{28}$ und seine Mitarbeiter fanden, dass das Galaktomannan sich in heissem Wasser, leichter noch in verdünnter Lauge aulöst und durch Fehlinglösung claraus als Kupferverbindung gefallt werden kann.

Als günstiges Ausgangsmaterial für Glukomannan haben sich dic

25 Zischr, phisio. Cheme. if. 35 u. 240 (1901).

27 Journ. f. pr. Chem. so3. $\delta_{j}(1921+1922)$.

26 P. KARR and B. Joks, unveröffentlich : P. K.AkkEk, Polymere Kohlenhydrate, S. 268 (1925), Icipzis, 
Konjakknollen erwiesen, besonders in Form des Pulvers, wie sic in grossem Massstabe auf dem Markt verkauft werden. Setzt man dem pulverisicrten Konjakmannan grenügend viel Wasser unter Umrühren zu, so erhält man das Produkt in kolloidaler Form. Durch Lirhitzen mit Waseer unter Druck (I-I,5 Atm.) im Autoklaven wird das Konjakmamnan verfüssigt und man gewinnt dann durcli Absaugen ein klares, hellgelbes Filtrat, aus dem durch Fehlingsche Losung das schön blau gefarbte, voluminöse Kupfermannan ausgefallt wird. Mit alkcholischer Salzö̈ure zerlegt man diese Aufschlämmung, filtriert das erzeugte GIukomannan ab, wäscht es mit Alkohol und Aether und trocknet es im Vakuum auf Phosphorsaureanhydrid. Das Produkt ist eine feinpulverige, reinweisse Masse, dic mit Jod nicht mehr blau färbt uncl Fehlingsche Iösung nicht mehr recluziert.

Die Ausbeute an Glukomannan und dessen $A$ schengehalt sind sehr schwankend :

\begin{tabular}{|c|c|c|}
\hline Nr. & Ausberte & Aschengehalt \\
\hline $\mathbf{I}$ & $47,4 \times \%$ & $0,40 \%$ \\
\hline 2 & $43,62 \%$ & $0,20 \%$ \\
\hline 3 & $67,7=\%$ & $0,10 \%$ \\
\hline 4 & $65,59 \%$ & $0,19 \%$ \\
\hline 5 & $64,06 \%$ & $0,45 \%$ \\
\hline 6 & $62,65 \%$ & $0,3=\%$ \\
\hline$i$ & $57,66 \%$ & $0,3=\%$ \\
\hline
\end{tabular}

Dic von verschice' 'nen "orscleen hergestellten Produkte enthielten nachoolgenden Aschengehax't.

\begin{tabular}{|c|c|c|}
\hline Forticler & Arien des, vluki, : & Aschengehalt \\
\hline SALKONGKI & Xylan & $2,20-3,93 \%$ \\
\hline ", & $"$ (Nacle der Iyalyse) & $0,68-\mathrm{r}, 44 \%$ \\
\hline L. IIFAl:k & " & $0,25-0,34 \%$ \\
\hline S. MYYAKE & Konjakmanuan (Fruktoglakonannan) & $6,+1 \%$ \\
\hline K. Corpo & Kinjakimaman (Glukomannan) & $0,12 \%$ \\
\hline K. Nisinits & Konjakmasnan (Ghukemsanuan) & $0,1 \mathrm{I}-0,47 ?$ \\
\hline
\end{tabular}

Das durch oben geschriebene Verfahren gewonnene Glukomanna: bestcht aus Mannose und Glukose, während dic Reaktion auf Fruktose negativ ausfiel. Besonders interessant ist hier, dass das Glukomannan 
aus Konjakpulver durch das Auskochen mit Wasser unter Druck im Autoklaven nicht in sciner ursprünglichen, sondern in einer bereits chemisch veranderten Form crhalten wird, was äusserlich daran zu erkennen ist, dass die Bestandteile des ursprünglichen Konjakmannans Mannose, Glukose und dazu Fruktose oder nur Mannose und Glukose sind. Is war also eine Verflüssigung durch Enzyme und Bakterien erfolderlich, um Ausblicke auf dieses Ziel zu erreichen.

Hierzu verwendet man Io \% ige Pankreatin-Lösung mit Toluol, welche de:m Konjakpulver zugefügt werden und mit welchen es $\mathrm{jm}$ Thermostaten auf $35^{\circ} \mathrm{C}$. erwämt und in zwei Wochen verflissigt wird. Die kolloidale Flüssigkeit wurde wie vorher behandelt. Nach dem Trocknen ergab sich ebenfalls ein weisses, lockeres Pulver. Die Ausbeute betrïgt $57 \%$, der Aschengehalt $0,47 \%$. Darin sehen wir cine weitere, vollkommene Analogic zwischen diescn durch beide Verfahren gewonncne Glukomannanarten.

\section{EXPERTMENTELLES}

\section{Daksteillung Des GlukomanxaNs}

Verfaluren-1. 20-40 gr pulverisierte Konjakknollen wurden mit 2-4 Litem Wasser ubergossen, in denen sie sich nach guter Mischung duch die Turbine kolloidal lösten. Darauf wurden sie im Autoklaven erhitzt und 3 Stunden bei $120^{\circ}-125^{\circ} \mathrm{C}$. I-I,5 Atm gehalten. Nach dem Irkalten wurden 2-3 Liter Wasser zusetzt und von deni Rückstand über weissem Hanfgewebe abgenutscht. Das durchgelaufene Jiltrat wurde nochmals rlurch cin Seidentuch sorgfältig abfiltriert. So wurde ein klares, hellgelbes Filtrat erhalten. $Z u$ den etwa 2 I itern Filtrat wurde nun unter Umrïhren cin Jiter Fehlinguche Lösung hinzugefügt. Die schön blan gefarbte, voluminöse Fällang wurde auf weissen Hanfgewebe abfiltriert und dann je dreimal mit $500 \mathrm{ccm} 50 \%$ igem Alkohol und nachher nochmals mit $85 \%$ igen Alkohol gewaschen. Darauf wurde die Kupfermannanverbindung in einen Erkenmeyerkolben mit $300 \mathrm{ccm} 95 \%$ igem Alkohol gebracht, darin mit $300 \mathrm{ccm}$ kalter 2 \% iger alkoholischer Salzsäure übergossen. Dieses Verfahren wurde so oft wierlerholt, bis die Farbe der Aufschlammung uber Grün und Gelb in Reinveiss uberging. llierzu waren 5-6 Stunden, 3-4 Mal Auswaschung mit 2 \% iger alkoholischer Salzsäure erforderlich.

Der von Kupfer befreite Niederschlag wurde nunmehr abgenutscht und die Salzäure mit $50 \%$ igem und mit $85 \%$ igem Alkohol aus- 
gewaschen, bis der Waschalkohol mit Silbernitrat nicht melnr reagierte. Das scharf abgenutschte Material wurde über Nacht unter $9^{6} \% \mathrm{igem}$ Alkohol, den wir mehrmals erneuerten, gestellt und dann in Aether aufbewahrt. Nach Abgiessen des Aethers und Trocknen im Vakuum auf Phosphorsäureanhydrid ergab sich ein weisses, lockeres Pulver, das mit Jod keine Blaufärbung mehr zeigte und Fehlingsche Lösung nicht mehr reduzierte.

Verfahren-B. $20 \mathrm{gr}$ Konjakpulver wurden nit 2 I.itern Wasser unter Unrühren übergossen und einc halbe Stunde über einer freien Flamme gekocht, dann auf $35^{\circ} \mathrm{C}$. abgekühlt, bei dieser Temperatur im Thermostaten gehalten und larauf $20 \mathrm{ccm} 10 \%$ ige Pankreatin-Lösung und $40 \mathrm{ccm}$ Toluol zugesctzt. Die Lösung wurde ofter ungerührt, bis auf Jodzusatz kcine Spur von Blaufärbung festzustellen war und dic Menge reduzierenden Zuckers nicht mehr zunahm. Dann wurde dic kolloidale Lösung über wcissem I lanfgewebe von Rückstand abfiltriert, bis eine klare Iösung gewonnen wurde, clarauf mit I'elhlingscher Lösung umgefällt und weiter wie oben beschrieben verfahren. Ausbeute und Aschengehalt waren die folgenden:

\begin{tabular}{|c|c|c|c|c|c|c|c|c|c|}
\hline \multirow[b]{2}{*}{$\mathrm{Nr}$. } & \multirow[b]{2}{*}{$\underset{\mathbf{s} \mathbf{r}}{\text { Material }}$} & \multirow[b]{2}{*}{$\begin{array}{l}\text { Ver- } \\
\text { fabren }\end{array}$} & \multirow[b]{2}{*}{$\begin{array}{c}\text { Wasser. } \\
\text { gehalt } \\
\%\end{array}$} & \multicolumn{2}{|r|}{ Ausbeate } & \multirow[b]{2}{*}{$\%$} & \multicolumn{3}{|c|}{ Ascliengehalt } \\
\hline & & & & $\mathrm{gr}$ & $\begin{array}{c}\text { Wasser- } \\
\text { gehalt } \\
\%\end{array}$ & & $\begin{array}{l}\mathrm{I} \\
\%\end{array}$ & II & $\begin{array}{c}\mathrm{Im} \text { Mittel } \\
0_{0}^{\prime}\end{array}$ \\
\hline I & $20(1)$ & A & ${ }_{1} 8,63$ & 8,250 & 6,82 & $47,4 \mathrm{I}$ & 0,40 & 0,40 & 0,40 \\
\hline 2 & $20(\mathrm{I})$ & $A$ & $1 \%, 6_{3}$ & $7,640^{\circ}$ & 7,20 & 43,62 & 0,27 & 0,29 & 0,28 \\
\hline 3 & $20(11)$ & A & 16,03 & 12,3790 & 8,13 & $67,7^{2}$ & 0,11 & 0,10 & 0,10 \\
\hline 4 & 40 (II) & $A$ & 16,03 & $2_{3}, 837^{\prime \prime}$ & $7,5^{i}$ & 65,59 & $\mathrm{c}, \mathrm{I} 6$ & 0,23 & 0,19 \\
\hline 5 & $40(\mathrm{II})$ & $A$ & $16,0_{3}$ & 23,1826 & 6,00 & 64,80 & 0,49 & $0,4^{2}$ & 0,45 \\
\hline 6 & $40(11)$ & $A$ & 16,03 & 22,7057 & 7,32 & 62,65 & 0,32 & 0,32 & 0,32 \\
\hline 7 & $20(1)$ & $\mathrm{B}$ & 13,63 & 10,4166 & 9,92 & 57,66 & 0,43 & $0,4 \mathbf{I}$ & 0,42 \\
\hline
\end{tabular}

II. KAPITEI,

Hydorolyse des Glukomanxaxs

Wesentlich grösseres Interesse kommt nun der Zusammensetzung des durch das A-bezw. B-Verfahren hergestellten Mannans zu, dem 
Glukomannan oder Fruktoglukomannan, und weiter der Frage, ob sich darin Mannose, Glukose und auch noch Fruktose und in welchem Verhältnissc vorfinden. Ein geeigneter Weg zur Aufklärung dieser Fragen schicn uns nun die quantitativ durchgeführte Hydrolyse zu sein. Zum Verzuckern der höhcren Kohlenhydrate sincl von verschiedenen Forschern verschiedene Reagentien gesucht worden und als gccignetes Mittel dienen hochkonzentrierte Salzsäure und verdünnte Salz- und Schwefelsäure. Die Hydrolyse durch konz. Salzsäure verläuft in der Kalle vollständig und verdient wohl ausgedehntere Anwendung zur Untersuchung der polymeren Kohlenhydrate. WILsTAE1'ER und ZECIIEISTER $^{29}$ haben auf reine Baumwolle bei $1-2$ tagelange Einwirkung von Salzsäure vom sp Gew. 1,2I in der Kältc eine Ausbeute an Glukose erreicht, die von 106-107\% des Gewichts der Baumwolle, also 95-96\% der theoretisch an Glukose zu erwartenden beträgt.

Zur Ilydrolyse des Glukomannans verwendeten wir Salzsaure in 3 verschiedenen hohen Konzentrationen, nämlich vom spez. Gew. 1,21, I,223 und I,23. Dic Verzuclierung wurde so ausgefülrt, dass eine abgewogene Menge Glukomanman mit der auf $0^{\circ} \mathrm{C}$. abgekühiten Säure in einen Messkolben versetzt und unter häufigen Umschütteln die Temperatur während ${ }_{5}$ Minuten auf $0^{\circ} \mathrm{C}$ erhalten wurde. Das Glukomannan ging alsdann in einer Minute oder einigen wenigen Minuten ganz klar in Lösung. Zunächst wurcle es gelatiniert, dann entstand eine von Gasblasen etwas getrübte viskose Iösung, die in ciner Viertelstunde dünnflüssig wurde, wobei mit der Säure vom spez. Gew. I,23 die Iösung am raschesten erfolgte. I) Kolben liessen wir bei $15{ }^{\circ} \mathrm{C}$. in Schrank stehen. Nach zwei Tagen war die Lösung schon durch die abgeschiedenen Huminstoffe braun gefarbt. Die Zuckerbestimmung wurde durch die Methode von Berrianis als Glukose ausgefiilnt. Die folgenden Ergebnisse wurden erhaiten:

\begin{tabular}{|c|c|c|c|c|}
\hline & Probecntnalime & $\begin{array}{l}\text { Entstebende } \\
\text { Zuckermenge als } \\
\text { G]ukose }\end{array}$ & $\begin{array}{l}\text { Hydrolysiertes } \\
\text { Gilukomamnan }\end{array}$ & $\begin{array}{l}\text { Sp. Gew. der } \\
\text { Salzsiure }\end{array}$ \\
\hline $\begin{array}{l}\text { I. IJydrolyse von } \\
\text { Sulstanz }(A)\end{array}$ & Nach $8 \mathrm{St}$. & $\begin{array}{c}\% \\
79,93\end{array}$ & 719 & $\mathrm{I}, 2 \mathrm{I}$ \\
\hline$"$ & " 24, & 102,02 & $9 \mathbf{I}, 6 \mathbf{z}$ & " \\
\hline " & $" 30 "$ & 102,27 & 92,05 & " \\
\hline " & $" 4 \ddot{\circ}$, & $99,6 z$ & 89,66 & , \\
\hline
\end{tabular}




\begin{tabular}{|c|c|c|c|c|c|}
\hline $\begin{array}{l}\text { II. Hydrolyse vou } \\
\text { Substanz-(A) }\end{array}$ & Nacli & ; st. & $70,5^{6}$ & 71,61 & $\mathrm{I}, 2 \mathrm{I}$ \\
\hline " & $"$ & 24, & 98,59 & 80,74 & ", \\
\hline$"$ & $"$ & $30 "$ & 99,30 & $89,3^{3}$ & $"$ \\
\hline $\begin{array}{l}\text { III. Iyylrolyse von } \\
\text { Sulostanz }(\mathrm{A})\end{array}$ & Nach & $24 \mathrm{si}$. & $10 ;, 60$ & 97,75 & $I, \geq 2 j$ \\
\hline $\begin{array}{l}\text { IV. Hydrolyse von } \\
\text { Sulstanz-(I3) }\end{array}$ & Nach & $24 \mathrm{St}$. & $106,6 \mathrm{~J}$ & 95,95 & $\mathrm{I}, 23$ \\
\hline $\begin{array}{l}\text { 1V. Hydrolyse vou } \\
\text { Substanz (I3) }\end{array}$ & Nach & $24 \mathrm{St}$. & 104,48 & 93,97 & 1,23 \\
\hline
\end{tabular}

Aus diesen Versuchen geht also hervor, dass die Verzuclerungr des Glukomannans in 24 Stunden ihrer Ende creicht und schwankende Zuckermengen, nämlich zwischen 102-108 \% vom Gewicht des Glukomannans (theoretisch 1 I I, $\%, 6$ ) ergibt. Dic Frage der quantitativen Iydrolyse des Glukomannans ist dadurch gelöst und wir halten damit die vollkommene Analogie zwischen Cellulose ${ }^{2 ;}, X^{3}$ Xylan ${ }^{30}$ und Glukomannans als erwiesen.

Un die Verzuckerung mittels hochkonzentrierter Salzsäure durch dic IIydrolyse mit verclünnter Salz- und Schwefelsäure vergleichen zu konnen, haben wir das Glukomannan durch Erhitzen mit to \% igen, $5 \%$ igen und $2 \%$ iggen Lösungen beider Säuren aufgespalten. $\mathrm{Zu}$ jedem Versuche wurden 0,5 gr absolut trockenen und aschefieien Glukomannaus mit drei verschiedenen Säure-Konzentrationen in $\mathbf{I} \%$ iger Lösung hydrolysiert und, wic im experimentellen Teil beschrieben, nacheinander bestimmte Zcit in kochencle Wasserbade gchalten. Dic Bestimmung des Zuckers in der Iösung geschah nach BerTinsin durch Doppelprolen wie in den bisherigen Versuchen. IDie folgenden Ergebnisse und Kurven wurden erhalten:

Bei I Iydrolyse (V) mit $10 \%$ iger Saizsaure wurde nach 40 Minuten der maximale Reduktionswert rhalten, d. h. es wurden $92 \%$ Glukomannan in Zucker verwandelt. Bercits nach 1 Stunde wurde die ganze Substanz hyclrolysiert und nach it Stunden trat tcilweise Verkohlung ein, die nach \& Stunchen so weit vorgeschnitten war, dass sich dunkelbraune lluminstoffe abschieden.

Nach Io Stunden der Hydrolyse (VI) mit $5 \%$ iger Salzsäture wurde der IIöchstzuckerwert, der $9^{8} \%$ vom Gewicht des Glukomannans, also $88 \%$ der theoretisch an Zucker zu erwartenden Menge betrug,

x) Rer. (l. Dectseli. Chem. (ies. 46. 2401 (19r3)

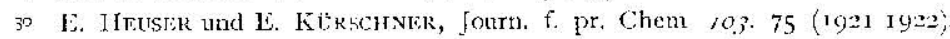




\begin{tabular}{|c|c|c|c|c|c|c|c|c|c|}
\hline \multirow{3}{*}{ 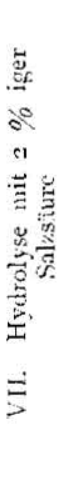 } & 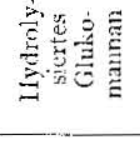 & $0_{0}^{m}=8$ & 范 & $\frac{3}{+2}$ & $\begin{array}{l}\infty \\
i n \\
2 \hat{0} \\
c 0\end{array}$ & 总 & $\begin{array}{l}2 \\
5 \\
5\end{array}$ & $\begin{array}{l}g \\
\dot{S} \\
0 \\
0\end{array}$ & \\
\hline & 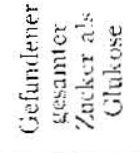 & $10 \%$ & 8 & 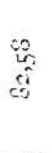 & \begin{tabular}{l}
00 \\
0 \\
\multirow{2}{*}{}
\end{tabular} & $\begin{array}{l}\text { 点 } \\
5\end{array}$ & \begin{tabular}{l}
0 \\
0 \\
05 \\
0.5 \\
\hdashline
\end{tabular} & 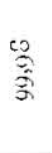 & \\
\hline & है & 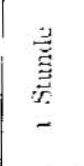 & 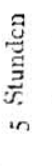 & 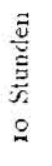 & 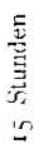 & 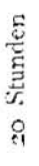 & 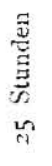 & 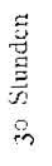 & \\
\hline 尊 & 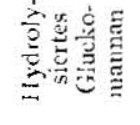 & $20 \frac{0}{2}$ & $\begin{array}{l}\text { 令 } \\
\vdots \\
\text { n. }\end{array}$ & $\begin{array}{l}0 \\
0 \\
0 \\
0 \\
0 \\
0\end{array}$ & $\begin{array}{c}\dot{3} \\
\text { ch } \\
00\end{array}$ & 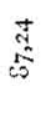 & 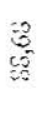 & 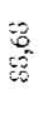 & कै \\
\hline 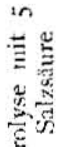 & 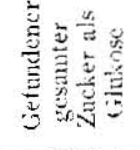 & $a_{0}^{8} 8$ & $\begin{array}{l}\stackrel{8}{\circ} \\
\stackrel{\text { :ै }}{0}\end{array}$ & 足 & 兽 & Зू & 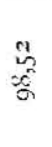 & 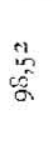 & אू \\
\hline 5 & 胥 & 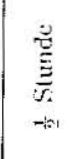 & 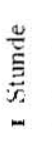 & 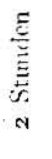 & 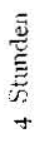 & 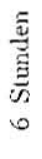 & 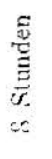 & 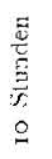 & 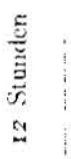 \\
\hline$\frac{5}{8}$ & 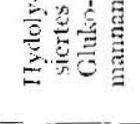 & 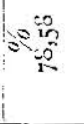 & 管 & 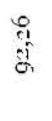 & $\begin{array}{l}\text { o } \\
\text { ii }\end{array}$ & $\begin{array}{l}0 \\
0 \\
06 \\
06\end{array}$ & $\begin{array}{l}8 \\
8 \\
8\end{array}$ & $\begin{array}{l}4 \\
0 \\
0 \\
0\end{array}$ & $\begin{array}{l}\overrightarrow{0} \\
\text { ô } \\
\text { co }\end{array}$ \\
\hline 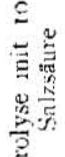 & 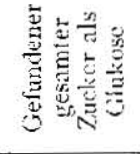 & $\frac{i}{\infty}$ & 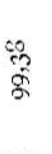 & $\begin{array}{l}\stackrel{\circ}{2} \\
\text { di } \\
\varrho\end{array}$ & 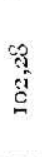 & 清 & $\begin{array}{l}\bar{J} \\
\delta \\
0\end{array}$ & \begin{tabular}{l}
8 \\
\multirow{2}{*}{}
\end{tabular} & 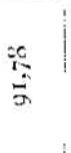 \\
\hline $\begin{array}{l}\exists \\
\Rightarrow\end{array}$ & $\stackrel{N}{N}$ & 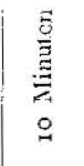 & 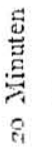 & 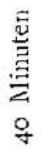 & 竞: & 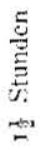 & 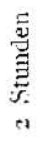 & $\underset{m}{\tilde{y}}$ & 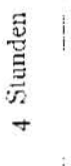 \\
\hline
\end{tabular}




\begin{tabular}{|c|c|c|c|c|c|c|c|c|}
\hline \multicolumn{3}{|c|}{$\begin{array}{l}\text { VIII. Iydirolyse mit 10 \% iger } \\
\text { Schwefelsäure }\end{array}$} & \multicolumn{3}{|c|}{ IX. Hydrolyse mit $5 \%$ iger } & \multicolumn{3}{|c|}{$\begin{array}{c}\text { X. Hydrolyse mit } 2 \\
\text { Schwefelshiure }\end{array} \%$ iger } \\
\hline Zeit & $\begin{array}{l}\text { Cefundener } \\
\text { gesamter } \\
\text { Zucker als } \\
\text { Glukose }\end{array}$ & $\begin{array}{c}\text { Hydroly- } \\
\text { siertes } \\
\text { Gluko- } \\
\text { mannan }\end{array}$ & Zeit & $\begin{array}{l}\text { Gefundener } \\
\text { gesamter } \\
\text { Zucker als } \\
\text { Glukose }\end{array}$ & $\begin{array}{l}\text { Ifydroly- } \\
\text { siertes } \\
\text { Gluko. } \\
\text { mannan }\end{array}$ & Zcit & $\begin{array}{l}\text { Gefundencr } \\
\text { gesamter } \\
\text { Zucker als } \\
\text { Gluckose }\end{array}$ & $\begin{array}{l}\text { Hydroly. } \\
\text { siertes } \\
\text { Gluko- } \\
\text { mannan }\end{array}$ \\
\hline$\frac{1}{2}$ Stunde & $\begin{array}{l}\% \\
60,22\end{array}$ & $\%$ & $\frac{1}{2}$ Stunde & $\begin{array}{c}\% \\
40,9 \mathrm{I}\end{array}$ & $\frac{\%}{3^{6,8}}$ & I Stunde & $\begin{array}{c}\% \\
3^{1}, 93\end{array}$ & 28,55 \\
\hline I Stunde & 71,36 & 64,23 & 1 Stunde & $4 r, 54$ & 37,39 & 5 Stunden & 59.52 & 53,57 \\
\hline$\approx$ Stuuden & 81,36 & 73,14 & 3 Stunden & 58,94 & 53,05 & ro Situnden & 76,32 & 68,69 \\
\hline 4 Stuntien & 85,14 & 76,63 & 6 Stunden & 66,02 & 59,42 & $I_{5}$ Stunden & 86,49 & 77,65 \\
\hline 6 Stunden & $90,5^{\circ}$ & $8 \mathrm{r}, 46$ & 9 Stunden & 79,78 & $71,8 \mathbf{1}$ & 20 Stunden & $\delta_{9,54}$ & 80,59 \\
\hline 8 Stunden & 95,06 & 85,56 & Is Stunden & $\Leftrightarrow \xi, 52$ & 79,68 & 25 Stunden & 89,54 & 80,59 \\
\hline 1o Stunden & 99,72 & 89,76 & 15 Stunden & 89,16 & 80,25 & $3^{\circ}$ Stunden & $190,8,4$ & $8_{1,76}$ \\
\hline \multirow[t]{4}{*}{ I2 Stunclen } & 98,64 & 88,78 & 20 Stunden & $99, \mathbf{1 8}$ & 89,27 & 35 Stunden & $6,6,96$ & $\ddot{8} 7,29$ \\
\hline & & & 25 Stunden & 99,54 & 89,60 & 40 Stunden & 93,96 & $8_{4,57}$ \\
\hline & & & 30 Stunden & 102,00 & $91,6 \mathrm{r}$ & & & \\
\hline & & & 35 Stunden & 103,44 & $93, \mathbf{I I}$ & & & \\
\hline
\end{tabular}



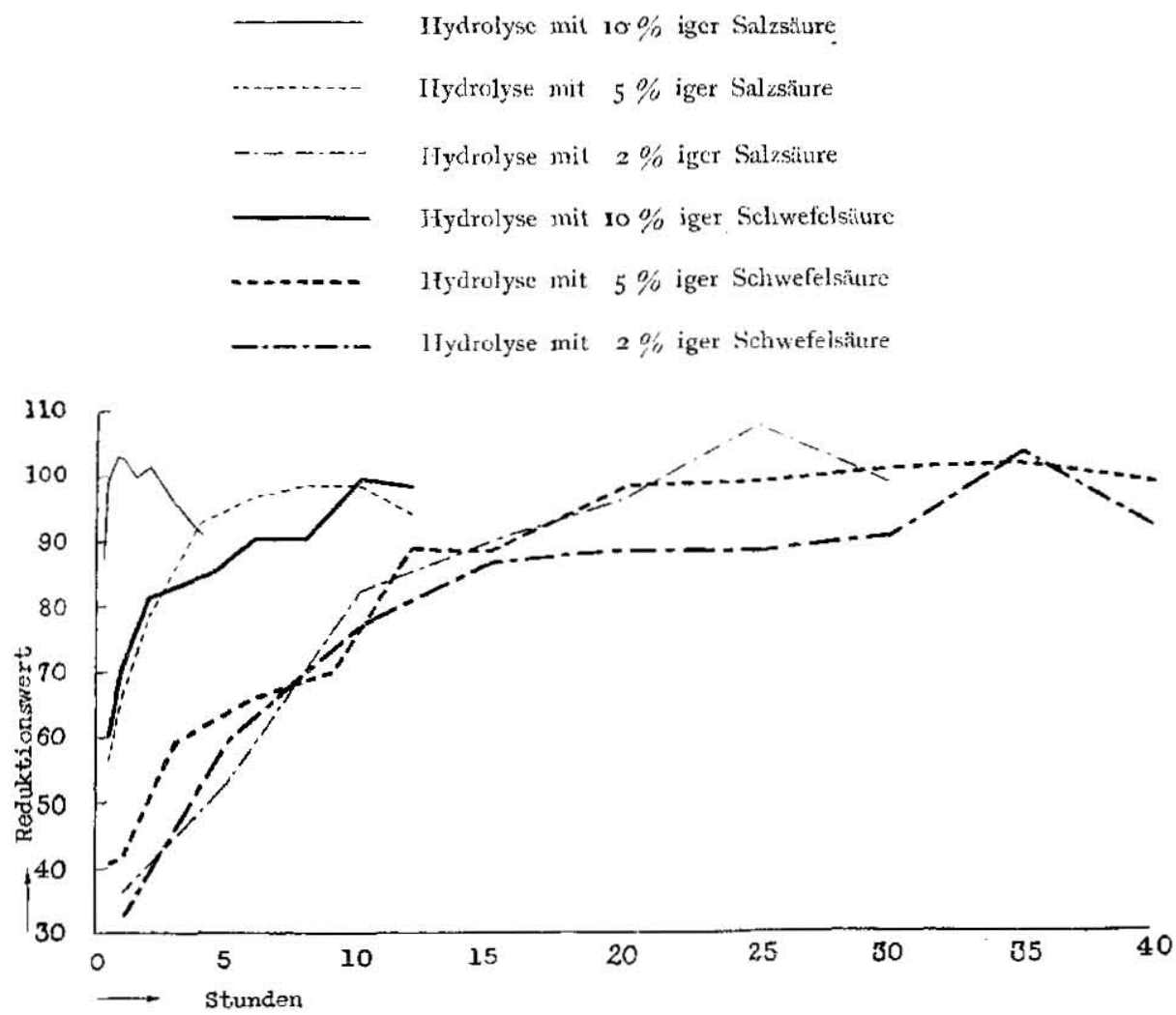

erreicht. Nach i2 Stunden trat ganz schwache Verkohlung ein, daher auch das niedrige Reduktionsvermögen. Die Lösung war dunkelbraun gefärbt.

Dic Hyarrolyse (VII) bei $2 \%$ jger Salzsäure dauerte wesentlich länger. Nach 25 Stunden wurde der IIöchstwert der Verzuckerung erreicht und zwar ergab sich eine Ausbeute von ro8,8 \% Zucker als Glukose (entsprechend 97,9\% Glukomannan). Hier war die Flüssigkeit noch vollständig klar, gelbbraun und 20 Stunden erst trat eine geringe Abscheidung von I Iuminsubstanzen ein, die beim V. Versuche mit 10 \% iger Salzäure schon nach $I_{2}^{\frac{1}{2}}$ Stunden und beim VI. Versuche mit $5 \%$ igger Salzsäure nach 4 Stunden begonnen hatte.

Die Verzuckerung (VIII) mit $10 \%$ iger Schwefelsäure ging bekanntlich weniger energisch vor sich als mit Salzsäure. Eirst nach to Stunden waren bei diesem Versuche 99,7\% Zucker (entsprechend $89,7 \%$ Glukomannan) zersetzt worden, während mit Salzsäure schon 
nach 40 Minuten das maximale Reduktionsvermögen entwickelt wurden und nach $\mathbf{I}_{2}^{\frac{1}{2}}$ Stunden meist schon beträchtliche Verkohlung eintrat. Aus diesem Versuche (VIII) erhellt die Finwirkung mit ro \% iger Schwefelsäure in Vergleich zu der 5 \% igen Salzsäure.

Nach 35 Stunden der Ilydrolyse (IX) mit $5 \%$ iger Schwefelsäure war der höchste Reduktionswert erreicht, und nach dieser Zeit fast die gesamte Substanz in Zucker (103,44\% d. h. $93 \%$ des Glukomannans) übergefülırt worden.

Die viel schwächere hydrolysierende Wirkung $(\mathrm{X})$ der $2 \%$ igen Schwefclsäure ninmt längere Zcit in Anspruch und es konnte im günstigsten falle erst nach 35 Stunden eine Zuckerausbeute von $97 \%$ erreicht werden. In den letzten zwei fallen hat die Schwefelsäure nur wenig Verkohlung verursacht und zu knde des Versuches blieb ein braungefärbter unhydrolysierter Rückstand zurïck. In einer Reihe von Versuchen zeigte es sich, dass der Aufschluss von Glukomannan durch verdünnte Schwefelsäure sehr langsam verläuft und es erhellt, dass man durch Hydrolyse nit $2 \%$ iger Salzsäure während 25 Stunden im Wasserbade die beste Zuckerausbeute erzielt.

Da cler Abbauprocess des Glukomannans am eingehendsten studiert worden ist, so scien hier zunächst nähere Mittcilungen über das Verhältnis der Hexosen gebracht. Ueber den genanen Sitz der Fruktose wurde früher von Mrwake berichtet, doch lässt sich über dieses Glukomannan nichts sicheres aussagen. Der Nachweis der lirultose fiel in den hier ausgefüluten Versuchen nach Selmwanowit mittcls der Resorcinprobe negativ aus, dagegen wurde nach PINor ${ }^{32}$ mit Amnoniummolybdatlösung cine geringe $\mathrm{Bl}$ iufärbung beobachtet. Wahrscheinlich aber handelte es sich im letzteren Falle nun Glukose, da die Intensitat der Färbung genau so stark war, als wenn die Lösung nur 0,03 gr Fruktose enthalten hätte.

An besten hat sich bei Abwesenheit von Fruktose dic Bcstimmung von Aldose nach Kolthoris bewährt. Die zu der l'robe verwendetc Lösung war frei von Bleichlorid oder Bariumchlorid, und enthielt natürlich keinen Alkohol. ' Zu ro ccm der $0,5-0,7 \%$ Zucker enthaltenden Flüssigkeit fügten wir $25 \mathrm{ccm}$ o, I N-Jodlösung und darauf unter Lmschütteln $30 \mathrm{ccm}$ O,I N-Natronlauge hinzu. Nachdem das Gemisch

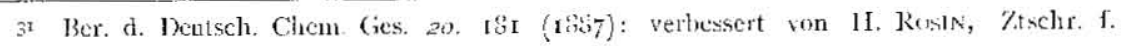
phisi). Chen). 38. 555 (1503).

12 Chem. Zts. 3S. 625 (1914).

33 Ztschr. 1. Untersuch. d. Nahr. 4. Genussmittel 45. 131 (1923). 
5 Minuten lang gestanden hatte, wurde mit $0,2 \mathrm{~N}$-Schwefel:äure angesäuert und mit $\mathrm{O}, \mathrm{I}$ X-Thiosulfatlösung zurücktitriert. So erhielten wir die nachstehenden, als gut zu bezcichnenden Ergebnisse.

\begin{tabular}{|c|c|c|c|c|c|}
\hline & & Hydrolysemittel & $\begin{array}{c}\text { Gicfundiener } \\
\text { Vucker als } \\
\text { Glukose nach } \\
\text { GHRTRAND }\end{array}$ & $\begin{array}{l}\text { Ciefundenc } \\
\text { Aldose } \\
\text { nach } \\
\text { Kortitus: }\end{array}$ & $\begin{array}{c}\text { Abweichung } \\
\text { in } \\
y \%\end{array}$ \\
\hline & Afyctrolyse: & Salssinte vom s). (ifw $\mathbf{I}, 2 \mathrm{I}$ & $\begin{array}{r}111 \mathrm{~g} \\
65,5\end{array}$ & $\mathrm{mg}_{66,1}$ & $-3,50$ \\
\hline III, & " & Salzsăure vom s]. (iew. 1,223 & 73.91 & 72,4 & $-2,04$ \\
\hline IV. & ; & Salzsäure rom. sp. Gew. 1,23 & 99,36 & 95,53 & $-3,60$ \\
\hline$x 1$. & $\therefore$ & $=$ \% Sullsoîure & 50,23 & 76,23 & -4.69 \\
\hline XII. & $"$ & $1 \%$ Salzsüure & 70,88 & 69,57 & $-\mathbf{r}, 85$ \\
\hline XIII. & $"$ & $5 \%$ schwefelsäure & 75,34 & 75,15 & $-0,25$ \\
\hline XIV. & , & $2 \%$ Schwefelsäure & 73,16 & 74,02 & $+\mathrm{I}, \mathrm{I} 3$ \\
\hline
\end{tabular}

Aus diesen Versuchen geht hervor, dass man den gesamten hydrolysierten Zucker als Aldose ausgezeichnet jocimetrisch bestimmen kann und dass die Lösung kcine fruktose enthält. Was die Bestandteile des durch das A-bezw. B-Verfahren hergestellten Clukmanmans angeht, so schen wir, dass das Glukomannan bei der Darstellung curch knchendes Wasser unter Druck, gleich wic das durch Enzyme verflitscigte Glukomannan, so gut wie keine Fruktose enthält. Da bei der Verzuckerumg mit Salzsäure, besonders mit hochkonzentricrter Säure, die Fruktose zersetzbar ist, verwendeten wir ausser der hochkonz. Salzsäure, verdünnte Salzäure in Konzentrationen von I \% bezw. 2 \%, und Schwefelsäure in Konzentrationenen von 2 \% bezw 5 \%. Dabei ergab die Lösung die oben bescluriebene Aldose und enthielt keine Fruktose. Wic vorher beschrieben, wurde das Glukommann mit hochkonz. Salzsäure fast vollständig hydrolysiert, (d. h IO8-IO2 \%, entsprechend 97,7-91,8:ó Glukomannan) und bei verdünntem Säureabbau blieb noch unlyydrolysierter Rückstand, in dem auch keine Fruktose vorhanden war. Die Fruktose (wic von Mrake angegeben) kommt wahrschcinlich als alssozierter und chemisch nicht gebundener Begleiter des Konjakm:tnmons in cen Konjakknollen vor. Diese Versuchreihe berechtigt zu dem Schlusse, dass die Fruktose kein Bestandteil des Konjakmannans ist.

Da bei der Verzuckerung als Abbauprodukt Mannose und Glukose zu erwarten sind, war es von Wichtigkeit, deren Verhalten in Lösung 
zu beobachten. $\mathrm{Zu}$ diesem Zwecke war Manroscbestimmung mit Phenylhydrazin erforderlich. Wir fügten zu $10 \mathrm{ccm}$ Zuckerlösung I 5 ccm Wasser und eine mit Eisessig angesäuerte Mischung von I,2 Mol. Phenylhydrazinlösung, danu $2 \mathrm{ccm}$ Eisessigg hinzu, liessen nach häufigen Umschütteln 12 Stunden in Eisschrank stehen, filtrierten, wuschen mit kaltem Wasser, mit Alkohol und mit Aether aus, trockneten unter Vakuum, dann bei $100^{\circ} \mathrm{C}$. und wogen.

Finc andere gecignete Methode zur I estimmung der Glukosc und Mannose schien uns die Feststellung des Drehungsvermögens zu sein, dabei als annähernde Polarisationszahlen die folgenden angenommen werden können :

Bei $20^{\circ} \mathrm{C}$ und bei Anwendung des $220 \mathrm{~mm}$ Rohres ist $+1^{\circ}$ Kreisdrehung $=\frac{100}{52,5 \times 2,2}=0,866 \mathrm{gr}$ Glukose in $100 \mathrm{ccm}$ I 0 sung.

$+1^{\circ}$ Kreisdrehung $=\frac{100}{14,25 \times 2,2}=3,190 \mathrm{gr}$ Mannose in $100 \mathrm{ccm}$ Lösung.

Nehmen wir an, dass durch Bestimmung der Reduktion in einer Iösung a Gramme Glukosen in $100 \mathrm{ccm}$ und b Grade Rechtsirehung finden, und sei $\mathrm{x}$ die Menge der Gluliose und $\mathrm{a}-\mathrm{x}$ dic Menge der Mannose, so erhaiten wir:

$$
\mathrm{b}=\frac{\mathrm{x}}{0,885}+\frac{\mathrm{a}-\mathrm{x}}{3,190}
$$

In dieser Gleichung ist :

$$
x=\frac{(2,76254 \times b)-(0,865 \times a)}{2,324}
$$

Bcide Werte beziehen sich auf Gramme in $100 \mathrm{ccm}$

Bei $20^{\circ} \mathrm{C}$. und bei Anwendung des $100 \mathrm{~mm}$ Rohres ist

$+\mathrm{I}^{\circ} \mathrm{Kr}$ eisdrehung $=\stackrel{100}{{ }_{52,5} \times \mathrm{I}, \mathrm{O}}=\mathrm{I}, 9047 \mathrm{gr}$ Glukose in $100 \mathrm{ccm}$ Lösung.

$+1^{\circ}$ Kreisdrehung $=\frac{100}{14,25 \times 1,0}=7,0175 \mathrm{gr}$ Mannose in $100 \mathrm{ccm}$ Lösung

Man erhält :

$$
\begin{aligned}
& \mathrm{b}=\frac{\mathrm{x}}{1,9047}+\frac{\mathrm{a}-\mathrm{x}}{7,0175} \\
& \mathrm{x}=\frac{(13.3662 \times \mathrm{b})-(0,904 \times \mathrm{a})}{5,1128}
\end{aligned}
$$

Ergebnisse der Mannosebestimmung nach zwei Methoden. 
(gr in so ccm der Lösung)

\begin{tabular}{|c|c|c|c|c|c|c|c|c|}
\hline \multirow[b]{2}{*}{ Nr. } & \multirow[b]{2}{*}{ Iydrol! semiltel } & \multirow{2}{*}{$\begin{array}{l}\text { Zuckermenge } \\
\text { als Clukose } \\
\text { (a) }\end{array}$} & \multicolumn{3}{|c|}{ Durch Manuosephenylhydraron } & \multicolumn{3}{|c|}{ Durch Drehungsvermögen } \\
\hline & & & $\begin{array}{c}\text { Mannosemenge } \\
\text { (b) }\end{array}$ & $\begin{array}{l}\text { Glukosemenge } \\
(\mathbf{a})-(\mathbf{b})=(\mathrm{c})\end{array}$ & $\begin{array}{l}\text { Verhältnis } \\
(b):(c)\end{array}$ & $\begin{array}{l}\text { Mannosemenge } \\
\text { (d) }\end{array}$ & $\begin{array}{c}\text { Glukosemenge } \\
(\mathrm{a})-(\mathrm{d})=(\mathrm{c})\end{array}$ & $\begin{array}{l}\text { Verlualluis } \\
\text { (d): (e) }\end{array}$ \\
\hline I & $\begin{array}{l}\text { Salzsäure vom sp. } \\
\text { (Eew. I,2I }\end{array}$ & 0,685 & 0,3237 & $0,36 r_{3}$ & I $: I$ & 0,340 & 0,345 & $1: 1$ \\
\hline II & $\begin{array}{l}\text { Salzs.zure vom sp. } \\
\text { (iew. 1,21 }\end{array}$ & 0,537 & $0,25^{\circ 6}$ & $0,27 \mathrm{~S}_{4}$ & $1 ; \mathbf{I}$ & 0,354 & $0,1 \delta_{3}$ & $2: 1$ \\
\hline III & $\begin{array}{l}\text { Salzsäure vom sp. } \\
\text { Gew. 1,22; }\end{array}$ & $0,7,39 \mathrm{I}$ & 0,3922 & 0,3469 & $1: 1$ & $0,45^{24}$ & 0,2867 & $2: \mathrm{I}$ \\
\hline IV & $\begin{array}{l}\text { Salzsäure vom sp. } \\
\text { Gew. } 1,23\end{array}$ & 0,4968 & 0,2476 & 0,2492 & I : $\mathbf{I}$ & 0,2838 & 0,2130 & $3: 2$ \\
\hline $\mathrm{XI}$ & $2 \%$ Salzsïure & $0,69 \mathrm{r} 4$ & 0,321 & 0,370 & $1: I$ & 0,4340 & 0,2574 & $2: 1$ \\
\hline XII & $1 \%$ Salzsäure & 0,6977 & $0,36 \hat{3}$ & 0,330 & I: $\mathbf{I}$ & 0.4375 & 0,2603 & $z: \mathbf{I}$ \\
\hline XIII & $5 \%$ Schwcflañurc & 0,7446 & $0,35^{\circ} 5$ & $0,3^{361}$ & $1: 1$ & 0,5051 & 0,2395 & $2: 1$ \\
\hline XIV & $2 \%$ Schwefelsäure & $0,45 \circ 5$ & 0,217 & $0,2,34$ & I : $\mathbf{I}$ & $0,279 \mathrm{r}$ & 01714 & $2: \mathrm{I}$ \\
\hline
\end{tabular}


Die durch Feststellung des Drehungsvermögens bei konz. Säurehydrolyse gewonnenen Ergebnisse stimmten nicht so genau ïberein, dass wir die Behauptung, das Glukomannan sei aus 2-Mol Manmose und 1-Mol Glukose aufgebaut, aufrecht erhalten könnten. I Iier seicn dic Fälle, bei den Vergleichsproben in denen Glukomannan mit verdimnter Säure verzuckert wurden, berücksichtigt; bei solchen Proben entspricht die Genauigkeit der polarisierenden Kraft etwa der Genauigkeit der Bestimmung der Zuckerverhältniszahlen. Aus diesen Zahlen ist nun zunächst in Uebereinstimmung mit der Angabe MarenA's zu folgrern, dass das Glukomannan aus 2-Mol Mannose and I-Mol Glukose aufgebaut ist.

Nach mannigfaltigen Versuchen mit hochkonzentriertem und verdünntem Säureabbau die Zuckerverhältnisse in bezug auf die Mcnge durch Hanuosephenyihydrazonbestimmung wurde befriedigenden Jirgebnisse angeführt. Aus dieser Reile von Vorversuchen ergibt sich, dass das Konjakmannan bei der Hyclrolyse I-Mol Glukose und I-Mol Mannose lieferte, danach es also als ein Glukomanuan aufzufassen wäre. Ijese Verhältuiszahlen sind, da I,2-Mol Phenylhydrazin theoretisch genügen, *praktisch aber viel weniger hinzugesetzt wurde, nicht brauchbar, wic

Zuckerverhältnisbestimmung durch Mannosephenylhydrazon. (gr)

\begin{tabular}{|c|c|c|c|c|c|}
\hline IIydrolysemitte] & $\begin{array}{l}\text { Verlorauchte } \\
\text { Phenyl- } \\
\text { liydrazin- } \\
\text { nenge }\end{array}$ & $\begin{array}{c}\text { Gefundene } \\
\text { Zuckermengc } \\
\text { als Gluknse } \\
\text { (a) }\end{array}$ & $\begin{array}{l}\text { Gefundene } \\
\text { Mannose- } \\
\text { menge } \\
\text { (b) }\end{array}$ & $\begin{array}{l}\text { Gilukosemenge } \\
(a)-(b)=(c)\end{array}$ & $\begin{array}{l}\text { Verlitilnis } \\
(1):(c)\end{array}$ \\
\hline * $2 \%$ Salzsäure & I, 2 -Mol & 0,2833 & 0,1337 & $0,149^{6}$ & I: 1 \\
\hline " & $\mathrm{I}, 2 \mathrm{Mol}$ & 0,2833 & 0,1729 & $0, \mathrm{I} \mathbf{1 0 4}$ & $3: 2$ \\
\hline , & $3-M_{n) 1}$ & 0,2933 & c, I':34 & 0,999 & $2: 1$ \\
\hline " & $3-\mathrm{Mol}$ & 0,2033 & 0,1849 & 0,984 & $2: 1$ \\
\hline , & $5 \cdot \mathrm{Mol}$ & $0,263.3$ & 0,1889 & 0,044 & $2: 1$ \\
\hline$"$ & 5-Mol & $0,2 \delta_{33}$ & 0,1899 & 0,934 & $2: 1$ \\
\hline
\end{tabular}

* hei diesen Fiillen wurden 1,2.Yol J'henylhydmain im Jeeker alyewogen und darau die

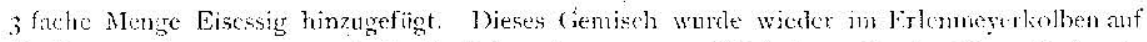

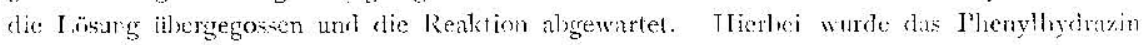

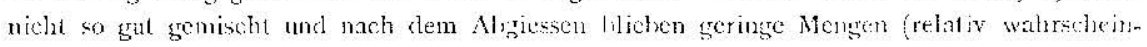
lich zicmlicls grosst:) in dem Jecher atrick.

** wie vorher (Ar. I-IV und Nr. XI-XIV; helandelt. 
in folgenden näher dargelegt werden soll. In Hyclrolyse (XV) soll versincht werden, eine zihlmässige Schlussfolgerung diescr Angabe hersulciten, wobei die Emittulung mit $\mathrm{r}, 5-\mathrm{Mol}, 3-\mathrm{Mol}$ and $5-\mathrm{Mol}$ Phenylhydrazinzusatz aufgeführt wurde.

Bei der Betrachtung der Analyseergebnisse fällt zunächst auf, dass die Fehlerquellen und dic Ausabeitung genügend fehlerficie Bestimmungsverfahren gelöst, und ein deutliches Bild der Verhältniszalılen erlialten werden kann. Das Polarisationsverfahren bei vorclünner Säurehydrolysc zeigt fast völlige Uebereinstimmung nit dem Phenylhycliamonsverfahren. Danach ist das Glulsomannan von Konjak ein polymeres Kohlenhydrat, das aus 2-Mol Mannose und I-Mol Glukose bestcht, d. h. es ist Glukomannan.

\section{EXPERTMENTELLES}

Hydrolyse des Glukomaninans mit ifocinonz. Salzsaure.

(I) Hydrolyse mit Salasüure aom spes. Gew. I,2I

$6,9392 \mathrm{gr}$ Chlukomannan $=6,409 \mathrm{rgr}$ wasser- und aschefreie Substanz wurden mit etwa $50 \mathrm{ccm}$ Salzsäure vom spcz. Gew. I, 2 I bei $0^{\circ} \mathrm{C}$. versetzt und gut gesclüttelt. Darauf wurlen wieder ctwa $180 \mathrm{ccm}$ analoge Salzsäure hinzugefügt und I 5 Minuten unter ofterem Umschütteln bei $0^{\circ} \mathrm{C}$. grehalten, dann auf $15^{\circ} \mathrm{C}$. erwärmt, auf $250 \mathrm{ccm}$ aufgefïllt und der Messkolben dicht verschlossen. Nach gewissen Zeitabständen wurien dann Proben entwommen, in denen die Zuckenmenge nach BuRTRAN1) bestimmt wurde. Dic l'rote wurde mit Natriunkarbonat neutralisiert und mit Wasser auf genau $50 \mathrm{ccm}$ gebracht. Diese $15 \mathrm{ccm}$ wurden nit $20 \mathrm{ccm}$ Kupfersulfutlösung und $20 \mathrm{ccm}$ Seignettesalzlösung veretzt, genat 3 Minuten siedend gehalten, das gewonnene Kupferoxydul dann durch ein Asbestfilter unter Waschen mit Wasser abfiltriert und in schwefelsaurer Forrisulfatlösung gelöst. In dieser I.ösung wurde das Kupfer mit Kaliumpernanganatlösung titriert.

1)as Chukomannan löst sich ! Stunde nach dem Ansetzen vollstandic klar auf. Dic hydrolysicrte Lösung war hellgclb und nahm in Verlauf cler crsten 3-6 Stunden eine gelblichbraune Färbung an. Iei der ersten Probeentnahme, die nach 8 Stunden erfolgte, war die Iösung braun gefärbt, und noch vollständig durchsichtig. Nach 24 Stunden nahm die Lösung eine etwas braune Färbung an, war aber noch durch- 
sichtig; ebenso war dics bei der dritten Entnahme der Fall, nach 48 Stunden war dic Probe bereits dunkelbraun und undurchsichtig.

\begin{tabular}{c|c|c}
\hline Stuinden & $\begin{array}{c}\text { Entstchende 7uckermenge } \\
\text { als Glukose }\end{array}$ & $\begin{array}{c}\text { Iydrolysiertes } \\
\text { Glukomanuan }\end{array}$ \\
\hline 8 & $\% 9,93$ & $\%$ \\
24 & 102,02 & $7 \mathrm{~T}, 94$ \\
30 & 102,27 & 91,82 \\
43 & 99,62 & 89,66 \\
\hline
\end{tabular}

Aus der Hydrolyselösung, die nach 48 Stunden entnommen wurde, wurde durch Luftblasen ein möglichst grosser 'leil der Salzsäure verjagt. Dann wurde sie mit Bleikarbonat neutralisiert, vom Bleichlorid abfiltriert und im Vakuum bei $35-45^{\circ} \mathrm{C}$. eingeclampft. Das in Lösung befindliche Bieichlorid wurde durch Alkohol abgeschieden und mit Tierkohle entfärbt. Dieses Verfaluren wurde so oft wiederholt, bis kein Chlor mehr nachweisbar war. Der Zucker-Sirup wurde zwecks Entfernung des Alkohols mit Wasser verdünnt und erneut im Vakuum cingeengt; eventuell wurde die Operation wiederholt. Schliesslich wurde der Sirup mit Wasser auf $50 \mathrm{ccm}$ aufgefüllt. Aus dieser Lösung wurcle $5 \mathrm{ccm}$ entnommen und mit Wasser auf $50 \mathrm{ccm}$ aufgefüllt. Für jede Zuckerbestimmung wurden $10 \mathrm{ccm}=1 \mathrm{ccm}$ der ursprünglichın Lösung verwendet.

Verbrauch an Kaliunpermanganat $12,82 \mathrm{ccm}=127,25 \mathrm{mg} \mathrm{Cu}=68,50$ mg Glukose, nach der von BerTRAn! gegebenen Tabelle berechnet.

\section{Mannosebestimmung durch Drelunngsvermögen}

Bei $20^{\circ} \mathrm{C}$. und bei Anwendung eines $220 \mathrm{~mm}$ Rohres betrug dic polarisierende Kraft $(+) 5,05$ Grad. Fs ergibt sich die Gleichung :

$x=-\frac{(2,76254 \times b)-(0,866 \times a)}{2,324}$ Gibt $a=6,85, b=5,05$, so hat man $x=\frac{(2,76254 \times 5,05)-(0,866 \times 6,85)}{2,324}=3,45$ gr Glukose und $6,85-3,45$ $=3,40 \mathrm{gr}$ Mannose. 


\section{Mannosebestimmung durch Mannosephenylhydrazon}

Will man den Mannosegehalt dieser I.ösung nach anclerer Methode bestimmen, so mischt man Io ccm der ursprünglichen Lösung (entsprechend $0,685 \mathrm{gr}$ Zucker) in einem Erlenmeyerkolben von $100 \mathrm{ccm}$ Inhalt mit $I_{5} \mathrm{ccm}$ Wasser und fügt cine mit Eisessig angesäuerte Phenyllydrazinlösung $\left({ }^{*}, 2-\mathrm{M} \circ\right)$ hinzu, lässt unter öfterem Umschütteln 12 Stunden im Eisschrank stehen, filtriert den Nicderschlag curch ein gewogenes Filtrierpapier, wäscht mit $100 \mathrm{ccm}$ kaltem Wasser, dann mit $50 \mathrm{ccm}$ Alkohol und $30 \mathrm{ccm}$ Aether aus, trocknet im Vakuum über Schwefelsäure, dann auf $\mathrm{ICO}{ }^{\circ} \mathrm{C}$. und wiegt.

Es wurden gefunden : 0,4766 und $0,4945 \mathrm{gr}$ Mannosephenylhydrazon $=0,3177$ und $0,3297 \mathrm{gr}$ Mannose, im Mittel $0,3237 \mathrm{gr}$.

Der Schmelzpunkt des so gewonnenen Mannoscplienylhydrazons wurde auf $197^{\circ} \mathrm{C}$. bestimmt.

$7,21 \mathrm{mg}$ Substanz gaben $0,530 \mathrm{ccm}$ auf $17^{\circ} \mathrm{C}$. unter $775 \mathrm{~mm}$ Atm. $=9,86 \%$ Stickstoff (theoretisch $10,37 \%$ N-haitig).

\section{Nachacis der Fruktose mittels der Resorcinprobe nach Selizenoff}

Eine Spur der mit Salzsäure hydrolysierten Zuckerlösung wurde mit dem gleichen Volumen Wasser erhitzt und einige Kristallc Resorcin hinzugefügt. Beim Lirwärmen färbte sich die Flüssiggeit braunrot aber nicht tiefrot und liess keinen Farbstoff, der sich in Alkohol wieder mit tiefroter Farbe löst, ausfallen. Dieser erwärmten Lösung wurde so viel Natriumkarbonat hinzugefugt, bis kein Aufbrausen mohr eintrat. I)ann wurde mit Amylalkohol kräftigs ausgeschüttelt, danach sicl kein Sticlı ins Gelbliche zcigte und die Iösung auch nicht schwach grün fluoreszierte.

\section{Nachavis der Frutetose mit Amnoniummolybdatlosung}

$6 \mathrm{gr}$ feingepulvertes Ammoniummolybdat wurden mit $5 \mathrm{ccm}$ Wasser in der Siedenhitze grelöst, auf $40^{\circ} \mathrm{C}$. abgekühlt und $z$ u $5 \mathrm{ccm}$ der ursprünglichen Zuckerlösung gefügt. Es wurcle nun bei $40^{\circ} \mathrm{C}$. I 5 Minuten langr im Wasserbade erhityt, worauf eine geringe Blaufärbung eintrat, falls Glukose und keine Fruktose vorhanden war.

Aldosebestimmung

$5 \mathrm{ccm}$ der ursprïnglichen Iösung wurden mit Wasser auf $50 \mathrm{ccm}$

\footnotetext{
* Sieh S. zgé.
} 
aufgefüllt; davon dienten je $10 \mathrm{ccm}$, entsprechend $0,685 \mathrm{gr} Z$ Zucker, für eine Bestimmung. $\mathrm{Zu}$ diesen Proben fügten wir $25 \mathrm{ccm} \mathrm{o,} \mathrm{I} \mathrm{N-Jodlösung}$ hinzu und darauf unter Umschüttein $30 \mathrm{ccm}$ O, I N-Lauge. Nach 4 Minuten lang Stehen in verschlossenen Gefäss wurcle das Genisch mit 0,2 N-Schwefelsäure angesäuert uncl der Jodüberschluss wit $0, \mathrm{I}$ N-Thiosulfatlösung zurücktitriert.

Verbrauch an $0, \mathrm{I}$ N-Jo(1, 7,33, 7,33 und $7,36 \mathrm{ccm}$, im Mittel 7,34 $\operatorname{ccm}=0,066 \mathrm{I}$ gr Aidose.

(II) Hydrolyse mit Salssäure vom spez. (jeze. I,2I

$5,4006 \mathrm{gr}=4,9745 \mathrm{gr}$ absolut trockenes und aschefreies Glukomannan wurden mit $250 \mathrm{ccm}$ Salzsäure, wie bei (I) beschrieben, hydrolysiert. Dic Lösung zeigte dasselbe Aussehen, wie es schon w.o beschrieben wurde. Dic Zuckermenge wurde nach BerTrano bestimmt und betrug danach :

\begin{tabular}{|c|c|c|}
\hline Stunten & $\begin{array}{c}\text { Fntsteliende Zuckcrmenge } \\
\text { als Giulose }\end{array}$ & $\begin{array}{l}\text { Jydrolysiertes } \\
\text { Glukomaman }\end{array}$ \\
\hline 8 & $\begin{array}{c}\% \\
79,5^{6}\end{array}$ & $\begin{array}{c}\% \\
71,93\end{array}$ \\
\hline 24 & 93,59 & $\$ \&, 74$ \\
\hline 30 & 99,30 & 39,33 \\
\hline
\end{tabular}

Das so gewonnene Abbauprodukt wurcle mit Bleikarbonat neutralisiert, im Vakuun bei niedriger Temperatur eingedickt, das geloste Bleikarbonat nit Alkohol verjagt, wie oben unter Vakuum eingedamplt, bis kein Alkohol menr vorhanden war und damn mit Wasser auf $50 \mathrm{ccm}$ aufgefullt. IJic Zuckerbestimmung aus dieser Iösung wure wie bei (I) ausgefülnt. I,5 ccm der entsprcchenden Lösung reduzicrten 1.7 .72 $\mathrm{cm}$ Kaliumpermanganat $=146,90 \mathrm{rug} \mathrm{Cu}=80,5 \mathrm{mg}$ Zucker als Glukose, daher entsprechen $5,37 \mathrm{gr}$ Zucker in $100 \mathrm{ccm}$ Iösung.

Mannosebestimmung durch Fieststollung des Drelungszermögens

Die polarisiercnde Kraft in $220 \mathrm{~mm}$ Rohr bei $20^{\circ} \mathrm{C}$. war $(+) 3,22$ Grad. Es ergibt sich die Gleichung: 
$\mathrm{x}=\frac{(2,76254 \times \mathrm{b})-(0,866 \times \mathrm{a})}{2,324} \quad$ Gibt $\mathrm{a}=5,37, \mathrm{~b}=3,22$, so hat man $\mathrm{x}=\frac{(2,76254 \times 3,22)-(0,866 \times 5,37)}{2,324}=\mathrm{I}, 83 \mathrm{gr}$ Glukose und $5,37-1,8$,

$=3,54 \mathrm{gr}$ Mannose.

Mannosibestimmung durch Mannosephenyllydrazon

Io ccm Zuckerlösung wurden wie vorher behandfit ur.1 gaben 0,3899 und $0,3860 \mathrm{gr}$ Mannoseplenylhydrazon $=0,25 \%$ ' un' $0,2573 \mathrm{gr}$ Mannose, im Mittel also $0,2586 \mathrm{gr}$.

Nachucis dor Irnktose

Der Nachweis der Fruktose mittels d _r Resc.cin-Probe nach SEl,IWANorF und der Ammoniummolybdatlö ung fie', wie w. o. auch schon, negativ aus.

(III) Hydrolyse nit So'zsäure v me spez. Geai. 1,223

$5,4224 \mathrm{gr}=5,1366 \mathrm{gr}$ wa ser- und aschefreies Glukomannan wurden, ebenso wie bei (I) und ( $\mathrm{I}$.) beschri ben, mit $250 \mathrm{ccm}$ Salzäure vom spez. Gew. 1,223 behan selt. Nar.1 24 Stunden war die Lösung dunkelbraun gefärbt und ur.turchsicht's. Es ergab sich eine Zuckemenge von $108,60 \%$ al Glukose, d.h. es wurden $97,75 \%$ Glukomannan verzuckert. Tlese Flüssi keit wurde mit Bleikarbonat neutralisiert und wie vor'er geengt nachler mit Wasser auf $50 \mathrm{ccm}$ aufgefullt. I ccm $10 \%$ ang verbraw nte $13,56 \mathrm{ccm}$ Kaliumpermangan it mug $\mathrm{Cu}=0,07391 \mathrm{gr}$ Licker als Glukose.

Mar.nosebestimm ner durch Feststellung des IDrehungsvermïgens.

Bei $20^{\circ} \ldots$ und bei Anwendung eines $100 \mathrm{~mm}$ Rohres betrug die polarisierc de Kraft $(+)$ 2,15 Grad. Is ergibt sich die Gleichung:

$x=-\frac{(3,3662 \times b)-(1,9047 \times a)}{5,1128}$ Gibt $a=7,391, b=2,15$, so hat man

$x=\frac{(\mathrm{I} 3,3662 \times 2, \mathrm{I} 5)-(\mathrm{I}, 9047 \times 7,39 \mathrm{I})}{5, \mathrm{II} 28}=2,867$ gr Glukose und $7,39 \mathrm{I}$

$-2,867=4,524 \mathrm{gr}$ Mannose. 


\section{Mannosebestimmung durch Mannosephenylhydrason}

$10 \mathrm{ccm}$ Zuckerlösung wurden wie oben bestimnt und gaben 0,5782 und $0,5983 \mathrm{gr}$ Mannosephenylhydrazon $=0,3855$ und $0,3989 \mathrm{gr}$ Mannose, im Mittel also $0,3922 \mathrm{gr}$.

\section{Nachioeis der Fruktose}

In den Abbauprodukten liess sich, wie bei (I) beschrieben, Fruktose nicht nachweisen.

\section{Aldosebestiminung}

IO ccm, entsprechend I ccm der ursprünglichen I.ösung, wurclen nach KoLTHofr wie w. o. die Aldosemenge bestimmt; und dazu wurden 8,00 und $8,08 \mathrm{ccm}$, in Mittel also $8,04 \mathrm{ccm}$ o, $1 \mathrm{~N}$-Jodlösung verwendet $=0,0724 \mathrm{gr}$ Aldose.

(IV) IJydrolyse mit Salsä̈ure von spez. Geze. 1,23

$0,5577 \mathrm{gr}=0,5000 \mathrm{gr}$ absolut trockenc und aschefreie Substanz aus durch das Darstellungsverfahren-B gewonnenem Glukomannan wurden mit $100 \mathrm{ccm}$ Salzsäure vom spez. Gew. I,23 auf Zimmertemperatur (ca. $8^{\circ} \mathrm{C}$ ), wie w.o. beschrichen, hycirolysiert. Nach 24 Stunclen war die I.ösung braun gefärbt und durchsichtig. $5 \mathrm{ccm}$ wurden mit Soda neutralisiert und dann auf $50 \mathrm{ccm}$ aufgefiullit; davon dienten je $10 \mathrm{ccm}$ für eine Zuckerbestimmung und zw.ar in der folgenden Weise: 10,02 ccm Kaliumpermanganatlösung $=100,65 \mathrm{mg} \mathrm{Cu}=53,3 \mathrm{mg}$ Zncker als Glukose. Das Abbauprodukt enthielt insgesamt I06,60\% Zucker, d.h. es wurclen $95,95 \%$ Glukomannan hyclrolysiert.

$5,5766 \mathrm{gr}=5,000 \mathrm{gr}$ derselben (B) wasser- und aschefreic Substanz wurden mit $250 \mathrm{ccm}$ Salzsäure vom spez. Gcw. 1,23 wie obcn hydrolysiert. Die Iösung zeigte dassclbe Aussehen wie vorher. $5 \mathrm{ccm}$ Lösung reduzierten $9,85 \mathrm{ccm}$ Kaliumpermanganatlösung $=98,94 \mathrm{mg} \mathrm{Cu}=52,24$ mg Zucker als Glukose, d.h. es wurden ro4,48 \% Zucker gewonnen und 93,97\% Glukomannan verzuckert.

Diese zwei Hydrolyselösungen wurden dann zusammen mit Bleikarbonat neutralisiert und wie bei (I) beschrieben behandelt, Jann auf $50 \mathrm{ccm}$ aufgefüllt; davon wurde I $\mathrm{ccm}$ der entsprechenclen Lösung für jede Bestimmung entnommen.

Verbrauch an Kaliumpermanganat $4,9 \mathrm{I} \mathrm{ccm}=40,27 \mathrm{mg} \mathrm{Cu}=24,84$ ing Zucker. 


\section{Mannosebestimnung durch Feststellung des Drchungsvermögens}

Bei $20^{\circ} \mathrm{C}$. in $220 \mathrm{~mm}$ Rohr betrug die polarisierende $\mathrm{Kraft}(+)$ 3.35 Grad. Es ergibt sich die Gleichung:

$\mathrm{x}=\frac{(2,76254 \times \mathrm{b})-(\mathrm{o}, 866 \times \mathrm{b})}{2,324} \quad$ Gibt $\mathrm{a}=4,968, \mathrm{~b}=3,35$, so hat man $\mathrm{x}=\frac{(2,76254 \times 3.35)}{2,324}=2, \mathrm{-1} 30 \mathrm{gr}$ Glukose und 4,968 $-2, \mathrm{I} 30=2,838 \mathrm{gr}$ Mannose.

Mannosebestimmung durch Mennosephenylhydrazon

$20 \mathrm{ccm}$ und $15 \mathrm{ccm}$ Zuckerlösung gaben 0,6562 und $0,6220 \mathrm{gr}$ Mannosephenylhydrazon $=0,218$ und $0,2764 \mathrm{gr}$ Mannose, im Mitlel also $0,2476 \mathrm{gr}$.

\section{Nacheveis dor Fruktose}

In der Flüssigkeit war, wie bei (I), Fruktose nicht nachzuweisen.

\section{Aldosibestimmung}

$20 \mathrm{ccm}$, entsprechend $2 \mathrm{ccm}$ der ursprünglichen Iösung, wurien nach KolmiorF wie vorher die Aldosemenge bestimmt; und dazu wurden $10,64,10,52$ und $10,70 \mathrm{cctr}$, in Mittel also $10,62 \mathrm{ccm} 0, \mathrm{r}$ $\mathrm{N}$-Jodlösung verwendet $=0,09558 \mathrm{gr}$ Aldose, daher betrugen $4,779 \mathrm{gr}$ in $100 \mathrm{ccm}$.

\section{Hydrolyse des Glukomannans mis verdünnter Salz- und SCIIWEFELSÄURE}

\section{(V) Hydrolyse mit 10\% iger Salzsäurt}

Je $0,5345 \mathrm{gr}=0,5000 \mathrm{gr}$ absolut trockenes und aschefreies Glukomantran wurden mit $50 \mathrm{ccm}$ 10 \% iger Salzsäure übergossen, nacheinander IO, 20 und 40 Minuten, I, I $\frac{1}{2}, 2,3$ und 4 Stunden im Wasserbade in Sieden gehalten, wozu ein Rückflusskühler gebraucht wurde. Nach dem Abkühlen wurde eine gewissen Menge der Probe das Reduktionsvernögen nach BERTRAND bestimmt. Es wurde dann die nichthydrolysierte Substanz oder die Abscheidung von Huminsubstanz abfiltriert und zum Neutralisieren wurde Natriumkarbonat entnommen. 


\begin{tabular}{|c|c|c|c|c|}
\hline & Zeil & $\begin{array}{l}\text { Gefundener } \\
\text { resanter } \\
\text { Zucler } \\
\text { als Gilukose }\end{array}$ & $\mid \begin{array}{c}\text { Itydroly- } \\
\text { siertes } \\
\text { Cilukmanman }\end{array}$ & Bemerkumigen \\
\hline 10 & Minulea & $\because 7,30$ & 78,58 & 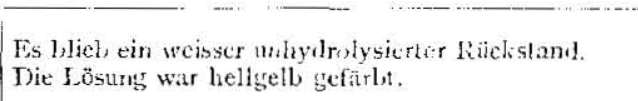 \\
\hline 20 & Minuten & 99,33 & 89,45 & Dits. \\
\hline 43 & Minuten & $102,5^{\circ}$ & $9 \geq 26$ & Dit, \\
\hline ! & Stunde & 102,28 & (y2, of & 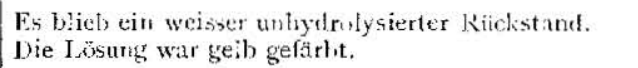 \\
\hline $\mathrm{I}$ & Stunden & 99,84 & 89,86 & $\begin{array}{l}\text { Ls wurde ein hellbrauner Ifuminstolf alygeschieden. } \\
\text { Die Iobsung war loraun gefẗrbt. }\end{array}$ \\
\hline & Stunden & 100,94 & yo,86 & Dilis. \\
\hline 3 & Stunden & 95,60 & 86,05 & $\begin{array}{l}\text { Es wurie ein dunkelbrauner flumiust lf atrgeschicden. } \\
\text { Die Lösung war braun gefärltt. }\end{array}$ \\
\hline 4 & Siunden & (y), 78 & 32,61 & 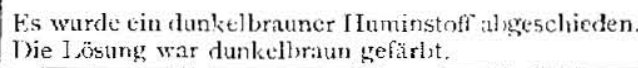 \\
\hline
\end{tabular}

\section{(VI) Hydrolyse mit $5 \%$ iger Salasäure}

$\mathrm{Zu}$ jedlem Versuche wurden wieder $0,5345 \mathrm{gr}=0,5000 \mathrm{gr}$ wasserund aschefreies Glukomannan angewandt. Dic I Iydrolysierzeiten betrugen in dieser Versuchreihe $\frac{1}{2}, 1,2,4,6,8$, Io und 12 Stunden. Behandlung und Bestimmung geschahen in derselben Weise wic im vorhergehenden Versuche. Gefunden wurden:

\begin{tabular}{|c|c|c|c|c|}
\hline & Leit & $\begin{array}{l}\text { Gefundener } \\
\text { gesamter } \\
\text { /ucker } \\
\text { als Glukise }\end{array}$ & $\begin{array}{c}\text { Mydroly. } \\
\text { siertes } \\
\text { Glukemannan. }\end{array}$ & Benerkumgen \\
\hline$\frac{1}{2}$ & Sturide & 57.06 & 51,36 & 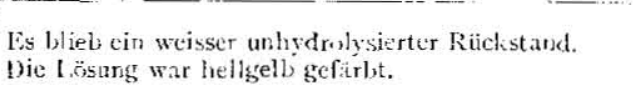 \\
\hline I & Stunete & 65,96 & 59,37 & Jit"s. \\
\hline 2 & Stusden & 75,70 & $70, \% 4$ & 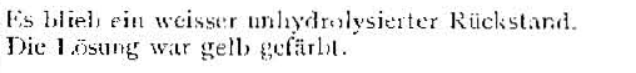 \\
\hline 4 & Stunden & 92,50 & $8,6=$ & $\begin{array}{l}\text { Fis wurde ein hrauner fluminstiff abgeschicien. } \\
\text { Die I ösung war helluraun gefirbt. }\end{array}$ \\
\hline 6 & Stunclen & $96,9=$ & $\mathrm{s}_{7}, 24$ & 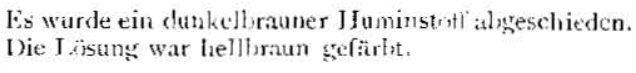 \\
\hline$\ddot{o}$ & Stunden & 98,52 & $\ddot{0}, 63$ & Dito. \\
\hline IO & Stunden & 96,52 & $8 \%, 63$ & Dits. \\
\hline 12 & sicunden & 93,63 & 64,32 & 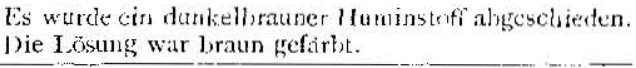 \\
\hline
\end{tabular}




\section{(VII) Hydrolyso mit $2 \%$ iger Salssäurt}

$\mathrm{Zu}$ jeder Hydrolyse wurden ebenfalls, $0,5345 \mathrm{gr}=0,5000 \mathrm{gr}$ absolut trockener uuxl aschefreier Substanz verwendet. Die Hydrolyse war die gleiche wie vorher und dic 7eit betrug $1,5,10,15,20,25$ und 30 Stunden. Der Zuckerwert wurde in dor gleichen Weise wic vorher bestimnt.

\begin{tabular}{|c|c|c|c|}
\hline Zeit & $\begin{array}{l}\text { Gefunclence } \\
\text { gesaniter } \\
\text { Zuclier } \\
\text { als Cilukrose }\end{array}$ & $\mid \begin{array}{c}\text { Jydroly- } \\
\text { siertes } \\
\text { Glukmmannan }\end{array}$ & Jeuterkungen \\
\hline r situnde & $\begin{array}{c}30 \\
36,36\end{array}$ & 32,73 & $\begin{array}{l}\text { Es l,liel, ein weisser mhydmiysierter Rüekstand. } \\
\text { Die lösung war firlotos. }\end{array}$ \\
\hline 5 Stunden & $6_{3}, \infty$ & 56,71 & $\begin{array}{l}\text { Es blieb ein weisser unhydrolysierter Riickstand. } \\
\text { Jie Iüsung war hellgell gefärl,t. }\end{array}$ \\
\hline 1. Stunden & 82,58 & 74,33 & Jitn. \\
\hline I 5 Stunden & 95,08 & 85,53 & Ibito. \\
\hline 20 Stunden & 97,76 & $87,(2)$ & 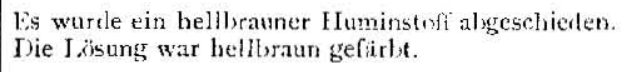 \\
\hline 25 Situnden & $108, \$)$ & 97,93 & Dito. \\
\hline 30 Silurden & 94,98 & 8,99 & $\begin{array}{l}\text { Es wurde ein l,ratuner } 1 \text { Iuminstofi al,geschieden. } \\
\text { I)ie Lösung war braun gefärbt. }\end{array}$ \\
\hline
\end{tabular}

(VIII) Ifydrolyse mit to \% iger Schaefolsüure

$\mathrm{Zu}$ jedem Versuche wurden $0,5499 \mathrm{gr}=0,5000 \mathrm{gr}$ wasser- und aschefreies Glukonannan angewand und nacheinander $\frac{1}{2}, 1,2,4,6,8$, 10 und 12 Stunden lang im Wasserbale im Sieden gehalten, wozu cin Rückflusskühler gebraucht wurde. Pehandlung und Bestimmung geschahen in derselben Weise wic im vorhergehenden Versuche. (:efunden wurden :

\begin{tabular}{|c|c|c|c|}
\hline Zeil & $\begin{array}{l}\text { Gefundener } \\
\text { gesunter } \\
\text { Zucker } \\
\text { als Ciluknse }\end{array}$ & $\begin{array}{c}\text { IIydroly. } \\
\text { siertes } \\
\text { Gilukomannan }\end{array}$ & Bemerkungen \\
\hline$\frac{1}{2}$ Stuncle & 60,22 & $\begin{array}{c}\% \\
54,20\end{array}$ & $\begin{array}{l}\text { Es blich ein weisser unhythrolysierter Rükstand. } \\
\text { Die lösung war nicht geffirbt. }\end{array}$ \\
\hline I situmele & 75,35 & 64,26 & Dito. \\
\hline
\end{tabular}




\begin{tabular}{|c|c|c|c|}
\hline 2 Stunden & $8 \mathrm{I}, 26$ & 73,14 & $\begin{array}{l}\text { Sehr wenig gefärbtes Glukomannan im liückstand, } \\
\text { die lösung war hellbraun gefärbth. }\end{array}$ \\
\hline 4 Stunden & 85,14 & 76,63 & I Dito. \\
\hline 6 Stunden & $90,5^{\circ}$ & 81,46 & Dito. \\
\hline$\&$ Stunden & 95,06 & 85,56 & $\begin{array}{l}\text { Es wurde ein hellbrauner Huninstrof abgeschieden. } \\
\text { Die Lösung war gelblich braun gefïrbt. }\end{array}$ \\
\hline Io Stunden & 99,72 & 89,76 & $\begin{array}{l}\text { Es wurde in brauncr Huminstoff al,geschieden. } \\
\text { Die Yössung war braun gefärbt. }\end{array}$ \\
\hline I2 Stunden & 98,64 & 88,78 & Dit \\
\hline
\end{tabular}

\section{(IX) Hydrolyse mit $5 \%$ iger Schaefelsäure}

Zu jeder Hydrolyse wurden ebenfalls $0,5449 \mathrm{gr}=0,5000 \mathrm{gr}$ absolut trockener und aschefreicr Substanz verwendet. Die IIydrolyse war die gleiche wie vorher und die Zeit betrug $\frac{1}{2}, 1,3,6,9,12,15,20,25$, 30 und 35 Stunden. Der Zuckerwert wurde, wie w.o. beschrieben, bestimmt.

\begin{tabular}{|c|c|c|c|}
\hline Zeit & $\begin{array}{l}\text { Gefundener } \\
\text { gesamter } \\
\text { Zucleter } \\
\text { als Gluknse }\end{array}$ & $\begin{array}{c}\text { Mydroly- } \\
\text { sicrtes } \\
\text { Gluknmannan }\end{array}$ & Berncrkungen \\
\hline$\frac{1}{2}$ Stunde & $\begin{array}{l}\% \\
4 \%, 9 \mathrm{r}\end{array}$ & $3 \%$ & $\begin{array}{l}\text { Es blieb ein weisser unhydrolysierter Kückstand. } \\
\text { Dje Lösung war farblıs. }\end{array}$ \\
\hline I Stunde & $4 \mathrm{I}, 54$ & 37,39 & Ditn. \\
\hline 3 Stunden & $5^{8,94}$ & 53,05 & Dits. \\
\hline 6 Stunden & 66,02 & 59,42 & $\begin{array}{l}\text { Es blieb ein weisser unhydrolysierter Rückstand. } \\
\text { Die Lösung war gelb gefärbt. }\end{array}$ \\
\hline 9 Stunden & $79,7^{\circ}$ & $7 \mathrm{I}, 8 \mathrm{I}$ & $\begin{array}{l}\text { Es blieb ein weisser unhydrolysierter Rückstand. } \\
\text { Die Lösung war hellbraun gefärbt. }\end{array}$ \\
\hline I 2 Stunden & 88,52 & 79,68 & Dito. \\
\hline 15 Stunden & 89,16 & 80,25 & $\begin{array}{l}\text { Es wurde ein hellbrauner I Iurninstoff abgeschicden. } \\
\text { Die Lösung war hellbraun gefärht. }\end{array}$ \\
\hline so Stunden & $99, \mathrm{IB}$ & 89,27 & $\begin{array}{l}\text { Es wurde ein helibrauner Huminstoll algeschieden. } \\
\text { Die Iösung war braun gefärbt. }\end{array}$ \\
\hline 25 Stunden & 99,54 & 89,60 & $\begin{array}{l}\text { Es wurde cin brauner Ifuminstoff ahgeschieden. } \\
\text { Die T,ösung war braun gefärbt. }\end{array}$ \\
\hline 30 Stunden & 102,00 & 91,81 & $\begin{array}{l}\text { Es wurde ein dunkelbrauner Huminstoff abgeschieden. } \\
\text { Die Lösung war braun gefärbt. }\end{array}$ \\
\hline 35 Stunden & $\mathrm{r} 03,44$ & 93,11 & $\begin{array}{l}\text { lis wurde ein dunkelbrauner Huninst } n f f \text { abgeschieden. } \\
\text { Die Lösung war dunkelbraun gefärbt. }\end{array}$ \\
\hline
\end{tabular}




\section{(X) Hydrolyse mit $2 \%$ igser Scluavefelsäure}

Zu jedem Versuche wurden wieder $0,5449 \mathrm{gr}=0,5000 \mathrm{gr}$ wasserund aschefreies Glukomannan angewandt. Die Hydrolysicrzeiten betrugen in dieser Versuchreihe 1, 5, 10, 15, 20, 25,30, 35 und 40 Stunden. Bestimmung und Bchandlung waren dieselbe wie im vorhergehenden Versuche. Gefunden wurden:

\begin{tabular}{|c|c|c|c|}
\hline /eit & $\begin{array}{l}\text { Gefundener } \\
\text { gesamter } \\
\text { Zucker } \\
\text { als Cilukiose }\end{array}$ & $\begin{array}{c}\text { Hydroly- } \\
\text { sicrtes } \\
\text { Glukomannan }\end{array}$ & Bermerkungen \\
\hline I Stunde & $\begin{array}{c}\% \\
31,93\end{array}$ & $2 \%, 5$ & $\begin{array}{l}\text { Fs blieb ein weisser unhydrolysierter Rüickstand. } \\
\text { Die Lösung war farblos. }\end{array}$ \\
\hline 5 Stunden & 59,52 & 53.57 & Lito. \\
\hline ro Stunden & 76,32 & 68,69 & Dito. \\
\hline Is Stunden & 86,49 & 77,85 & $\begin{array}{l}\text { Es lilieb ein weisser unhydrolysierter Riickstand. } \\
\text { Die Lösung war hellgelly gefärlt. }\end{array}$ \\
\hline 2o Stunder & 89,54 & 80,59 & $\begin{array}{l}\text { Es wurde ein hellgelber ITuminstulf abgeschieden. } \\
\text { bie Iüsung war gelb gefürb. }\end{array}$ \\
\hline 25 Stunden & 89,54 & 80,59 & $\begin{array}{l}\text { Fis wurde ein gelber Huminstoff abgeschieden. } \\
\text { T)ie I.̈̈stung war helibratur gefïrbt. }\end{array}$ \\
\hline 30 Stunden & 90,34 & is, 76 & $\begin{array}{l}\text { Es wurde ein brauner Huminstolt abgeschieden. } \\
\text { J hie I.̈口sung war hellbratun gefärbt). }\end{array}$ \\
\hline 35 Stunden & 96,98 & 87,29 & $\begin{array}{l}\text { Es wurde ein brauner IIuminstoff abgeschieden. } \\
\text { Die Lösung war braun gefürbt }\end{array}$ \\
\hline 40 Stunden & 93,96 & 84,57 & Inito. \\
\hline
\end{tabular}

\section{(XI) Hydrolyse mit 2 gó iger Salsäure}

$2,13^{8} \mathrm{gr}=2,0000 \mathrm{gr}$ absolut trockenes und aschefreics Glukomannan wurden mit $200 \mathrm{ccm} 2 \%$ iger Salzsäure übergossen und 35 Stunden im Wasserbade im Sicden gehalten, wozu cin Rückflusskühler gebraucht wurde. Nach Abküblen wurde die verzuckerte Lösung mit Wasser auf $250 \mathrm{ccm}$ aufgefüllt. $5 \mathrm{ccm}$ dienten für eine Zuckerbestimmung.

$7,73 \mathrm{ccm}$ Kaliumpermanganatlösung $=77,75 \mathrm{mg} \mathrm{Cu}=40,14 \mathrm{mg}$ Zucker als Glukose $=2,007$ Zucker in $250 \mathrm{ccm}=100,35 \%$ Zucker wurden gewomen, d.h. es wurden $90,32 \%$ Glukomannan verzuckert. 


\section{Aldoscbestimmung}

Io ccm der Lösung wurden nach KoLThofr wie oben bei Bestimmung der Aldosemenge bestimmt und zwar wurden 8,45 und $8,49 \mathrm{ccm}$, im Mittel also 8,47 ccn o, I N-Jodlösung angewendet $=0,07623 \mathrm{gr}$ Alifose: gegen $0,08028 \mathrm{gr}$ gesamten Zucker.

\section{Mannosibestimmung durch Feststelhng des Drelnngsiernögins}

Die Iösung wurde mit Bleikarbonat neutralisiert und in Vakuum auf $35-45^{\circ} \mathrm{C}$. eingedampft, mit Tierkohle entfärbt, Wasser hinzugefügt, dann nochmals in Vakuum, bis sämtlicher Alkohol beseitigt worden war, auf ca. $20 \mathrm{ccm}$ eingeengt. Aus dieser Lösung wurden $5 \mathrm{ccm}$ entnonmen und mit Wasser auf $50 \mathrm{ccm}$ aufgefüllt. Für jecle Zuckerbestimmung wurden $5 \mathrm{ccm}$ verwendet.

Verbrauch an Kaliumpermanganat $6,70 \mathrm{ccm}=67,39 \operatorname{lng} \mathrm{Cu}=34,57$ mg Zucker als Glukose $=6,9 \mathrm{I} 44 \mathrm{gr}$ Zucker in $100 \mathrm{ccm}$ Lösung.

Bei $20^{\circ} \mathrm{C}$. in $100 \mathrm{~mm}$ Rohr betrug die polarisierende Kraft $(+)$ 1,97 Grad. Es ergibt sich die Gleichung:

$x=\frac{(13.3662 \times b)-(1,9047 \times a)}{5,1128} \quad$ Gibt $a=6,9144, b=1,97$, so hat man $\mathrm{x}=\frac{(\mathrm{I} 3,3662 \times 1,97)-(\mathrm{I}, 9047 \times 6,9 \mathrm{r} 44)}{5,1128}=2,574 \mathrm{gr}$ Glulose und $6,9 \mathrm{I} 44$ $-2,574=4,3402$ gr Mannose.

\section{Mannosebstimmung durch Mannoseplenylhydrexon.}

5 ccn Zuckerlösung wurden wie vorher behandelt und gaben 0,2407 gr Mannosephenylhydrazon $=0,1605 \mathrm{gr}$ Mannose, entsprechend $3,2 \mathrm{Igr}$ in I $00 \mathrm{ccm}$ Lösung.

(XII) Iydrolyse mit $I$ \% iger Salasäur

$2,13^{8} \mathrm{gr}=2,000 \mathrm{gr}$ wasser- und aschefreier Substanz wurden, wic w.o. beschrieben, mit $200 \mathrm{ccm}$ I \% iger Salzsäure behandelt. Nach 33 Stunden war die Lösung gelb gefärbt und durchsichtiog. Es waren auch noch nicht hydrolysicrte, dunkelbraun gefarbte Huminstoffe vorhanden. Nach Abkühlen wurde mit Wasser auf $250 \mathrm{ccm}$ aufgefuillt. F־ür jede Zuckerbestimmung wurden $5 \mathrm{ccm}$ verwendet.

$6,87 \mathrm{~cm}$ Kaliumpermanganatlösung $=69, \mathrm{IO} \mathrm{mg} \mathrm{C}_{\mathrm{u}}=35,44 \mathrm{mg}$ Zucker als Glukose $=1,7723 \mathrm{gr}$ in $25^{\circ} \mathrm{ccm}=88,35 \%$ Zucker. 
Aldosebestimunung

In 10 ccm Lösung, die 0,07088 gr Zucker enthielt, wurde die Aldosemenge nach Koltworf bestimmt. Verbrauch 7,70 und $7,76 \mathrm{ccm}$, im Mittel also 7,74 ccm 0,1 N-Jodlösung=0,06957 gr Aldose.

Mannosebestimmung durch Feststellung des Jrelungsvermögens

Diese Flüssigkeit wurde mit Bleikarbonat neutralisiert und wie vorher behandelt. $0,5 \mathrm{ccm}$ der cntsprechenden Lösung verbrauchten $6,77 \mathrm{ccm}$ Kaliumpernanganatlösung $=68,09 \mathrm{mg} \mathrm{Cu}=34,89 \mathrm{mg}$ Zucker als Gilukose $=6,9777 \mathrm{gr}$ Zucker in $100 \mathrm{ccm}$.

Bei $20^{\circ} \mathrm{C}$. und bei Anwendung cines $100 \mathrm{~mm}$ Rohres betrug die polarisierende Kraft $(t)$ 1,99 Grad. Nach der bereits gegebenen Gleichung ergibt sich : $a=6,9777, b=1,99$, so hat man

$\mathrm{x}=\frac{(\mathrm{r} 3,3662 \times \mathrm{I}, 99)-(\mathrm{r}, 9047 \times 6,9777)}{5, \mathrm{I} 128}=2,6029 \mathrm{gr}$ Glukose und 6,9777 $-2,6029=4,3748$ gr Mannose.

\section{Mannosebestimmung durch Mannosephenylhydrazon}

$5 \mathrm{ccm}$ dieser Lösung gaben 0,2768 und $0.2760 \mathrm{gr}$ Mannosephenyihydrazon $=0,1845$ und $0,1840 \mathrm{gr}$ Mannose, entsprechend 3,59 und 3,68 $\mathrm{gr}$ Mannose in $100 \mathrm{ccm}$ Lösung.

\section{(XIII) Hydrolyse mit .5\% iger Schavefelsäure}

$2,138 \mathrm{gr}=2,000 \mathrm{gr}$ absolut trockenes und aschefreies Glukomannan wurden mit $200 \mathrm{ccm} 5 \%$ iger Schwefelsäure übergegossen und 33 Stunden lang im kochenden Wasserbade am Rückffussizühler erhitzt. Nach Abkühlen wurde die hydrolysierte Flüssigkeit nit Wasser auf 250 ccm aufgefüllt. Für jede Zuckerbestimmung wurden $5 \mathrm{ccm}$ verwendet.

$7,26 \mathrm{ccm}$ Kaliumpermanganatlösung $=73,12 \mathrm{mgCu}=37,62 \mathrm{mg}$ Zucker als Glukose $=1,881 \mathrm{gr}$ Zucker in $250 \mathrm{ccm}$ Lösung $=93,05 \%$ Zucker wurden gewonnen, d.h. es wurden $84,65 \%$ Glukomannan abgebaut.

\section{Aldosebestimnung}

Io ccin wurden mit $\mathrm{N}$-Natronlauge genau neutralisiert und nach Kolтhof wie oben die Aldosemenge bestimmt. 8,36 und $8,34 \mathrm{ccm}$, 
im Mittel also $8,35 \mathrm{ccm}$ 0,1 N-Jodlösung wurden verwendet $=0,07515 \mathrm{gr}$ Aldose gegen 0,07534 gr Zucker.

\section{Mannosebcstimmung durch Feststellung des Drehungsvermögens}

Diese Iösung wurde mit Bariumkarbonat neutralisiert und im Vakuum auf $35-45^{\circ} \mathrm{C}$. eingedickt, mit dem 3 fachen Volumen starken Alkohols versetzt, darauf filtriert und dann wieder mit Alkohol gewaschen. Das Filtrat wurde eingedampft, mit Tierkohle entfärbt, lann im Vakuum völlig vom Alkohol befreit, was durch wiederholten Wasserzusatz und erneutes Findampfen erreicht wurde. $\vdots \mathrm{ccm}$ dieser ca. $20 \mathrm{ccm}$ Lösung wurden mit Wasser auf $50 \mathrm{ccm}$ aufgefüllt und davon dienten $5 \mathrm{ccm}$ für eine Zuckerbestimmung.

Verbrauch an Kaliumpermanganat $7,20 \mathrm{ccm}=72,42 \mathrm{mg} \mathrm{Cu}=37,23$ $m g$ Zucker ais Glukose $=0,7446 \mathrm{gr}$ in den ursprünglichen $10 \mathrm{ccm}$ Lösung.

Bei $20^{\circ} \mathrm{C}$. in $100 \mathrm{~mm}$ Rohr betrug das Drehungsvermögen $(+)$ I,98 Grad. Aus der oben gegebenen Gleichung ergibt sich : $a=7,466$, $\mathrm{b}=1,98$, so hat man

$\mathrm{x}=\frac{(\mathrm{I} 3,3662 \times 1,98)-(1,9047 \times 7,466)}{5, \mathrm{I} 128}=2,395 \mathrm{gr}$ Glukose und 7,446 $-2,395=5,05 \mathrm{I}$ gr Mannose.

\section{Mannosebestimmung durch Mannosephenylhytrazon}

$5 \mathrm{ccm}$ dieser Lösung gaben 0,2702 und $0,2676 \mathrm{gr}$ Mannosephenylhydrazon=0,180 I und $0,1784 \mathrm{gr}$ Mannose, im Mittel also 0,1793 gr, entsprechend $0,3586 \mathrm{gr}$ Mannose in $10 \mathrm{ccm}$ Lösung.

(XIV) Hydrolyse mit $2 \%$ iger Schuefelsäure

2,138 $\mathrm{gr}=2,000 \mathrm{gr}$ wasser- und aschefreies Glukomannan wurden mit $200 \mathrm{ccm} 2 \%$ iger Schwefelsäure wie bei (XIII) beschrieben zersetzt. Nach 40 Stunden war das Produkt gefarbt und es wurcle ein hellbrauner Huminstoff abgeschieden. Nach dem Abküllcn wurde mit Wasser auf $250 \mathrm{ccm}$ aufgefüllt. $5 \mathrm{ccm}$ dienten für eine Zuckerbestimmung.

Verbrauch an Kaliumpermanganat $7,08 \mathrm{ccm}=71,21 \mathrm{mg} \mathrm{Cu}=36,5^{8}$ $\mathrm{mg}$ Zucker als Glukose $=1,329 \mathrm{gr}$ in $250 \mathrm{ccm}=9 \mathrm{I}, 45 \%$ 'Zucker wurden gewonnen, d. h. es wurden $82,31 \%$ Glukomannan abgebaut.

\section{Aldosebestimmung}

Für ro ccm wurden 8,20 und $8,25 \mathrm{ccm}$, in Mittel also $8,23 \mathrm{ccm}$ 
0,I N-Jodlösung verbraucht $=0,07402 \mathrm{gr}$ Aldose gegen $0,0736 \mathrm{gr}$ Gesamtzucker.

\section{Mannosebestimmung durch Feststellung des Drehungsvermögens}

Dicses Abbauprodukt wurde mit Bariumkarbonat neutralisiert und wie oben behancielt. I ccm dieser eingcdampften Lösung verbrauchte $8,60 \mathrm{ccm}$ Kaliumpermanganat $=84,49 \mathrm{mg} \mathrm{Cu}=45,05 \mathrm{mg}$ Zucker $=4,505$ $\mathrm{gr}$ in $100 \mathrm{ccm}$ Lösung.

Bei $20^{\circ} \mathrm{C}$. und bei Anwendung eines $220 \mathrm{~mm}$ Rohres betrug die polarisierende Kraft $(+) 2,57$ Grad. Nach der obigen Gleichung betragen $a=4,505, b=2,57$, so hat mat

$\mathrm{x}=\frac{(2,76254 \times 2,57)-(0,866 \times 4,505)}{2,324}=\mathrm{I}, 7 \mathrm{I} 4 \mathrm{gr}$ Glukose und 4,505 $-\mathrm{I}, 7$ I 4 = 2,791 gr Mannose.

\section{Mannosebestimmung durch Mannosephenylhydrazon}

Io ccm dieser Lösung gaben 0,3209 und 0,3307 gr Mannosephenylhydrazon $=0,214$ und $0,220 \mathrm{gr}$ Mannose, im Mittel also 0,2 $7 \mathrm{gr}$.

\section{(XV) Hyctrolyse mit $2 \%$ iger Salzsäzure}

$2,000 \mathrm{gr}^{\circ}=\mathrm{I}, 776 \mathrm{gr}$ absolut trockenes und aschefreies Glukomannan wurden mit $300 \mathrm{ccm} 2 \%$ iger Salzsäure im Glyzerinbade bei $115^{\circ} \mathrm{C}$. hydrolysicrt. Nach 15 Stunden war die Lösung gelbbraun und es wurde Huminstoff abgeschieden.

Verbrauch an Kaliumpermanganat $8,65 \mathrm{ccm}=86,5 \mathrm{I} \mathrm{mg} \mathrm{Cu}=4,5,06$ $\mathrm{mg}$ Zucker $=\mathrm{r}, 8025 \mathrm{gr}$ in $200 \mathrm{ccm}=100,55 \%$ Zucker wurden gewonnen, danach wurden also $90,50 \%$ Glukomannan verzuckert.

Diese Flüssigkeit wurde mit Bleikarbonat neutralisiert und wie vorher behandelt. I ccm der entsprechenden Lösung verbrauchte 5,60 $\mathrm{ccm}$ Kaliumpermanganatlösung $=28,33 \mathrm{mg} \mathrm{Cu}=56,66 \mathrm{mg}$ Zucker als Glukose $=5,666 \mathrm{gr}$ Zucker in $100 \mathrm{ccm}$.

\section{Mannosebestinnmung durch Feststelhng des Drehungsvernögens}

Bei $20^{\circ} \mathrm{C}$. in $100 \mathrm{~mm}$ Rohr betrug das Drehungsvermögen $(+)$ 1,55 Grad. Aus der w. o. gegebenen Gleichung ergeben sich für $a=5,666, b=1,55$, so hat man 
$x=\frac{(13,3662 \times 1,55)-(1,5046 \times 5,666)}{5,1128}=\mathrm{I}, 94 \mathrm{I} \mathrm{gr}$ Glukose und 5,666

$-\mathrm{I}, 94 \mathrm{I}=3,725 \mathrm{gr}$ Mannose.

Mannosebestimmung durch Mannosephenyllydrazon

5 ccm dieser Lösung ergaben :

\begin{tabular}{|c|c|c|}
\hline $\begin{array}{l}\text { Gebrauchtes } \\
\text { Phenylhydrazin }\end{array}$ & $\begin{array}{c}\text { Gefundenes } \\
\text { Mannosephenylhydrazon }\end{array}$ & Fintsprechende Mannose \\
\hline$\because \mathrm{r}, 2-\mathrm{Mol}$ & $\begin{array}{c}g r \\
0,2306\end{array}$ & $\begin{array}{c}\mathrm{gr} \\
\mathrm{o}, \mathrm{I} 3337\end{array}$ \\
\hline $\mathrm{I}, 2-\mathrm{Mol}$ & 0,2592 & 0,1729 \\
\hline 3. $\mathrm{Mol}$ & $c, 275 \mathrm{I}$ & $0,1 \delta_{34}$ \\
\hline 3- $\mathrm{Mol}$ & 0,2774 & 0,1849 \\
\hline 5-Mol & $0,2 \ddot{3} 3$ & 0,1889 \\
\hline 5- $\mathrm{M} / \mathrm{ll}$ & 0,2843 & 0,1899 \\
\hline
\end{tabular}

Der Schmelzpunkt Jieses Mannosephenylhydrazons betrug in allen Fällen $197^{\circ} \mathrm{C}$.

\section{KAPITEL,}

\section{Achtylierung des Giduomannans}

$\mathrm{Da}$ in de:n Glukomannan auf $6 \mathrm{C}$-Atome drei freie, alkoholische Hydroxylgruppen vorkommen,-ähnlich wie bei Cellulose, Ijchenin ${ }^{34}$, Stärke und Xylan ${ }^{35}$, - auch dic Triester, also die "Glukomannotriacetate" die höchsten Veresterungsstufen darstellen können.

$$
\left[\mathrm{C}_{6} \mathrm{H}_{7} \mathrm{O}_{2}\left(\mathrm{OCOCH}_{3}\right)_{3}\right] \text {. }
$$

$\mathrm{Zu}$ erfolgreicher Acetylierung der Kohlenhydrate verwendet man Essigsäurederivate, besonders IFssigsäureanhydrid bei Gegenwart verschiedener Katalysatoren, z. B. Zinkchlorid, Schwefelsäurc u. a. m.

PATrensox ${ }^{-19}$ stellte durch Erhitzung von Tagua-Palm-Mannan nach

* Sieh S, 296.

34 P. KARRER und B. Joos, Biochem. 7.tschr, f.36. $53^{3}$ (ry 23 ).

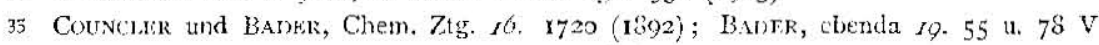
(r895); S. Komatsu und K. Kashima, Menn. Coll. Sci. Kinto Imp. Univ. Vol. V No. 5 (1922); F. Hutuser und P. Scitlasser, leer. d. Deutsch. Chem. Ges. 5b. 392 (1923)

r) 1. cit. 
Bannetr's Verfahren das Triacetat dar, das folgende Eigenschaften zeigt :

$$
\begin{array}{cc}
\text { Schmelzpunkt } & 128 \sim 145^{\circ} \mathrm{C} . \\
{[\alpha]} & (-) 3^{\circ} \text { (in Chloroform) }
\end{array}
$$

S. MIYAKE $\mathbf{E}^{25}$ hat durch Linwirkung von verschiedenen Acetylierungsmițtelı auf Konjakmannan (Fruktoglukomannan) das Reaktionsprodukt mit $62,95-64,1$ I $\%$ Essigsäure, $197-221^{\circ} \mathrm{C}$. Schmelzpunkt und $[\alpha]_{D}$. $=-35,{ }^{\circ} 52$ crhalten. Durch Acetylierung des Konjakmannans (mit Alkohol dargestellt) mit Essigsäuteanhydrid und Zinkchlorid entstand ein Produkt, dessen Essigsäuregehalt $62,08 \%,[\%]_{j}^{10}=-13^{\circ}, 3^{36}$ in Accton. Aber nach der Darstellung sind diese Mannane von Konjak sehr wahrscheinlich nicht einheitlich, sondern setzten sich noch aus verschiedenen Mannaneñ zusanimen.

Zur Acetylicrung des Glukomannans verwendeten wir Essigsäure-anhydrid bei Gegenwart von Pyridin, Zinnchlorid und Zinkchlorid. Die folgende Tabelle enthält die Werte der nach verschiedener Acetylierung

\begin{tabular}{|c|c|c|}
\hline Katitlysator & Schmelzpunkt & Fssigsture \\
\hline I'yridin & $216-226^{\circ} \mathrm{C}$. & $31,50 \%$ \\
\hline Zinnelitorid & $210-220^{\circ} \mathrm{C}$ & $59,79-64,23 \%$ \\
\hline Zinkenlorid & I $60-I c \sigma^{2} \mathrm{C}$ & $62,63 \%$ \\
\hline
\end{tabular}
erhaltenen. I'rodukte :

Wenn Pyridin als Katalysator verwendet wurde, so war das entstehende Produkt hauptsächlich ein Glukomannomonoacetat (Essigsäure 29,4 \% ). Wenn mit Zinnchlorid und Zinkchlorid acetyliert wurde, so enthielt es im wesentlichen ein Triacetat (Essigsäure 62,50\%). Die Schmelzpunkte der Ester waren sehr unscharf und weit schwankender.

Betr. der Veresterung kann die Frage aufkommen, warum es zur Acetylierung der polymeren Kohlenhydrate immor der Anwesenheit von Katalysaturen bedarf. Die Wirkung dieser Reaktionsbeschleuniger kann man sich verschieden vorstellen: als katalytische (indem sich etwa reaktionsfähige $Z$ wischenprodukte bilden), als eine auf die Cellulose quellungsförderncie, das Micellargefüge lockernde und damit den Dis-

25 1. cit.

36. T. Orsnk, !ourn. Chem. Soc. Japan 4y. 32r (1926). 
peritätsgrad erhöhende, cder endlich als ein hydrolysierence, spaitende. Einc ausgezeichnete Vorbesserung in dor Acetylicrung wegen dieser eintretenden Zersetzungr wird durch dic Verwendung von Sulfurylchlorid als Katalysator erzielt. Wenn man ein Gemisch von Chlor und Schwefeldioxyd benutzt, so erhalt man Ester, die in ihrer Crundzusammensetzung nur sehr wenig-bei diesen Verfahren ist die Bildung von Abbauprodukten nicht ausgeschlossen-verändert sind.

In einem Falle wurden die Mischung von Iisessig und Iissigsäureanhydrid, das $0,84 \%$ Chlor und $6,08 \%$ Schwefeldioxyd enthielt, auf ciem Wasserbade crhitzt. Fs wurde allnählich gelatinös und nach 5 Minuten langer Erhitzung wurde Alkohol hinzugefügt, cann der Ester nit Chloroform und mit P'ctroleunather als ein weiser, feiner Niedcrschlag abgeschieden. Das Produkt enthielt 60,77 ó Essigsäure und hatte cincn Schmelzpunkt von $170-187^{\circ} \mathrm{C}$. Wenn Essigsäureanhydrid anstatt Eiscssig verwendet wurde, der Prozentsatz von Chlor und Schwefeldioxycl verschieden war und bei Zinnertemperatur 1-3 Stunden Jung geschüttelt wurde, erhielt man fast dic gleichen Produkte:

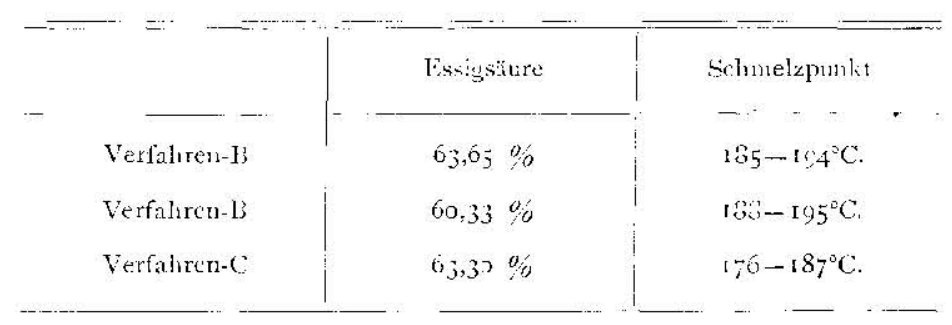

Je nach dem Mengenverhältnis der zugesetzten Acetylicrungsmittel erhielt man eine verschiedenhohe Ausbeute. Ls bedarf der Durcliführung einer grossen Anzahl von Versuchen, um die besten Bedingungen festzustellen.

Es wurde weitcr versucht, die Triester möglichst cinhcitlich durch Ausscheidung mit Chloroform und Petrolemäther zu trennen. Durch melurmaliges Umlösen liess sich der Schmelzpunkt auf $187^{\circ} \mathrm{C}$. bis $190^{\circ} \mathrm{C}$. bringen, dabei $174-180^{\circ} \mathrm{C}$. fing es an $\mathrm{zu}$ sintern. Ls ist wenig niedriger als bei Fruktoglukomannan $\left(197-221^{\circ} \mathrm{C}\right.$.). Dic Präparate lösen sich leicht in Chloroform mit Alkohol, Aceton, Bromoform, aber nicht in Wasser, Aether, Alkohol, Benzol und Petroleumäther.

Das spezifische optische Drehungsvermögen des Esters (in I:9 Alkohol-Chloroform) ist $[\alpha]_{D}^{15}=-21^{\circ}, 5$. 


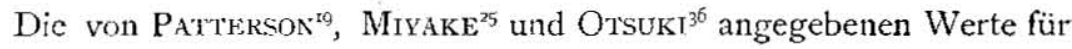
verschiedenen Mannane liegen zwischen $-3^{\circ}$ und $-35^{\circ}, 52$.

\begin{tabular}{|c|c|c|c|}
\hline Verfasser & & Lösungsmittel & \\
\hline PATTEKSON & Triacetylmannan & Chloroform & {$[a]=-3^{\circ}$} \\
\hline MUYAKF. & Triacetylfruktoglukomannan & Chlaroform & {$[\theta]=-35^{\circ}, 52$} \\
\hline OTsuki & l'riacetylgluknmannan & Aceton & {$[1 \%]_{D}^{: 0}=-13^{\circ}, 3$} \\
\hline Nisillol & Triacetylglukomannau & $\begin{array}{c}\text { Alkohol + Chloroform } \\
(\mathbf{I}: 9)\end{array}$ & {$[\alpha]_{j}^{15}=-2 \mathrm{I}^{0}, 5$} \\
\hline
\end{tabular}

Triacetylester wurde vakuumtrocknen analysiert und gab folgende Zahlen :

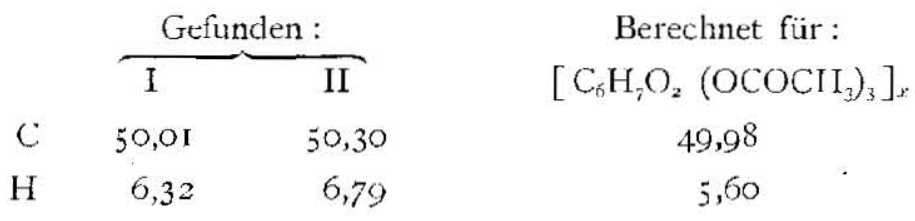

Als Molekulargewicht fanden wir, durch Gefrierpunktserniedrigung der bromoformigen Lösung, die Zahlen 2299 und 2382; aus den Formeln $\left[\mathrm{C}_{5} \mathrm{H}_{7} \mathrm{O}_{2}\left(\mathrm{OCOCH}_{3}\right)_{3}\right]$, und $\left[\mathrm{C}_{6} \mathrm{H}_{2} \mathrm{O}_{2}\left(\mathrm{OCOCH}_{3}\right)_{3}\right]_{5}$ berechnen sich dic Molckulargewichte 2592 und I 782 . Die Wahrscheinlichkeit spricht für dic Formel $\left[\mathrm{C}_{6} \mathrm{H}_{7} \mathrm{O}_{2}\left(\mathrm{OCOCH}_{3}\right)_{3}\right]_{8}$.

\section{EXPERIMENTELLES}

\section{(I) Acetylierung mit Essigsäureanhydrid bei Gegenzerart von Pyridin}

$3,5 \mathrm{gr}$. Glukomannan wurden mit $70 \mathrm{gr}$ Essigsäureanhydrid in einem Kolben gemischt und dazu $3 \mathrm{gr}$ Pyridin mit $15 \mathrm{ccm}$ Eisessig hinzugefügt. Die Mischung wurde auf dem Wasserbade mit Rückflusskühler ca. 5 Minuten erhitzt und in absoluten Alkohol gegossen, wobei das alkoholunlösliche Acctat als feincr, weisser flockiger Nicderschlag ausfiel. Die Temperaturerhöhung und die Reaktionswärme wurden durch Kühlen mit Eis beseitigt. Nun wurde abgesogen und gründlich mit Alkohol ausgewaschen. Das Produkt wurde mit Chloroform gelöst, abfiltriert

36 1. cit. 
und dann mit Petroleumäther ausgeschieden, filtriert, ausgewaschen und nochmals mit Chloroform gereinigt und getrocknet. Aus 3,5 gr Glukomannan wurden $0,8 \mathrm{gr}$ (Ausbeute $23 \%$ ) von folgenden Eigenschaften gewonnen :

Schmelzpunkt $218-226^{\circ} \mathrm{C}$ Essigsäure $31,50 \%$

(Theoretischer Wert 29,4I \% als Monoacetat)

Zur Bestimmung der Essigsäure wurden $0,29 \mathrm{gr}$ Acetat mit $75 \mathrm{ccm}$ $\mathrm{N} / 2$ - Schwefelsäure auf dem Wasserbade ro Stunden erhitzt und mit normal $\mathrm{NaOH}$ - I.ösung zurücktitriert.

(II) Acetylienng mit Essigsäureanhydrid bei Gegenwart von Zinnchlorid

Durch Erhitzung mit 30 gr Essigsäureanhydrid bei Gegenwart von 4 gr Zinnchlorid auf Wasserbade während 5 Minuten wurcle das Glukomamnan ( 2 gr) acetyliert. Man gewinnt daraus Jurch Alkohol ein weisses Rohacetat, das durch Chloroform und Petrolcumäther wie vorher vielmals gereinigt wurde. Aus $2 \mathrm{gr}$ und $4 \mathrm{gr}$ lufttrockenem Glukomannan wurden $2,15 \mathrm{gr}$ (I) und 4,7 $\mathrm{gr}$ (II) wasserfreies Acetat erhalten (Ausbeute I07,5\% und I $17,5 \%$ ).

\begin{tabular}{lcc} 
& \multicolumn{1}{c}{$\mathrm{I}$} & \multicolumn{1}{c}{ II } \\
Schmelzpunkt & $210-220^{\circ} \mathrm{C}$ & $210-217^{\circ} \mathrm{C}$. \\
Essigsäure & $59,79 \%$ & $6420 \%$ \\
(Theoretischer Wert $62,50 \%$ & $\%$ als & Triacetat)
\end{tabular}

Die Essigsäurebestimmung wurde in dem Acetat durch Verseifen mit Aceton und mit Normal-Natronlauge ausgeführt.

(III) Acetylienung mit Essigsäureanhydrid bei Gegeniuart von Zinkchlorid

$4 \mathrm{gr}$ Glukommannan wurden mit $30 \mathrm{gr}$ Essigsäureanhydrid und $4 \mathrm{gr}$ Zinkchlorid wie vorher behandelt und gereinigt.

Schmelzpunkt $\quad 180-190^{\circ} \mathrm{C}$. Essigsäure $62,68 \%$

Dic Essigsäure wurde nach der Vorschrift von $\mathrm{OsT}^{37}$ durch Verseifen des Acetats mit $50 \%$ igrer Sclıwefelsäure und Destillation im Wasserdampfstron bestimut.

37 7tscher. f. angew. Chem. 19. 095 (10j06) 
(IV) Acetylierung mit Essigsäureanhydrid durch die Verwendung von Sulfurylchlorid als Katalysator

Verfahren-A. 3 gr Glukomannan wurden mit $20 \mathrm{gr}$ Lisessig über gegossen und dann $40 \mathrm{ccm}$ Fssigsäureanhydrid, das $0,84 \%$ Chlor und $10 \mathrm{ccm}$ Essigsäureanhydrid, das 6,08\% Schwefeldioxyd enthielt, hinzugefügt. Die Mischung wurde auf dem Wasserbacle 5 Minuten lang erwärmt, so entstand eine klare Lösung, aus der Fster mit Wasser isoliert werden konnte. Das Produkt wurde mit Chloroform getrennt und mit Petroleumäther ausgefailt, dann getrocknet.

$$
\text { Schmelzpunkt } \quad 176-187^{\circ} \mathrm{C} . \quad \text { Essigsäure } 60,77 \%
$$

Die Essigsäurebestimmung wurde hier ebenso wie auch in den folgenden Versuchen wie vorher nach OsT ausgeführt.

Verfahren- $B$. In diesem Falle wurden $3 \mathrm{gr}$ Glukomannan mit 30 $\mathrm{ccm}$ Essigsäureanhydricl und $\mathrm{I} 4 \mathrm{ccm}$ Essigsäureanhydrid, das $0,66 \%$ Chlor und das gleiche Volum Anhylrid, das 6,08\% Schwefeldioxyd enthielt, hinzugefügt und dic Mischung 30 Minuten lang bei $20^{\circ} \mathrm{C}$. durch die Schüttelmaschine gut geschüttelt und isoliert. Nach 2 Mal wiederholter Acctylierung wurde der Ester wie gewöhnlich mit Wasser abgeschieden. Hierdurch erhielten wir dem Ester in Gestalt eines weissen, feinen Niederschlages und Breis; dann wurden die Produkte wie vorher gereinigt und getrocknet.

$\begin{array}{llc}\text { Acetat aus Brei } & 63,65 \% & 185-194^{\circ} \mathrm{C} \text {. } \\ \text { Acetat aus feinen Niederschlage } & 60,33 \% & 188-195^{\circ} \mathrm{C} \text {. }\end{array}$

Verfaluren-C. $5 \mathrm{gr}$ Glukomannan wurden wie vorher mit $32 \mathrm{gr}$ Essigsäureanhydrid, $27 \mathrm{~cm}$ Essigsäureanhydrid, das 2,65\% Chlor und $9 \mathrm{ccm}$ Anhydrid, das $8,4 \%$ Schwefeldioxyd enthielt, I Stunde lang geschüttelt, dann wieder das Rohacetat mit den Reagentien in gleichen Volumverhältnis 30 Minuten lang acetyliert. Dic Ausbeute betrug 3.7 gr also $74 \%$ und zeigte die folgenden Eigenschaften :

$$
\text { Schmelzpunkt } \quad 176-187^{\circ} \mathrm{C} \quad \text { Essigsäure } 63,30 \% \text {. }
$$

Versuche zur Reinigung des Triacetats fuhrten trotz eingehender Untersuchungen zu keinem konstanten Sclımelzpunkt:

Bei $174-180^{\circ} \mathrm{C}$. fing das Triacetat an $z u$ sintern und ging bei etwa

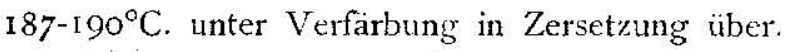




\begin{tabular}{|c|c|c|c|}
\hline Reinigung & Schinelzpunkt & Reiniguuy & Schmclzpunkt \\
\hline I Wal & $176-167^{\circ} \mathrm{C}$ & $4 \mathrm{Mal}$ & $177-182^{\circ} \mathrm{C}$ \\
\hline $2 \mathrm{Mal}$ & $174-185^{\circ} \mathrm{C}$ & $5 \mathrm{Mal}$ & $180-1 \delta 7^{\circ} \mathrm{C}$ \\
\hline $3 \mathrm{Mal}$ & $180-190^{\circ} \mathrm{C}$ & & \\
\hline
\end{tabular}

\section{Elementaranalyse}

Die Verbrennung des Triacetats ergab die folgenden Wert:

I) 4,78 $\mathrm{I} \mathrm{mg}$ Substanz gaben $8,767 \mathrm{mg} \mathrm{CO}_{2}$ und $2,72 \mathrm{Img} \mathrm{H}_{2} \mathrm{O}$, entsprechend 50,0I \% $\mathrm{C}$ und $6,32 \% \mathrm{H}$.

2) 5,579 $\mathrm{mg}$ Substanz gaben $10,290 \mathrm{mg} \mathrm{CO} \mathrm{CO}_{2}$ und 3,380 $\mathrm{mg} \mathrm{H}_{2} \mathrm{O}$, entsprechend $50,30 \% \mathrm{C}$ und $6,79 \% \mathrm{H}$.

Berechnet für Triacetylglukomannan, $\mathrm{C}=49,98 \%, \mathrm{II}=5,60 \%$.

\section{Spezifische Drehung}

Das spezifische Drehungsvermögen wurde in Alkoholchloroformlösung ( $1: 9)$ mit dem LANDOL-Lrricir'schen Polarimeter bestimmt:

$$
[a]_{1}^{15}=\frac{12,2,36 \times(-0,25)}{0,5 \times 1,4226 \times 0,2003}=(-) 21^{\circ}, 5 .
$$

\section{Molekulargeziclit}

Dic Molekulargewichtsbestimmung wurde nach der kryoskopischen Methode von Beckмanx ausgeführt, wobei Bromoform als I.osungsmittel diente.

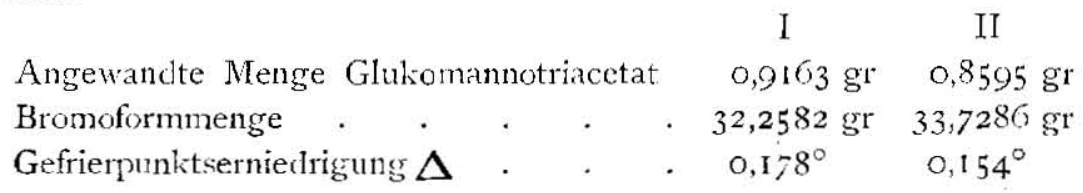

$$
\begin{aligned}
& M=\frac{144 \times 100 \times 0,9163}{32,2582 \times 0,178}=2299 \\
& M=\frac{144 \times 100 \times 0,8595}{33,7286 \times 0,154}=2383
\end{aligned}
$$

IV. KAPITEI

\section{Acerolyse des GLLkomannans}

Aus den Ergebnissen der Hydrolyse mit Salz- und Schwefelsäure 
geht also hervor, class das Glukomannan ein Mannose- und Glukosederivat $(2: i)$ ist, darüber hinaus haben wir eine Reihe neuartiger Cinsetzungsprodukte durch Acctolyse zu Tage fordern können. Aus dieser Klarstellung kommen wir der Fracre cler Stellung der Mannose und der Glukose in dem Gilukomannan bedentend näher.

Wir haben die Acetolyse des Glukomannans in der Wärme und in der Kälte mit einem Gemisch aus Essigsäureanhydrid und konz. Schwefelsaure nach Skracp und Koenig ${ }^{35}$ ausgeführt. Dabei ficl kein flockiges I'rodukt aus, das w.r wahrscleinlich in der I Iitze über das Zwischenprodukt zum ITexoseacetat abgebaut worden. Wir haben uns bemuht diese Umsetzung so zu vermindern und durch gecigncte Versuchsbedingungen die Acetolyse so zu leiten, dass eine möglichst gute Ausbeute des Zwischenproduktes gुewomen wurde. Wit Fisigsäureanlyylrid, Eisensig und konz. Schwefelsäurc in der Kälte ${ }^{3 ?}$ war die Ausbeute eine bessere und die Reinigung des crhaltenen Produktes leichter durchfuhrbar.

5-10 gr Glukomaninan wüden in einer Stopselhasche nil einem abgekühlten Gemisch von 20-25 gr Essigsäurcanhydrid, I 8-46 gr Eisessig und $\mathbf{1 , 6 - 4}$ gr konz. Schwefelsäure übergegossen, dabei bei erhöhter lemperatur mit Eis gekühlt wurde. Dic Lösung wurde in Zimmer bei $23-26^{\circ}, 5 \mathrm{C}$. oder im Warmeschrank bei $22-23^{\circ} \mathrm{C}$. während $8-20$ Tagen lang unter öfterem Umschütteln aufbewahrt, danach cer flockige Niederschlag vollständig säurefrei mit Wasser ausgewaschen. Darauf wurde das Roliacetat mehrere Male mit kaltem Allohol ausgezogen, wobei das hochmolekulare Acetat unlöslich, aber sich in warmem Alkohol als leicht löslich erwies. Nach Abdampfen wurde das Acetat als schneeweisses Pulver dargestellt. Die Ausbeute ist aus folgender Tabelle ersichtlich.

\begin{tabular}{|c|c|c|c|c|c|c|c|c|c|}
\hline Nr. & $\begin{array}{l}\text { Giuko- } \\
\text { mannan }\end{array}$ & $\begin{array}{c}\text { Essig- } \\
\text { säure- } \\
\text { anllyydrid }\end{array}$ & hisessig & $\begin{array}{c}\text { Sihweflel- } \\
\text { säure }\end{array}$ & $\begin{array}{l}\text { Tompe- } \\
\text { rature }\end{array}$ & $\begin{array}{l}\text { Reak- } \\
\text { tions- } \\
\text { daucr }\end{array}$ & $\begin{array}{l}\text { Roll- } \\
\text { acetat }\end{array}$ & Ausbente & $\begin{array}{l}\text { Roluacetat } \\
\text { in I'roz. } \\
\text { d. Th. }\end{array}$ \\
\hline & $g r$ & $g r$ & $\mathrm{Fr}$ & $3 r$ & & Tiste & $g r$ & $\%$ & $0 \%$ \\
\hline 1 & 5 & 20 & 16,4 & 1,6 & $22-23^{*} \mathrm{C}$ & 10 & $\begin{array}{c}4,9 \\
3,5+(1,4\end{array}$ & 93 & 49 \\
\hline 2 & 5 & 25 & 24,0 & 2,0 & $22-23^{\circ} \mathrm{C}$ & 10 & 5,9 & II & 59 \\
\hline 3 & 5 & 25 & 23,0 & 2,0 & $23=$ & 8 & $\left|\begin{array}{c}5,6 \\
3,6+2,0 ;\end{array}\right|$ & 112 & $5^{6}$ \\
\hline
\end{tabular}

33 ier. d. Deutsch. Chem. Ges. 3.t. III5 (I901); Monath. 1. Chem. 23. Ior I (Igor).

39) II. OST und G. Kxorit, Cell. 3. 25 (1uzz). 


\begin{tabular}{|c|c|c|c|c|c|c|c|c|c|}
\hline 4 & 5 & $30 \mathrm{ccm}$ & $200 \mathrm{~cm}$ & $2 \mathrm{ccm}$ & $23^{\circ} \mathrm{C}$ & $\ddot{3}$ & 5,6 & 112 & 56 \\
\hline 5 & 5 & 25 & 24,0 & 2,0 & $23-26^{2}, 5 \mathrm{C}$. & 12 & 5,4 & 108 & 54 \\
\hline 6 & $s$ & 40 & 37,0 & 3,2 & $22-23^{\circ} \mathrm{C}$ & 15 & $9, \mathbf{I}$ & $\mathrm{II}_{4}$ & 57 \\
\hline 7 & 3 & 40 & 37,0 & 3,2 & $32-26^{\circ}, 5 \mathrm{C}$. & 20 & 9,4 & II: & 59) \\
\hline 's & 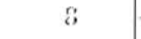 & 40 & 37,0 & $3 \cdot 2$ & $22-26^{2}, 5 \mathrm{C}$ & 20 & 10,6 & 133 & if \\
\hline 9 & 10 & 50 & $4^{6,0}$ & 4,0 & $23^{\circ} \mathrm{C}$. & 19 & 10,9 & 109 & 55 \\
\hline Io & 10 & 50 & $4^{6,0}$ & 4,0 & $=3^{\circ} \mathrm{C}$. & 19 & 11,7 & 117 & 59 \\
\hline 11 & $\begin{array}{c}12 \\
\text { (Triliexose- } \\
\text { acetat) }\end{array}$ & 60 & 55,2 & 4,8 & $23^{\circ} \mathrm{C}$ & 7 & 8,2 & 68 & 63 \\
\hline 12 & $\begin{array}{c}8,5 \\
\text { (Triacctyl- } \\
\text { gluksi- } \\
\text { naannan) }\end{array}$ & 42,5 & 39,1 & 3,4 & $23^{\circ} \mathrm{C}$. & 10 & 5,6 & 63 & $6 \mathrm{t}$ \\
\hline
\end{tabular}

Aus der obigen Tabelle geht dic Ausbcutc je nach den Variationen der Versuchsbedingungen hervor, sie betrug von $98 \%$ bis $133 \%$. Die maximale Ausbeule an Rohacetat geht aus diesen Versuchen mit ca. $67 \%$ d. Theorie, entsprechend ca. $72 \%$ d. Theorie für absolutes trockenes Glukomannan, hervor.

Das folgende Verbältnis der Reagentien wurde als zweckmässig gefunden.

$$
\begin{array}{rll}
8 \mathrm{gr} & \text { Glukomannan } \\
40 \mathrm{gr} & \text { Lissigsäureanhydrid } \\
46 \mathrm{gr} & \text { Fisessig } \\
4 \mathrm{gr} & \text { konz. Schwefelsäure }
\end{array}
$$

Die Reaktionsdauer bei Zimmertemperatur $\left(22-26,0_{5} \mathrm{C}\right.$ ) oder in dem Schrank $\left(23^{\circ} \mathrm{C}\right.$.) wurde mit etwa $15-20$ Tagen als die günstigste gefunden.

Das Rohacetat war hauptsächlich in kaltem Alkohol löslich, aber ein Teil von Nr. I und $\mathrm{Nr}$. 3 war unlöslich. Versuche zur Trennung und Reinigung des Rohacetates wurden in dieser Hinsicht (Lö.lichkeit) durchgeführt, alle Bemühungen seiner Isolierung aber blieben erfolglos.

Der Schmelzpunkt schwankte also zwischen $88-95^{\circ} \mathrm{C}$. und I Io- $\mathrm{I} 20^{\circ} \mathrm{C}$., bei dem unlöslichen Teil erhöhte er sich auf $\mathrm{I} 3 \mathrm{I}-140^{\circ} \mathrm{C}$ bis $145^{-}-149^{\circ} \mathrm{C}$. und war etwas schwankend. Das Produkt fing zuerst an zu sintern, bei $3-5^{\circ}$ unter dem Endpunkte, ging es hauptsächlich in die Schmelze über und wurde schliesslich unter Verfärbung zersetzt. 


\begin{tabular}{|c|c|c|c|c|c|c|c|}
\hline \multicolumn{4}{|c|}{ 1.̈̈slich in kaltem Alkohol } & \multicolumn{4}{|c|}{ Unlöslich in kaltem Alkohol } \\
\hline Nr. & $\begin{array}{l}\text { Wicderholte } \\
\text { Reinigung }\end{array}$ & $\begin{array}{l}\text { Schmelz- } \\
\text { punkt C. }\end{array}$ & $\begin{array}{c}\text { Essigsäure } \\
\% \%\end{array}$ & Nr. & $\begin{array}{l}\text { Wiederholte } \\
\text { Reinigung }\end{array}$ & $\begin{array}{l}\text { Schmelz- } \\
\text { punkt C. }\end{array}$ & $\begin{array}{c}\text { Essigsäuse } \\
\%\end{array}$ \\
\hline I & & $94-105^{\circ}$ & - & 1 & & $145-149^{2}$ & \\
\hline I & vielmal & $107-1: 5^{\circ}$ & 65,36 & 1 & $\mathrm{I}-\mathrm{mal}$ & $145-143^{\circ}$ & \\
\hline & & & & $\mathbf{r}$ & $2-m a !$ & $145-149^{\circ}$ & 62,26 \\
\hline 2 & $\mathrm{I} \cdot \mathrm{mal}$ & $120-125^{\circ}$ & & & & & \\
\hline 2 & $2-\mathrm{mal}$ & $127-125^{\circ}$ & & & & & \\
\hline 2 & $4^{-\mathrm{mal}}$ & $106-116^{\circ}$ & 67,73 & & & & \\
\hline 3 & & $109-115^{\circ}$ & & 3 & & $131-140^{\circ}$ & \\
\hline & 2 -mai & $110-115^{\circ}$ & $6 \mathbf{7}, 69$ & 3 & $2-\mathrm{mal}$ & $13 \mathrm{I}-140^{\circ}$ & 63,61 \\
\hline 4 & & $110-11 \delta^{a}$ & & & & & \\
\hline & 2-mal & $108-115^{\circ}$ & 65,54 & & & & \\
\hline 5 & viel mal & $110-120^{\circ}$ & 68,31 & & & & \\
\hline 6 & " & $107-116^{\circ}$ & 60,37 & & & & \\
\hline 7 & $"$ & $100-110^{\circ}$ & 70,64 & & & & \\
\hline 8 & ; & $80-95^{\circ}$ & 70,61 & & & & \\
\hline 9) & ", & $90-100^{\circ}$ & 70,23 & & & & \\
\hline 10 & ", & $103-115^{\circ}$ & 69,71 & & & & \\
\hline
\end{tabular}

Der Essigsäuregehalt schwankte zwischen $65,04 \%$ und $70,64 \%$ im löslichen Teil, zwischen $62,26 \%$ und $63,6 \mathrm{I} \% \mathrm{im}$ unlöslichen Teil. Es ist bemerkenswert, dass in dem Alkohol unlöslichen Teil, d.h. in dem durch der Acetolyse bei geringer Reaktionsdauer (8-10 Tagen) gewonnenen Produkte der Essigsäuregehalt ein nicdriger ist. Es bedeutet daher diese Schwankung zunächst einen Beweis dafür, dass in diesen Produkten ein hochmolekulares Acetat vorhanden ist. Bei der crsten Einwirkung des Acetolysemittels auf das Glukomannan hat die Veresterung zu Acetylglukomannan stattgefunden, dann wurde es über hochmolekulare Acetate zu Giukose- und Mannosepentaacetat umgewandelt, wie das folgende Schema zeigt:

Glukomannan $\longrightarrow$ Triacetylglukomannan (Essigsäure 62,50\%) $\longrightarrow$ Hochmolekulare Acetate des Glukomannans (Zwischenprodukt) $\longrightarrow$ Hendekaacetylglukomannotrihexose (Essigsäıre 68,29\%) $\longrightarrow$ Octaacetyl- 
mannobiose oder Octaacetylglukomannobiose (Essigsäure $70,80 \%$ ) $\rightarrow \rightarrow$ Pentaacetyl-mannose und -glukose (Essigsäure 76,92\%).

Die Acetate aus $\mathrm{Nr}$. I-A, Nr. I-B, Nr. 2, Nr. 3-A, Nr, 3-B und Nr. 4 waren Gemische von Triacetylglukomannan, hochmolekularen Acetaten des Glukomannans und Hendekaacetylglukomamotriliexose. Die Acetate aus $\mathrm{Nr}$. 5-Nr. Io stimmten mit der Hendekancetylglukomannotrihexose überein, dass darin bercits kleine Mcngen Octaacetylbiose und Pentaacetylhexose enthalten waren.

Die Verbrennung der Acetate aus Nr. I, Nr. 3 und Nr. 4 ergab die folgenden Werte:

\begin{tabular}{|c|c|c|c|c|c|}
\hline \multicolumn{2}{|c|}{ Löslich in kaltem } & Alkohel & \multicolumn{3}{|c|}{ Un'öslich in kaltem Alkohol } \\
\hline Nr. & C \% & $\mathrm{H} \%$ & Nr. & $\mathrm{C} \%$ & $\mathrm{H} \%$ \\
\hline I & 48,70 & 5,50 & I & $4 \hat{\&}, 70$ & $6,0^{\prime \prime}$ \\
\hline I & $4 \hat{0,67}$ & 5,63 & I & 48,46 & $6, \mathrm{It}$ \\
\hline 3 & $4 ;, 04$ & 5,89 & & & \\
\hline 3 & $4 \hat{6}, 33$ & 5,74 & & & \\
\hline 4 & $4 \delta, 90$ & 5,77 & & & \\
\hline 4 & 40,56 & 5,94 & & & \\
\hline
\end{tabular}

$$
\begin{aligned}
& \text { Bercchnet für Triacetylglukomannan }\left[\mathrm{C}_{6} \mathrm{H}_{7} \mathrm{O}_{2}\left(\mathrm{OCOCH}_{3}\right)_{3}\right]_{x} \\
& \mathrm{C}=49,98 \% \quad \mathrm{II}=5,60 \% \\
& \text {,I Iendekaacetyltrihexose }\left[\mathrm{C}_{12} \mathrm{H}_{21} \mathrm{O}_{5}\left(\mathrm{OCOCH}_{3}\right)_{3 \mathrm{r}}\right] \\
& \mathrm{C}=49,67 \% \mathrm{H}=5,63 \% \\
& \text {, Octaacetylbiose }\left[\mathrm{C}_{12} \mathrm{I}_{14} \mathrm{O}_{\hat{j}}\left(\mathrm{OCOCH}_{3}\right)_{s}\right] \\
& \mathrm{C}=49,56 \% \quad \mathrm{H}=5,65 \% \\
& \text { " , Pentaacelylhexose }\left[\mathrm{C}_{6} \mathrm{H}_{7} \mathrm{O}\left(\mathrm{OCOCH}_{3}\right)_{5}\right] \\
& \mathrm{C}=49,23 \% \mathrm{H}=5,69 \%
\end{aligned}
$$

Das Acctat aus Nr. 7 löste sich in weniger kaltem Alkohol nach vielmaligem Ausziehen mit heissem Wasser teilweise auf. Der zurückbleibende Sirup gab nach mehrmaligen Umfällen die Kristalle von Hendekaacetylglukomannotrihexose, die $69,78 \%$ Essigsäure enthalten, und bei denen $[\alpha]_{D}=+15^{\circ}, \mathrm{I}$ ist. Sie besitzen weisse Wetzsteinform, wie aus Figur I crsichtlich ist, fangen bei $90-93^{\circ} \mathrm{C}$. an zu sintern 
Fig. I.

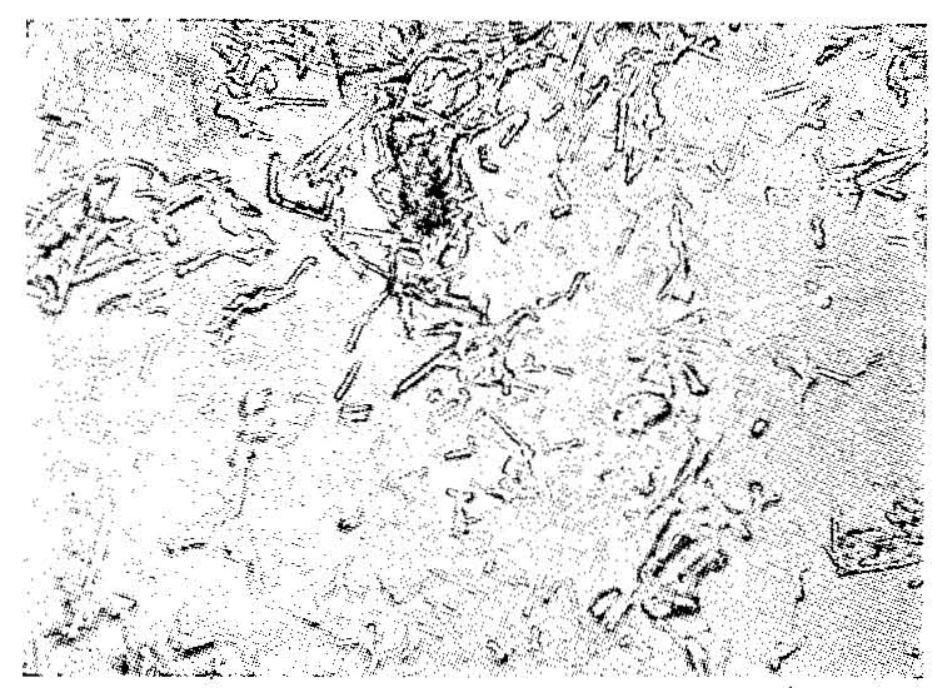

und schmelzen bei $108-110^{\circ} \mathrm{C}$. unter Bräunung und Zersetzung. Die Elementaranalyse erbrachte den Beweis dafür, dass es sich bei den Kristallen um Hendekaacetylglukomannotrihexose handelt:

\begin{tabular}{lrrr} 
I & \multicolumn{1}{c}{} & II & Befechnet für \\
C & $49,65 \%$ & $49,38 \%$ & $\mathrm{C}_{40} \mathrm{H}_{54} \mathrm{O}_{27}$ \\
$\mathrm{H}$ & $5,72 \%$ & $5,77 \%$ & $49,67 \%$ \\
$5,63 \%$
\end{tabular}

Das Molekulargewicht wurde durch Gefrierpunktserniedrigung der benzoligen Lösung ausgeführt, und die $\mathrm{Zahl}$ war 924 und IOI4; aus den Formeln $\left[\mathrm{C}_{18} \mathrm{IH}_{2 \mathrm{I}} \mathrm{O}_{5}\left(\mathrm{OCOCH}_{3}\right)_{11}\right]$ und $\left[\mathrm{C}_{22} \mathrm{H}_{14} \mathrm{O}_{3}\left(\mathrm{OCOCH}_{3}\right)_{8}\right]$ berechnet sich das Molekulargewicht auf 966 und 678 . Da das gefundene Molekulargewicht ein wenig zur Hcndekaacetylglukomannotrihexose überstimmte, ist anzunehmen, dass dic Kristalle wahrscheinlich noch kleine Mengen nieder- oder hochmolekularen Acetate enthiclten.

Wenn auch die Löslichkeit der Acetate nur wenig Unterschiede zeigt, so ist doch die Durchführung der Trennung sehr schwierig. Viel besser kommt man zum Ziel, wenn man mit Acther bis zur Erschöpfung auszieht. Iei ständiger Extrahierung klebte das Acetat als klumpige Masse zusammen, diese wurde herausgenommen, dann pulverisiert, wieder von neuem mit Aether ausgezogen. Es wurde nach mehrmaligem 
Ausziehen (14-60 Tagen) mit Alkohol als der Kristall (Figur I) von folgenden Eigenschaften erhalten:

\begin{tabular}{|c|c|c|c|c|c|}
\hline \multicolumn{6}{|c|}{ Das ätherlösliche Acetat } \\
\hline $\mathrm{Nr}$. & Schmelzpunkt & $\begin{array}{c}\text { Essigsüure } \\
o \%\end{array}$ & $\begin{array}{l}{[\alpha]_{D}^{20} \text { in }} \\
\text { Chloroformi }\end{array}$ & {$\left[\begin{array}{l}\alpha]_{1}^{23} \text { in } \\
\text { Benzol }\end{array}\right.$} & $\begin{array}{l}\text { Molekular- } \\
\text { gewicht }\end{array}$ \\
\hline$g+A$ & $35-100^{\circ}$ & $70, \hat{3}_{4}$ & $+18^{\circ}, 9$ & $+5^{\circ}, 2$ & $\begin{array}{l}919 \\
941\end{array}$ \\
\hline$I C-A$ & $100-105^{\circ}$ & $70,5 \mathrm{I}$ & $+17^{\circ}, 3$ & $+4^{\circ}, 6$ & 947 \\
\hline
\end{tabular}

\begin{tabular}{|c|c|c|c|c|}
\hline \multicolumn{5}{|c|}{ Das atherunlösliche Acetat } \\
\hline Nr. & $\begin{array}{c}\text { Schmelzpunkt } \\
\text { C. }\end{array}$ & $\begin{array}{c}\text { Hossigsäure } \\
\% \%\end{array}$ & $\begin{array}{c}{[\partial]^{20} b \text { in }} \\
b \text { Ciroloform }\end{array}$ & $\begin{array}{r}\text { Molekuiar } \\
\text { gewicht }\end{array}$ \\
\hline $9-B$ & $08-105^{\circ}$ & 69,82 & $+15^{\circ}, 5$ & 943 \\
\hline IO-I3 & $105-115^{\circ}$ & 68,69 & $+10^{\circ}, 8$ & II 34 \\
\hline
\end{tabular}

Aus diesen Versuchen geht also hervor, dass der ätherlösliche 'leil viele Acetylgruppen aufuimmt und zwar rund $70,7 \%$, darin wahrscheinlich Hexoseacetat vorhanden ist. Der Schmelzpunkt von dem ätherlöslichen Acetate war niedriger als der des ätherunlöslichen Teiles. Das Drehungsvermögen war in Chloroform erhöht und nach der Ausziehung mit Acther zeigte das Produkt ein höleres spezifisches Drehungsvermögen. Das gefundene Molekulargewicht bei $\mathrm{Nr}$. 9-A, Nr. IO-A und Nr. 9-B stimmt an besten mit der Formel $\left[\mathrm{C}_{18} \mathrm{H}_{21} \mathrm{O}_{5}\left(\mathrm{OCOCH}_{3}\right)_{11}\right]$ überein.

Aus dicsem Wege liess sich dic crfolgreiche Isolierung ( $\mathrm{-}-2$ Monatcn lang) bei Nr. I I und Nr. I2 wiederholen. Dic Konstanten ergaben :

Das ïtherlösliche Acetat

\begin{tabular}{|c|c|c|c|c|}
\hline $\mathrm{Nr}$. & $\begin{array}{c}\text { Sehmelzpun't } \\
\text { C. }\end{array}$ & $\begin{array}{l}\text { Essigsinure } \\
\% \\
\%\end{array}$ & $\begin{array}{c}{[u]^{23} \text { in }} \\
\text { Chrorolurm }\end{array}$ & $\begin{array}{l}\text { Nolckular- } \\
\text { gewicht }\end{array}$ \\
\hline II-A & $9^{\circ}-105^{\circ}$ & 69,92 & $17^{\circ}, 9$ & 979 \\
\hline $12-\mathrm{A}$ & $95-10 z^{\circ}$ & 70,77 & $1 y^{2}, 7$ & 936 \\
\hline
\end{tabular}


Das ätlicrumlüsliche Acctat

\begin{tabular}{|c|c|c|c|c|}
\hline $\mathrm{Nr}_{\mathrm{r}}$ & Sclmel punkt & $\begin{array}{c}\text { Essigsäure } \\
0 ;\end{array}$ & {$\left[\begin{array}{l}{[x]_{D}^{20} \text { in }} \\
\text { lienzol }\end{array}\right.$} & $\begin{array}{l}\text { Moleliular- } \\
\text { gewicht }\end{array}$ \\
\hline II $-\mathrm{T}$ & $102-115^{\circ}$ & 68,76 & $12^{\mathrm{c}}, 3$ & $\mathrm{r}_{4} \mathrm{I}_{3}$ \\
\hline $12-11$ & $123-126^{\circ}$ & - & $3^{\circ}, 7$ & $155=$ \\
\hline
\end{tabular}

Fine Reihe von Versuchen der Trennung wurde weiter fortgeführt, wobei Pentancetylhexose durch dic wiederholte Ausziehung nit heissem Wasser abgetrennt wurde. Schliesslich hat die Abtrennung der Einheiten durch viclmalige fraktionierte $\Lambda$ usscheioung nit $50 \%$ igem Metlylatkohol nar ergeben, dass die IIendekaacelylglukomaniotrihexose löslich ist, und durch l:ungssmes Abkühlen auf $5-0^{\circ} \mathrm{C}$ isolieren werden

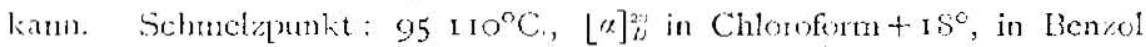
$+6^{\circ}$. Es löst sich in Chlorofom, Bromoform, Methyl- und Aethylalkohol, zienlich schwer in Aether und niclit in Wasser und Petroleumäther.

Die Verseifung wurde mit Barytwasser unter fontwährendem Schütteln bei $30^{\circ} \mathrm{C}$. ausgeführt. Nach etwa 6 Stunclen wurcle das Baryt mit Schwefelsiure epuantitativ entfernt und clas filtrat unter verminiertem 1) ruck eingeengt Nach langem Stchen im Exsiccator stelle sich keine Ausscheiklung von Kristallen der Glukomannotrihexose ein, die aber bei Zusatz von Alkolwol als weisses Pulver ausfiel, in dem noch ein Spur IBarium zurückgeblieben war. Schmelzpunkt: IIS-I20 C. unter Sintern, etwa $175^{\circ} \mathrm{C}$. unter starkem Aufschäumen, $182^{\circ} \mathrm{C}$. unter Zersetzung mit Braunverfarbung.

Die Darstellung der reinen Glukomannotrihexose aus Acetat gelang nur mit absoluten methylalkoholischem Ammoniak, in dem das Actat wurde bei $0^{\circ} \mathrm{C}$. ausgelöst. Die Mischung wurde 20 Stunden lang in Fisschrank aufbewahrt, dann im Valium eingedampft und mit absolutem Mothylalkohol ausgezogen. Der Methylalkoholauszug kristallisierte nach dem Zusat\% von Aether am Wande der Schale. I)ie crhaltene Glukomannotrihexose zeigte unter dem Mikroskope die in nachstehender Figrur II-A aufgeführte nadelige Forn.

Nach mehnualigem Umkristallisieren aus Methylalkohol und Aether zeigte die Glukomannotrihexose den Schmelzpunkt $216,5^{-2} 17^{\circ} \mathrm{C}$, unter Sintern von $206^{\circ} \mathrm{C} .,[\alpha]_{D}^{2 x}$ in Wasser $-16^{\circ}, 4$. 
Fig. II-A

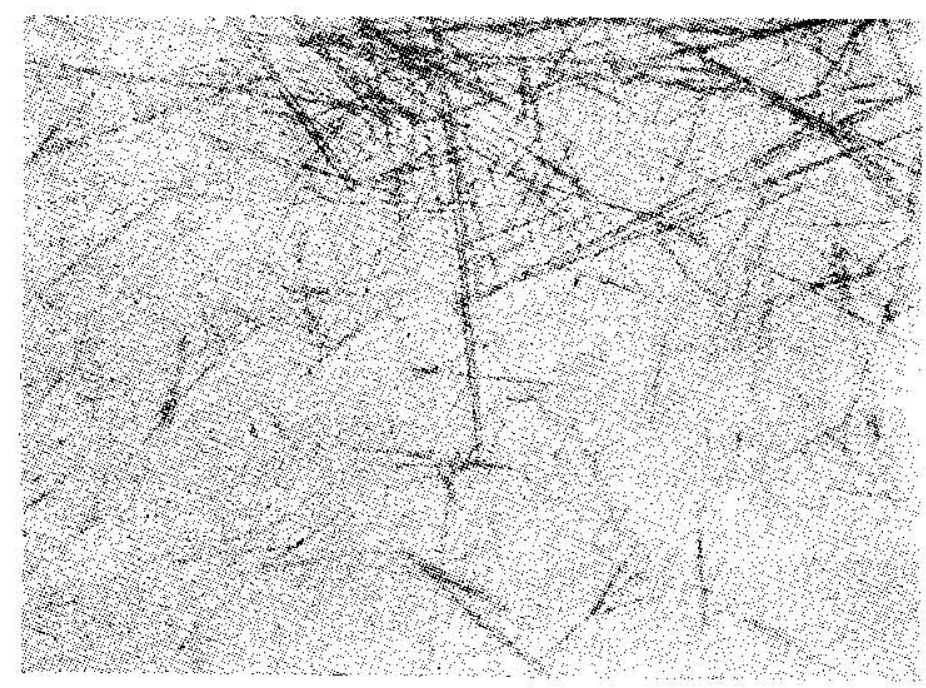

Die Mikroelementaranalyse ergab:

$$
\begin{aligned}
& \text { C } \quad 42, \overbrace{38 \%}^{\text {Gefunden : }}{ }_{42,64} \% \\
& \text { Berechnet für: } \mathrm{C}_{13} \mathrm{H}_{32} \mathrm{O}_{16} \\
& \text { H } \quad 6,94 \% \quad 6,94 \% \\
& 42,83 \% \\
& 6,40 \%
\end{aligned}
$$

Das Molekulargewicht fand sich durch Gefrierpunktsernicdrigung der wässerigen Lösung, welche Zahl 5 ‘3 betrug, cntsprechend der Formel $\mathrm{C}_{13} \mathrm{H}_{32} \mathrm{O}_{\mathrm{r}}=504$. Der Mutterlaugerückstand nach Zusatz von Aether wurde als Glukomannotrihexose abgeschicden, davon tin Anteil als nadelige Kristalle und andere Anteile als weisses l'ulver clargestellt wurden. Der Schmelzpunkt der Kristalle wat gleich gross wie cler der Glukomannotrihexose (lig. II-B).

Die Spaltung der Glukomanuotrihexose mit $2 \%$ iger Schwefelsäure hat ergeben, dass der Bestandteil der Glukomannotrihexose als Mannoseund Glukosederivate $(2: 1)$ in vollkommen gleicher Menge wie der des Glukomannans vorhanden ist. Dieses Ergebuis ist der Schlüssel zu dem Verhältnis der Glukomannankonstitution geworden. 
Fig. I1-B

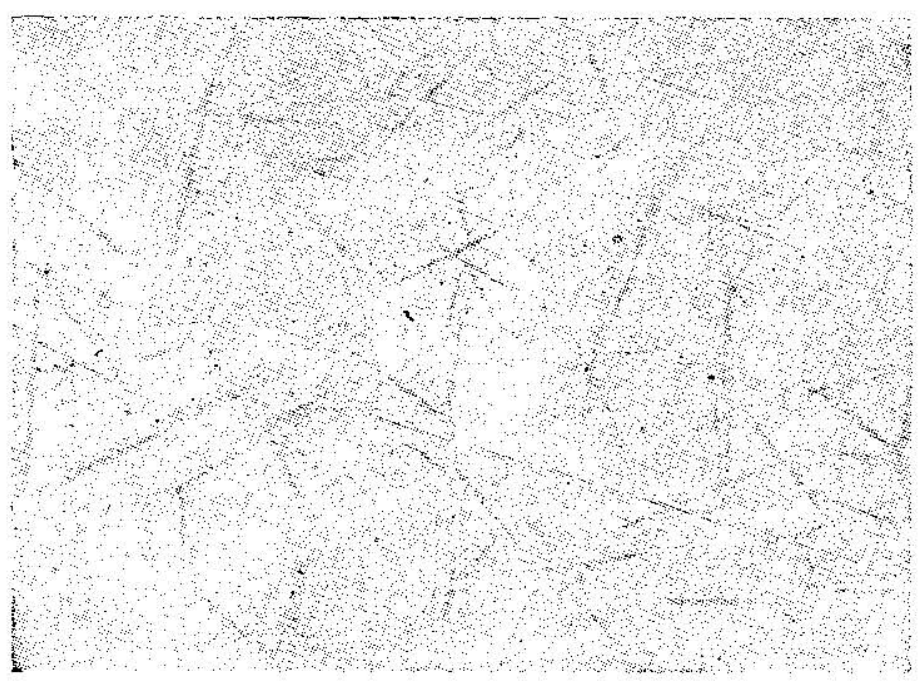

\begin{tabular}{|c|c|c|c|c|}
\hline Hest immungsweise & $\begin{array}{c}\text { Gefundete } \\
\text { gesante } \\
\text { Zuckermenge } \\
\text { als Clukose } \\
\text { (a) }\end{array}$ & $\begin{array}{l}\text { Gefundene } \\
\text { Mannose- } \\
\text { menge } \\
\text { (b) }\end{array}$ & $\begin{array}{c}\begin{array}{c}\text { Glukose- } \\
\text { menge }\end{array} \\
(a)-(b)=(c)\end{array}$ & $\begin{array}{l}\text { Verhältnis } \\
\text { (b) : (c) }\end{array}$ \\
\hline Durch Drchungsvernögen & $\begin{array}{c}g \mathrm{r} \\
2,560\end{array}$ & $\begin{array}{c}\mathrm{gr} \\
\mathbf{8 r}, 6: 4\end{array}$ & $\underset{0,676}{\mathrm{gr}}$ & $2: I$ \\
\hline Durch Itydazon & 2,560 & $\mathrm{I}, 66 \mathrm{I}$ & $0, \operatorname{sig} 9$ & $2: 1$ \\
\hline$"$ & 2,560 & 1,673 & 0,887 & $2: 1$ \\
\hline
\end{tabular}

Bei dem Versuche, der dieses Verhältnis klären sollte, hatte MAYEI ${ }^{23}$ auch das Zwischenprodukt durch enzymatische Wirlung einiger Mesentericusbalsterien als ein Trisaccharid "Lacvidulin" festgestellt. Es wurce nur weiss amorph erhalten und zeigte die spezifische Drehung $\left[\chi_{\jmath}=-11^{\circ}, 55\right.$ in wässeriger Lösung, aber es waren von ihm keine Kristalle oder kristallisierbare Derivate dargestellt worlen. Es wurde neuerdings von $\mathrm{T}$. OTuk ${ }^{36}$ als eine "I aevidulinose," $\mathrm{C}_{\mathrm{r} \delta} \mathrm{H}_{32} \mathrm{O}_{6}$ $\left[{ }^{2}\right]_{D}^{20}=+15^{\circ}$ auffel.tsst. Doch konnte bisher eine kristallisierbare Form nicht dargestellt werden. In ciner Bezichung bestcht zwischen der

23 1. $\mathrm{cll}$

6 1. cit 
spezifischen Drchung des Laevidulins und derjenigen der Laevidulinose und der kristallisierten Glukomannotrilhexose eine vollkommene Analogie.

Ilier war die Acetolyse schon über dem für Itendekaacetylglukomannotrihexose charakteristischen Zustand hinangegangen und es waren darüber dic zu sehr weit abgebauten Stoffe von kleinerem Molckulargewicht z. B. Bioseacetat, Hexoseacetat, abgespalten. Dabei lsonnte man zwei Arten Disaccharicle gewinnen.

Disaccharid (A) war cin Mikrokristali, Schmelppunt $150-160^{\circ} \mathrm{C}$,

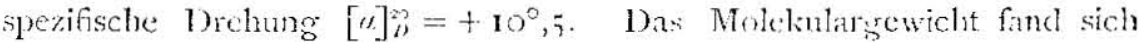
(lurch Gefrierpunlisernielrigung mit den Zahlen 396 und 375 , die der Fomel $\mathrm{C}_{12} \mathrm{H}_{2} \mathrm{O}_{1}-342$ entsprechen. I) urch Hycholyse mit 2 so joger Schrefelsäure licferte es ein Mol Mamnose und cin Mol Glukose wie folgt:

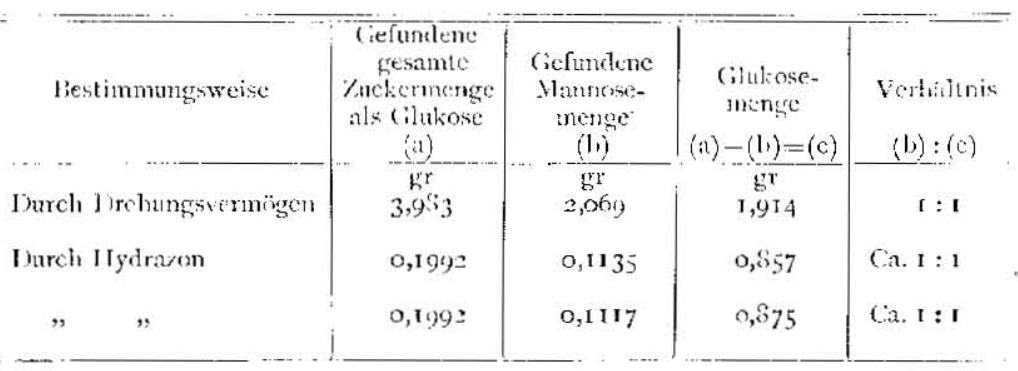

Disaccharid (B) gab ein warzenformiges Kristall, das die folgenden Konstanten aufwies: $[\alpha]_{11}^{*}$ in Wasser $-7^{\circ}, 9$, Molckulargcwicht $=324$. Jer Schmelzpunlit war unscharf und lag $135-140^{\circ} \mathrm{C}$. Dic Zuckermenge wurde durch Mydrazonsbestimmong in folgendem Verhälnis ausgefühıt :

\begin{tabular}{|c|c|c|c|}
\hline & $\begin{array}{l}\text { Gefundene Zuckermenge als } \\
\text { Mannose nach BHRTRANI } \\
\text { (a) }\end{array}$ & $\begin{array}{c}\text { Gefundene Mannosemenge } \\
\text { durch I-Iydrazon } \\
\text { (b) }\end{array}$ & $\frac{(b)}{(a)} \times 100$ \\
\hline I & $\underset{\substack{\mathrm{gr} \\
0,043 \mathrm{I}}}{ }$ & $\underset{0,0369}{g r}$ & 86 \\
\hline 2 & $0,043 \mathrm{I}$ & 0,0395 & 92 \\
\hline
\end{tabular}

Es licss sich in zwei Mol Mannose hydrolysieren, war also cine Mannobiose. Hierdurch waren die Präparate (A) und (B) nicht ein- 
heitlich, aber es liess sich etfassen, dass die Acetolyse nit Essigsäureanhydrid und Schwefelsäure über Trisaccharid- und 2 Arten Disacchariclacetat bis zu dem Mannose- und Glukoseacetat führt, claraus muss man sich das Glukomannanmolckül aus $2 \mathrm{Mol}$ Mannoseresten und I Mol Glukoserest, wie folgende Schema zeigt, aufgebaut denken.

Glukomannan [2 Mol Mannose + f Mol Glukose $]_{x} \stackrel{\text { Acetolyse }}{\longrightarrow}$ Hendekaacetyl-

Simp. $95^{-1} 10^{\circ} \mathrm{C}$

glukomannotrihexose $2 \mathrm{Mol}$ Manmose + I Mol Glukose] Verseifung

$[\alpha]_{j}^{* 3}=+18^{\circ}$

Sin $217^{\circ} \mathrm{C}$.

Glukomannotrihexose [2 Mol Mannose + I Mol Gluliose] (I aeviclulin $[1 /]_{i t}^{201}=-16^{\circ}$ oder Lacvidulinose)

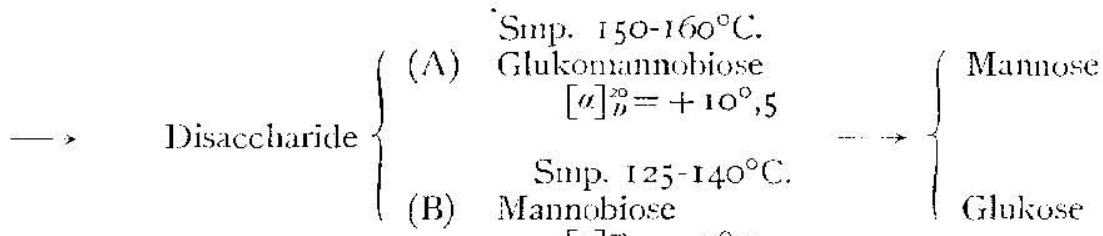
$[\%]_{i}^{2: 3}=-7^{\circ}, 9$

\section{Experiminteitas}

\section{Acholugse mis Grukomannanis}

(I) $5 \mathrm{gr}$ Glukomannan wurden in eincr Stöpselfiasche mit $20 \mathrm{gr}$ Lssigsäureanhydricl, $18,4 \mathrm{gr}$ Fisessig und $\mathrm{r}, 6 \mathrm{gr}$ konz. Schwefelsäure gennisclıt, dalsei die Temperaturerhohung und die Realitionswärme durch Kühlen mit Fis beseitigt wurden. Nach ausreichender Kühlung das Reahtionsgemisch wurde es in einem Warmeschrank von $22-23^{\circ} \mathrm{C}$. grestellt und des ofteren durclugeschiittclt. Mit dem fortschrcitenden Abbau wurce ständige Zunahme der Klarhcit des Sirups beobachtet. Die Farbe des Reaktionsgemisches ging dabei von Gelb zn Dunkelbraun über. Nach ro Tagen wurcle die Flüssigkeit mit I I iter Wasser übergossen, wobei das wasserunlossliche Acetat als feiner, weisser, flockiger Nieclerschlag ausfiel. Dicess wurde filtriert, gründlich ausgewaschen, bis auf Kongorotzusatz keine Blaufärbung mehr festzustellen war. Das so erhaltene Rohacetat wurde in kaitem Alkohol gelöst (A), wobei cin geringer Teil unlöslich (B) war. Nach Abdampfen des Alkohols stellte 
sich das Rohacetat (A) als ein weisses Pulver dar, dessen Ausbeute

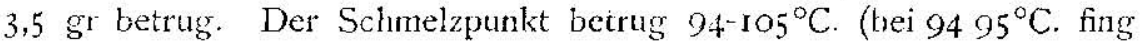
es an zu sintern, bei $100^{\circ} \mathrm{C}$. schmol\% der grösste Teil und bei $105-106^{\circ} \mathrm{C}$ ging er unter Verfärbung in Zersetzung über). Das Acetat wurde wieder in Alkohol gelöst, mit Tierkohle entfärbt, dann ein weisser Niederschlag erhalten.

Schmelzpunkt $\quad 107-115^{\circ} \mathrm{C} . \quad$ Essigsäure $\quad 65,36 \%$

Die Verbrennung des Acetats ergab folgende Werte:

$7,414 \mathrm{mg}$ Substan\% gaben $\mathrm{I}_{3}, 236 \mathrm{mg} \mathrm{CO}$, und $3,667 \mathrm{mg} \mathrm{H}_{2} \mathrm{O}$, entprechend $48,70 \% \mathrm{C}$ und $5,50 \% \mathrm{H}$.

$5.293 \mathrm{mg}$ Substanz gaben $9,445 \mathrm{mg} \mathrm{CO}_{2}$ und $2,680 \mathrm{mg} \mathrm{H}_{2} \mathrm{O}$, entsprechend $48,67 \% \mathrm{C}$ und $5,63 \%$ II.

Das Rolacetat (B) wurcle mit Alkohol im Sieclen gelöst und in Wärne abfiltriert, damn als feiner, weisser Niederschlag ausgefallt, dabei die Ausbeute I,4 gr betrug.

Schmelzpunkt . . . . . . . . $145-149^{\circ} \mathrm{C}$.

Schmelzpunkt (nach 1-mal Reinigung) . $145-149^{\circ} \mathrm{C}$.

Schmelzpunkt (nach 2-mal Reinigung) . $145-149^{\circ} \mathrm{C}$.

Essigsäure . . . . . . . $62,26 \%$.

$5,647 \mathrm{mg}$ Substanz gaben $10,084 \mathrm{mg} \mathrm{CO}$ und $3,090 \mathrm{mg} \mathrm{H}_{2} \mathrm{O}$, entsprechend $48,70 \% 6 \mathrm{C}$ und $6,08 \% \mathrm{H}$.

$5,027 \mathrm{mg}$ Substanz gaben 8,931 $\mathrm{mg} \mathrm{CO}_{2}$ und $2,763 \mathrm{mg} \mathrm{H}_{2} \mathrm{O}$, entsprechend $48,46 \% \mathrm{C}$ und $6,11 \% \mathrm{H}$.

(2) $5 \mathrm{gr}$ Glukomannan wurcen mit $25 \mathrm{gr}$ Essigsäureanhydrid, $24 \mathrm{gr}$ Eisessig und $2 \mathrm{gr}$ konz. Schwefelsäure wie oben acetolysiert. Nach 10 Tagen wurden $5.9 \mathrm{gr}$ eines weissen, feinen Pulvers gewonnen, das sich in kaltem Alkohol lösen liess.

$\begin{array}{ll}\text { Schmelzpunkt . . . . . . } & 120-125^{\circ} \mathrm{C} . \\ \text { Schmelzpunkt (nach i-mal Reinigung) } & 11 \%-125^{\circ} \mathrm{C} . \\ \text { Schmelzpunkt (nach 2-mal Reinigung). } & 108-116^{\circ} \mathrm{C} . \\ \text { Essigsäure . . . . . . . . . } & 67,73 \%\end{array}$

(3) $5 \mathrm{gr}$ Glukomannan wurden mit $25 \mathrm{cr}$ Essigsaureanhydrid, $23 \mathrm{gr}$ Eisessig und 2 gr konz. Schwefelsäure bei $23^{\circ} \mathrm{C}$. 8 Tage lang acetolysicrt.

A) Löslich in kaltem $\triangle$ kikohol, Ausbeute $=3,6 \mathrm{gr}$

Schmelzpunkt . . . . . . . $109-115^{\circ} \mathrm{C}$.

Schmelzpunkt (nach 2-mal Reinigung). $110-115^{\circ} \mathrm{C}$.

Essigsäure . . . . . . . . $67,69 \%$. 
5,296 $\mathrm{mg}$ Substanz gaben 9,329 $\mathrm{mg} \mathrm{CO}_{2}$ und $2,808 \mathrm{mg} \mathrm{H}_{2} \mathrm{O}$, entsprechend $48,04 \% \mathrm{C}$ und $5,89 \% \mathrm{H}$.

$5,863 \mathrm{mg}$ Substan $z$ gaben $10.499 \mathrm{mg} \mathrm{CO}_{2}$ und $3,029 \mathrm{mg} \mathrm{H}_{2} \mathrm{O}$, entsprechend $48,33 \% \mathrm{C}$ und $5,74 \%$ II.

B) Löslich in heissem Alkohol

$\begin{array}{lll}\text { Schmclzpunkt . . . . . } & \mathbf{1} 31-140^{\circ} \mathrm{C} . \\ \text { Schmelzpunkt (nach 2-mal Reinigung) } & \mathbf{1} 3 \mathbf{I}-140^{\circ} \mathrm{C} \\ \text { Essigsäure . . . . . . . . . . } & 63,61 \%\end{array}$

(4) $5 \mathrm{gr}$ Glukomannan wurden mit 3o ccın Essigsäureanhydrid, $28 \mathrm{ccm}$ Fisessig und $2 \mathrm{ccm}$ konz. Schwefelsăure acetolysiert, dabei 8 Tage lang bei $22-23^{\circ} \mathrm{C}$. stehen grelassen. Ausbeute $=5,6 \mathrm{gr}$. Es war löslich in kaltem Alkohol.

Sclimel\%punkt . . . . . . . . $110-118^{\circ} \mathrm{C}$.

Schmelzpunkt (nach 2-mal Reinigung) $108-115^{\circ} \mathrm{C}$.

Essigsäure . . . . . . . . . 65,04\%

$6,788 \mathrm{mg}$ Substanz gaben $12,199 \mathrm{mg} \mathrm{CO}$ und $3,529 \mathrm{mg} \mathrm{H}_{2} \mathrm{O}$, cint.prechend $48,90 \% \mathrm{C}$ und $5,77 \%$ II.

$5.685 \mathrm{mg}$ Substanz gaben $10.330 \mathrm{mg} \mathrm{CO}_{2}$ und $2,940 \mathrm{mg} \mathrm{H}_{2} \mathrm{O}$, entsprechend $49,56 \% \mathrm{C}$ und $5,94 \% \mathrm{H}$.

(5) $5 \mathrm{gr}$ Glukomantan wurden mit $25 \mathrm{gr}$ Essigräureanhydrid, $24 \mathrm{gr}$ Fisessig und $2 \mathrm{gr} \mathrm{kon}$. Schwefelsäure bei Zimmertemperatur $\left(23^{\left.-26^{\circ}, 5 \mathrm{C}\right)} 12\right.$ Tage lang acetolysiert. Das Rohacetat war löslich in kaltem Alkohol Ausbente $=5,4 \mathrm{gr}$.

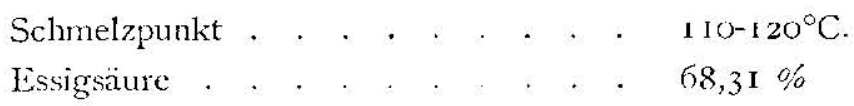

(6) $8 \mathrm{gr}$ Glukomannan wurden mit $40 \mathrm{gr}$ Essigsäurcanhydrid, $37 \mathrm{gr}$ IEisessig und $3,2 \mathrm{gr}$ konz. Schwefelsäure bei $22-23^{\circ} \mathrm{C}$. I 5 Tage lang acetolysiert. Das Acetat wurcle in kaltem Alkolol gelöst. Ausbeutc $=9, \mathbf{I} \mathrm{gr}$.

Schmelzpunkt . . . . . . . $107-1166^{\circ} \mathrm{C}$.

Essigsäure . . . . . . . . . . $69,27 \%$

(7) 8 gr Glukomannan wurden mit den oben verwandten Reagentien bei Zinmertemperatur $\left(2 \mathrm{r}-26^{\circ}, 5 \mathrm{C}\right) 20$ Tage lanes acctolysicrt. Ausbeute $=9,4 \mathrm{gr}$, löslich in kaltem Alkohol.

Schmcizpunkt . . . . . . $100-110^{\circ} \mathrm{C}$.

lissigsäure . . . . . . . . 70,64\% 
(8) $8 \mathrm{gr}$ Glukomannan wurden wie bei $(\tau)$ acetolysiert. Ausbeute $=10,6 \mathrm{gr}$, löslich in kaltem Alkochol.

Schmelzpunkt . . . . . . $88-95^{\circ} \mathrm{C}$

Essigsäure . . . . . . . . . 70,61\%

Das Acctat wurde in Alkolol gelöst, dann auf den Wasserbade cingedampft. Dem Sirup wurde zunächst zu der Abscheidung der Hendekaacetylglukomannotrihexose etwas Wasser zugesetzt. Das ausgefallene Acetat wurde abgesaugt, ofters mit Alkohol behandelt, dabei stelle dic Hendekaacetylglukomannotrihexose ein Kristall dar (Figur I).

Schmelzpunkt . . . . . . . $90-110^{\circ} \mathrm{C}$.

Essigsäure . . . . . . . $6,78 \%$

Spezifische Drchung $[1]]_{\nu}^{\infty 0}=\frac{10,008 \times(+0,31)}{0,5 \times 1,406 \times 0,2914}=+15^{\circ}, 1$

$0,1104 \mathrm{gr}$ Substanz gaben $0,2010 \mathrm{gr} \mathrm{CO}_{\mu}$ und $0,0564 \mathrm{gr} \mathrm{H}_{2} \mathrm{O}$, entsprechend $49,65 \% \mathrm{C}$ und $5.72 \% \mathrm{H}$.

$0,1447 \mathrm{gr}$ Substanz gaben $0,262 \mathrm{I} \mathrm{gr} \mathrm{CO}_{2}$ und $0,0746 \mathrm{gr} \quad \mathrm{I}_{2} \mathrm{O}$, entsprechend $49,38 \% \mathrm{C}$ und $5,77 \% \mathrm{II}$.

Das Molekulargewicht wurde nach kryoskopischer Methode bestimmt, wobei I3:nzol als lösungsmittel diente.

$$
\begin{aligned}
& \mathrm{M}=\frac{50,7 \times 100 \times 0,2934}{0,129 \times \mathrm{II}, 3726}=10 \mathrm{I} 4 \\
& \mathrm{M}=\frac{50,7 \times 100 \times 0,4228}{0,196 \times \mathrm{II}, 84 \mathrm{I} 2}=024
\end{aligned}
$$

(9) IO gr Glukomannan wurden mit $50 \mathrm{gr}$ Essigsäureanlıydrid, 46 gr lísessig und $4 \mathrm{gr}$ konz. Schwefelsäure bei $23^{\circ} \mathrm{C}$ im Wämeschrank 19 Tage lang acctolysiert. Man gewann das Acetat wic gewöhnlich Ausbeute nach vielmaliger Ausscheidung $=10,9 \mathrm{gr}$, löslich in kaltem Alkohol.

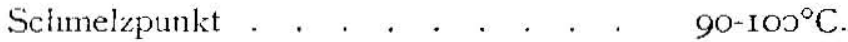

$$
\begin{aligned}
& \text { Essigsäture . . . . . . . . . . 70,23\% }
\end{aligned}
$$

Nach viclmaliger Auskristallisierung wurde das Acetat in Soxhletapparat mit Aether ausge\%ogen. Das Acetat klebte sich dabei stark zusammen, deshalb es wiederholt herausgebracht werden musste. Dann wurde es in Vakuum getrocknet, wieder rerricben und von neuem behandelt, was sehr mühsam und langwierigr (10 Tage) war. Die 
Actherlösung im Extraktionskolben färbte sich wenig hellgclb, und schied sich als diciser Klumpen aus, der sich bald zu Boden setzte. Der Acther wurde abolestilliert, dann den ätherlösliche Anteil mit Alkohol herausgelöst und nach Eindampfen schicden sich schneeweisse Flocken aus. Ausbcute $=2,4 \mathrm{gr}$. Wir wiederholten dieses Umfällen zur Reindarstellung mit verdünntem Alkohol. Scliliesslich wurde das Trihexoseacetat (A) kristallisicrt und im Vakuum äber l'hosphorsäureanhydric getrocknet.

Schmelzpunkt . . . . . $85-100^{\circ} \mathrm{C}$.

Essigsäure . . . . . . . . $70,84 \%$

Spezifische Drelung

$$
\begin{aligned}
& {[\%]_{\prime \prime}^{\circ} \text { in Cliloroform }=\frac{7,5171 \times(+0,70)}{0,5 \times 1,4.827 \times 0,3745}=-18^{\circ}, 9} \\
& {[\%]_{i}^{\circ} \text { in Benzol }=\frac{20,0649 \times(+0,15)}{1,0 \times 0,8950 \times 0,6776}=+5^{\circ}, 2}
\end{aligned}
$$

Wolckalargewicht $\mathrm{M}=\frac{50,7 \times 100 \times 0,2964}{0,148 \times 11,0449}=919$

$$
\mathrm{M}=\frac{50,7 \times 100 \times 0,38 \mathrm{I} 2}{0,207 \times 9,9200}=94 \mathrm{I}
$$

Jas ätherunlösliche Acetat (B) wurde auch wie der atherlöslich Tcil umkristallisicrt.

Schmclzpunkt . . . . . . $98-105^{\circ} \mathrm{C}$.

Essigsäure . . . . . . . . 69,82\%

Spexifiscle Dreliung

$$
\begin{aligned}
& {[x]_{i j}^{n} \text { in Chlorofom }=\frac{7,6481 \times(+0,57)}{0,5 \times 1,4918 \times 0,3810}=+15^{\circ}, 3} \\
& {[\%]_{j}^{20} \text { in Ben\%ol }=\frac{\mathrm{J} 0,0149 \times(+0,07)}{10, \times 0,8925 \times 0,3390}=+2^{\circ}, 3}
\end{aligned}
$$

Molekulargewicht $\mathrm{M}=\frac{50,7 \times 100 \times 0,3390}{0,18 \mathrm{I} \times 10,0149}=94.8$

(10) Io gr Glukomannan wurden wic oben acetolysicrt. Ansbente $=\mathrm{I}, 7 \mathrm{gr}$, löslich in kaltem Alkohol.

Sclunclzpunkt . . . . . . . $103-115^{\circ} \mathrm{C}$

Essigsäure . . . . . . . . 69,71 \% 
Das Acetat wurde mit Aether extrahiert und wiederholt umkristallisiert.

Das ätherlösliche Acetat (A).

Schmelzpunkt . . . . . . $100-105^{\circ} \mathrm{C}$

Essigsäure . . . . . . . . . 70,51\%

Spezifische Drehung

$$
\begin{aligned}
& {[a]_{D}^{20} \text { in Chloroform }=\frac{9,4359 \times(+0,50)}{0,5 \times 1,4843 \times 0,3675}=+17^{\circ}, 3} \\
& {[a]_{D}^{20} \text { in Benzol }=\frac{9,8446 \times(+0,10)}{1,0 \times 0,8914 \times 0,239 \mathrm{I}}=+4^{\circ}, 6}
\end{aligned}
$$

Molckulargewicht $\mathrm{M}=\frac{50,7 \times 100 \times 0,239 \mathrm{I}}{0, \mathrm{I} 30 \times 9,8446}=947$

Das ärtherunlösliche Acetat (B).

Schmelzpunkt . . . . . . $10_{5}-115^{\circ} \mathrm{C}$.

Essigsäure . . . . . . . . . $68,69 \%$

Spezifische Drehung

$$
[\alpha]_{D}^{20} \text { in Chloroform }=\frac{9,3559 \times(+0,42)}{0,5 \times 1,4758 \times 0,4934}=+10^{\circ}, 8
$$

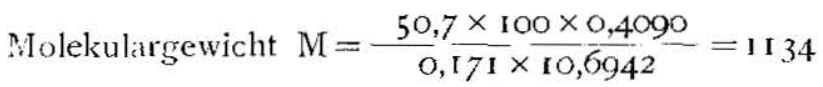

(I I) $12 \mathrm{gr}$ Acetat aus Nr. 4, Nr. 5, Nr. 6 und Nr. 7 wurden mit 60 $\mathrm{gr}$ Essigsäureanhydrid, 55,2 gr Eisessig und 4,8 gr kon\%. Schwefelsäure wie gewöhnlich bei $23^{\circ} \mathrm{C}$. im Wärmeschrank 7 Tage lang acetolysiert. Ausbeute $=8,2 \mathrm{gr}$.

Das ätherlösliche Acetat (A). Ausbeute $=4, \mathrm{I} \mathrm{gr}$.

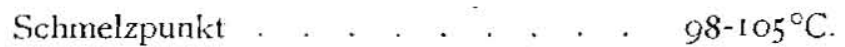

Essigsäure . . . . . . . . . $69,92 \%$

Spezifische Drehung

$$
\begin{aligned}
& {[\times]_{D}^{20} \text { in Chloroform }=-\frac{9,5972 \times(+0,57)}{0,5 \times 1,4834 \times 0,4105}=+17^{\circ}, 9} \\
& {[a]_{D}^{20} \text { in Benzol }=\frac{10,49^{2} 4 \times(+0,19)}{\mathrm{I}, 0 \times 0,8956 \times 0,35^{25}}=+6^{\circ}, 3}
\end{aligned}
$$

Molekulargewicht $\mathrm{M}=\frac{50,7 \times 100 \times 0,3525}{0,174 \times 10,4924}=979$ 
Das ätherunlösliche Acetat (B). Ausbeute $=3,8 \mathrm{gr}$.

Schmelzpunkt . . . . . . $102-115^{\circ} \mathrm{C}$.

Essigsäure . . . . . . . . . $68,76 \%$

Spezifische Drehung

$[\tau]]_{D}^{20}$ in Chloroform $=\frac{9,3536 \times(+0,47)}{0,5 \times 1,4788 \times 0,4853}=+12^{\circ}, 3$

Molekulargewicht $\mathrm{M}=\frac{50,7 \times 100 \times 0,2266}{0,069 \times \mathrm{J} 1,7886}=\mathrm{I} 4 \mathrm{I} 3$

(12) $8,5 \mathrm{gr}$ Triacetylglukomannan wurden mit 42,5 gr Essigsäureanhydrid, 39, I gr İiscssig und $3,4 \mathrm{gr}$ konz. Schwefelsäure wie vorher bei $23^{\circ} \mathrm{C}$. im Wämeschrank 10 Tage lang acetolysiert. Ausbeutc $=5.8 \mathrm{gr}$.

Das atherlösliche Acetat (A). Ausbeute $=3,5 \mathrm{gr}$.

Schmelzpunkt . . . . . . . . $95^{-102}{ }^{\circ} \mathrm{C}$.

Essigsäure . . . . . . . . 70,77\%

Spezifische Drehung

$[1]_{D}^{p o}$ in Chloroform $=\frac{9,7648 \times(+0,56)}{0,5 \times 1,4^{8} 36 \times 0,374 \mathrm{I}}=+19^{\circ}, 7$

Molekulargewicht $M=\frac{50,7 \times 100 \times 0,2234}{0,115 \times 9,9863}=986$

Das ätherunlösliche Acetat (B). Ausbeute $=1,6 \mathrm{gr}$.

Schmclzpunkt . . . . . . . I $23-128^{\circ} \mathrm{C}$.

Essigsäure . . . . . . . . . 68,99\%

Spezifische Drehung

$$
\left[{ }_{1}\right]_{D}^{\infty} \text { in Chloroform }=\frac{9,53^{82} \times(+0,17)}{0,5 \times 1,4826 \times 0,4636}=+3^{\circ}, 7
$$

Molekulargewicht $\mathrm{M}=\frac{50,7 \times 100 \times 0,33 \mathrm{I} 2}{0,092 \times 11,757^{6}}=1552$

Fraktionicrte Ausscheidung des Acetates mit heissem Worser

2,3 gr Acetat aus Nr. I 2-B wurclen mit heisscm Wasser ausgezogren, dabei klehte dic: llendekaicetylglukomannotrihexose stark zusammen. IE wurde wicderholt herausgebracht, getrocknet, wieder zerrieben und von neuem extrahiert Dabei wurde das Acetat mit heissem Wasser nur wenig ausgezogen. Das so erhaltene Acelat hat einen ähnlichen Schmelzpunkt $\left(95-105^{\circ} \mathrm{C}\right.$.). 
Fraktionierte Ausscheidung des Acetates mit $50 \%$ igem Methylalkohol

$6,3 \mathrm{gr}$ Acetat aus $\mathrm{Nr}$. 10 wurden in $200 \mathrm{ccm} 50 \%$ igen Methylalkohols bei $50^{\circ} \mathrm{C}$. gelöst und durch langsame $A b k u ̈ h l u n g$ auf $-10^{\circ} \mathrm{C}$. in vier Fraktionen zerlegt.

I. Fraktion, die auf $5^{\circ}-10^{\circ} \mathrm{C}$. ausgefällt wurde.

Schmelzpunkt . . . . . . $1 \mathrm{Cg}-115^{\circ} \mathrm{C}$.

Molckulargewicht $\mathrm{M}=\frac{50,7 \times 100 \times 0,3290}{0,175 \times 10,3294}=923$

II. Fraktion, die auf $5^{\circ}-\left(-10^{\circ}\right)$ C. ausgefallt wurde.

Schmelzpunkt . . . . . . $108-114^{\circ} \mathrm{C}$.

Molekulargewicht $\mathrm{M}=\frac{50,7 \times 100 \times 0,3424}{0,15 \mathrm{1} \times 1 \mathbf{1}, 3155}=\mathbf{1 0 1 6}$

III. Fraktion, die aus dem Filtrat der I. und II. Fraktion gefallt wurde.

Schmelzpunkt . . . . . . . . $85-88^{\circ} \mathrm{C}$.

Essigsäurc . . . . . . . . . $71,36 \%$

Molelsulargewicht $=\frac{50,7 \times 100 \times 0,3434}{0,188 \times 10,8014}=857$

IV. Fraktion, die in Methylalkohol unlöslich war.

Schmelzpunkt . . . . . . . $114-119^{\circ} \mathrm{C}$.

\section{VERSEIFUNG DES AcETATes}

\section{(I) ifit Barytlaztse}

5 gr I Iendekaacetylglukomannotrihexose wurden mit 1,5 facher $\mathrm{N} / 2$ Barytlauge in einer Stöpselibasche versetzt und das Genisch 6 Stunclen bei $30^{\circ} \mathrm{C}$. in der Scliuttelmaschine geschüttelt, dam filtriert. Das Filtrat wurle mit etwas weniger als cler berechneten Menge ciner $\mathrm{N} / 2$-Schwefelsäure ausgefallt, wobei eine Spur Baryt in Lösung blieb. Zuletzt wurde das letzte Barimn mit grosser Sorgfalt nit N/2-Schwefelsäure tropfenweise neutralisiert. Nach ciem Filtrieren und Abdampfen des Wassers in Valuum wurde es in absolutem Methylalkohol aufgelöst und mit Aether ausgefallt Dann wurcle auf noch etwa vorhandenes Barium wiederholt geprüft. Bei weiterer Reinigung wurde die grössere Mcnge der Glukomannotrihexose verbraucht, aber die Menge war inmer geringer geworden und schliesslich erhielten wi cin schneeweisses Pulver, in dem nur noch eine Spur Barium vorhanden war. 


\section{(II) Mit methylalkoholischem Ammoniak.}

I0,78 gr und 9,93 gr Henclekaacetylglukomannotrihexose wurden mit je $187 \mathrm{ccm}$ und $170 \mathrm{ccm}$ absolutem Methylalkohol in einer Stöpsclfasche gelöst, darin mit je $36 \mathrm{ccm}$ und $33 \mathrm{ccm} 3,4 \%$ igen absoluten metlyyl. alkoholischen Ammoniaks unter Abkiihlung mit lijs versetzt unci tas Gemisch im Eisschrank aubewahrt. Wir wicterholicn diesen Zusat\% mit methylalkoholisehem Ammoniak je nach 2 Stunclen 2 Mal, bis das Reaktionsgemisch I \% iges Ammoniak enthielt. Nach 20 Stunclon wurde: diss Reaktionsprodukt im Vakuum eingedimp ft und mit Ticrlohle entfabt, doch blieb es hellgell, Xach Alxdampfen wurde das Produkt in Wasser gelöst und wieder mit Tierkolile entfärbt, bis die Lösung farbles geworden war. Die Iösung wurde im Vakuum entwässert und in absolutem Mcthylatkohol gelöst, dann nach Zusatz von Acther ülor Nacht stehen gelassen. Wenn clas Verhälnis zwischen Methylalkohol und Aether geeignet war, setzten sich einige Kristalle von Glukomannotribexose ab, welche in Form von Strahlen aggregicrten und unter (cm Mikroskop als nadelig erkannt wurden (Figur II-A). Nach melxrmaligen Unikristallisieren änderte sich der Schmelzpunkt nicht und zeigte $216,5-217^{\circ} \mathrm{C}$. bei beginnender sinterung von $206^{\circ} \mathrm{C}$. 1)er Kristall ist in Wasser, in verdünntem Methyl- und Acthylalkohol leicht löslich, schwer in absolutem Alkohol und Aether.

Spezifische Drehung

$$
\left[{ }^{\prime}\right]_{D} \text { in Wasser }=\frac{12,7882 \times(-0,30)}{\mathrm{I}, 0 \times 1,0043 \times 0,2330}=-16^{\circ}, 4
$$

$4,37 \mathrm{mg}$ Substanz gaben 6,79 $\mathrm{mg} \mathrm{CO}_{2}$ lind $2,7 \mathrm{I} \mathrm{mg}$ II (), entsirechend $42,38 \% \mathrm{C}$ und $6,94 \% \mathrm{II}$.

$4,42 \mathrm{mg}$ Substanz gaben $6,91 \mathrm{mg} \mathrm{CO}_{2}$ und $2,74 \mathrm{mg} \mathrm{I}_{2} \mathrm{O}$, entsprschend $42,64 \%, 6 \mathrm{C}$ und $6,94 \% \% \mathrm{H}$.

$$
\text { Molckulargewicht } \mathrm{MI}=\frac{\mathrm{I} 8,6 \times 100 \times 0,2330}{0,066 \times \mathrm{I} 2,7882}=513
$$

Aus der Mutterlauge wurde dic Glukomannotrihexose auch mit Acther als weisser, flockiger Niederschlag ausgefält, dieser stelite nach Austrocknung ein weisses Pulver dar. Der Niederschlag wurde mit wenigem Wasser ausgelöst und im Exsiccator über konz. Schwefelsäure stehen gelassen. Nach einigen Tagen begannen sich nadelige Kristalle an der Wand der Schale auszuscheiden und der Sirup senkte sich zu Boden. Die so erhaltenen Kristalle wurden nach mehrmaliger Unkristallisierung 
mit ähnlichem Schmelzpunkt $\left(216-217^{\circ} \mathrm{C}\right.$ ) vereinigt (Figur II-B). Die Mutterlauge wurde mit Mcthylalkohol und Aether ausgefallt. Nach melumaliger Umfallung hat das weisse l'ulver den Schmelzpunkt $\left(150-160^{\circ} \mathrm{C}\right.$.) unter starkem Aufschäumen angenommen (Disaccharid A).

Spezifische Drelsung

$$
[\alpha]_{D}^{20} \text { in Wasser }=\frac{13,2268 \times(+0,32)}{1,0 \times 1,0106 \times 0,3990}=+10^{0}, 5
$$

Molekulargewicht $\mathrm{M}=\frac{\mathrm{I} 8,6 \times \mathrm{I} 00 \times 0,3990}{0,14 \mathrm{I} \times \mathrm{I} 3,2268}-398$

$$
M=\frac{18,6 \times 100 \times 0,3080}{0,122 \times 12,8912}=375
$$

$2,3 \mathrm{gl}$ Acetat (Lssigsäuregehalt 71,36\%) wurden mit absolutem methylalkololischem Ammuniak, wie bei cben beschrieben, 20 Stuncien verseift. Das Spaltprodukt wurde im Vakuum eingedickt und lann in Wethylalkohol gelöst, schliesslich mit Tierkohle entfärbt. Nach Zusatz. von Aether wurden Nadelkristalle (Schmelzpunkt 2 , 6,5-21 $7^{\circ} \mathrm{C}$.) abgreschieden. Die Mutterlauge wurde mit mehr Aether in Sodaexsiccator über Phosphorsäureanhydrid autbewahrt. Nach einigen Tagen wurden die warzenförmige Kristalle an der Wand der Schaie ausgeschieden. Bei $125^{-1} 30^{\circ} \mathrm{C}$. fangen diese an zu sintern und gingen bei $135^{-1} 40^{\circ} \mathrm{C}$. unter Verfärbung in Zersetzung über (Disaccharid B).

Spezifische Drehung

$$
[\alpha]_{D}^{20} \text { in Wasser }=\frac{\mathrm{I} 2,0442 \times(-0,15)}{1,0 \times 1,0102 \times 0,2246}=-7^{\circ}, 9
$$

Molekulargewicht $M=-\frac{18,6 \times 100 \times 0,2246}{0,107 \times 12,0442}=324$

\section{Hybrolise der Glukomannotrinexose}

$0,5 \mathrm{gr}$ Glukomannotrihexose wurden nit $50 \mathrm{ccm} 2 \%$ iger Schwefelsäure während I I Stunden siedend hydrolysiert. Die Lösung färbte sich hellbraun; es hatte sich dunkelbrauner IJuminstoff abgeschieden. Dann wurdc die Sätre mit Bariumkarbonat neutralisiert und eingedampft. Der sirupartige Rückstand wurde nehrmals mit Alkohol vom bleibenden Baryt getrennt und verdampft. Der wässerige Sirup wurde mit Wasser auf etwa $13 \mathrm{ccm}$ aufgefüllt. I ccm Lösung wurcle nach BERTRAND nit $0,0256 \mathrm{gr}$ Zucker als Glukose bestimmt. 
Bei $20^{\circ} \mathrm{C}$. und bei Anwendung eines $100 \mathrm{~mm}$ Rohres betrug die polarisiercnde Kraft $(+) 0,70$ Grad. Fs ergibt sich dic Gleichung:

$$
x=\frac{(13,3662 \times b)-(1,9047 \times a)}{5,1128} \text { Gibt } a=2,56, \quad b=0,70 \text {, so hat }
$$

man

$$
x=\frac{(13,3662 \times 0,70)-(1,9047 \times 2,56)}{5,1128}=0,876 \mathrm{gr} \text { Glukose und } 2,56
$$

$-0,876=1,684$ gr Mannose.

$5 \mathrm{ccm}$ Zuckerlösung gaben 0,1246 und 0, I $255 \mathrm{gr}$ Mamnosephenylhydrazon $=1,66 \mathrm{r}$ und $\mathrm{r}, 673 \mathrm{gr}$. Nannose in 1 co ccm Lösung. Schmelz punlt: $182^{\circ} \mathrm{C}$ bit langsamen Erhitzen.

5, 12 mg Mannosephenylhydrazon gaben $0,406 \mathrm{ccm}$ auf $14^{\circ} \mathrm{C}$. unter $769 \mathrm{~mm}$ Atm., cutsprechend 10,48 of Stickstorf.

\section{Hyorot.je des Iorsaccilakides (A)}

$0,5 \mathrm{gr}$ Disaccharid $\left([\alpha]_{D}^{20}=+10^{\circ}, 5\right)$ wurden, wie oben beschricben, mit $60 \mathrm{ccm} 2 \%$ iger Schwefelsäure hydrolysiert. Nach 30 Stunden wurde das Abbauprodukt mit Barytlauge neutralisiert und wie vorher bis $15 \mathrm{ccm}$ cingeengt.

I ccm Lösung verbrauchte $7,7 \mathrm{ccm}$ Kaliumpermanganatlösung $=77,20 \mathrm{mg} \mathrm{Cu}=39,83 \mathrm{mg}$ Zucker als Glukose.

Bei $20^{\circ} \mathrm{C}$. in $100 \mathrm{~mm}$ Rohr betrug die Drehungskraft $(+) \mathbf{r}, 30$ Grad. Nach der bereits gegebenen Gleichung gibt $a=3.983, b=1,30$, so nat man

$$
\mathrm{x}=\frac{(\mathrm{1} 3,3662 \times \mathrm{r}, 30)-(\mathrm{r}, 9047 \times 3,983)}{5, \mathrm{I} 128}=1,914 \mathrm{gr} \quad \text { Glukose und }
$$
$3,983-1,914=2,069$ gr Mannose.

5 ccn dieser Lösung gaben 0,1703 und 0.1675 gr Mannosephenylhydrazon $=0,1135$ und 0,1 I $77 \mathrm{gr}$ Mannose.

\section{Hydrolyse des Disaccharids (B)}

$0,2 \mathrm{gr}$ Disaccharid $\left([\mu]_{i}^{20}=-7^{\circ}, 9\right)$ wurclen wic vorher mit $25 \mathrm{ccm}$ $2 \%$ iger Schwefelsäure 30 Stunden hydrolysiert. $2 \mathrm{ccm}$ cingedampfte Lösung brauchten $3,5 \mathrm{ccm}$ Karliumpermanganatlösung $=35,68 \mathrm{mg} \mathrm{Cu}$ $=17,24 \mathrm{mg}$ Zucker als Mannose.

$5 \mathrm{ccm}$ dieser Lösung gaben 0,0554 und $0,0592 \mathrm{gr}$ Mannosephenylhydrazon $=0,0369$ und $0,0395 \mathrm{gr}$ Mannose. 


\section{KAPITEL}

\section{Methyliterung des Gluknmankans}

Der Methylierungsversuch gibt die Aufklärung über das Konstitutionsproblem des Glukomannans und durch ihn wird ein gewisser cindeutiger Abschluss erreicht. Wie die Arbeiten von IRvine, und [Jrest ${ }^{40}$ an rler

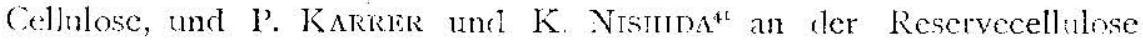
(Lichenin) gezeigt haben, gelang die Einfihhung von Methyl in dis Glukmmannammotekiil mittels Dimethylsulfat und $\wedge$ lkali, wohei eine gute Durchmischung gesorgt worden musste; um anch cincn zersetzenden Einfluss bölerer Temperaturen auszuschalten, wurde die Methylicrung unterlaalb $\mathrm{O}^{\circ} \mathrm{C}$. durchgeführt.

Zunächt wurden $10 \mathrm{gr}$ Glukomannan mit $200 \mathrm{ccm}$ I $5 \%$ iger Natronlange und $96 \mathrm{gr}$ Dimethy]sulfat methyliert. Nach 6-mal Methylicrung betrug der Methoxylgehalt $34 \%$. 1)urch weitere Methylierungen, unter Verwondung vou $20 \mathrm{gr}$ Glukomannam, $30 \mathrm{ccn} 30$ gó iger Natronlauge und $288 \mathrm{gr}$ Dimethylsulfat für jeclen Metlylierungsversuch, war dann der Methoxylgehalt ein böherer geworden und I2-14 malige Methylierung diesen Wert 4I,5\% hatte erreichen lassen.

Unter Verwendung von I $5 \%$ igcr Natronlauge:

3-mal methyliertes Glukomannan : $\mathrm{OCH}_{3}-$ Gehalt gef. $31,4^{2} ; 3 \mathrm{I}, 57 \%$; .

6-mal methyliertes Glukomannan: OCH $\mathrm{H}_{3}$ Gehalt gef. 34,02; 34,23 ón.

Lnter Verwendung von $30 \%$ iger Natronlauge :

2-mal methyliertes Glukomannan: $\mathrm{OCH}_{3}$-Gehalt gef. 24,13; 25,12 ón.

6-mal methyliertes Glukomannan: OCI ${ }_{3}$-Gehalt gef. 38,$80 ; 38,67$ ó IO-mal methyliertes Glukomannan: OCH -Gelale gef. 40,77; 40,4 $\%$

I 2-mal methyliertes Glukomannan : $\mathrm{OCH}_{3}$-Gellalt gef. $4 \mathrm{I}, 37 ; 41,03$ \%.

I4-mal methylicrtes Glukomannan: $\mathrm{OCH}_{3}$-Gehalt gef. 41,$67 ; 41,55$ ó.

Bei der Methylierung von $2 \mathrm{gr}$ methylierten Glukomannans (4.,6\% Methoxyl) mit $50 \mathrm{ccm}$ Mcthyljodid und $36 \mathrm{gr}$ Silberoxyd erreichte der Wert nicht über $4 \mathrm{I}, 6 \% \mathrm{OCH}_{3}$. Wir müssen hieraus den Schluss ziehen, dass das Glukomannan bei der Metlylierung mit Dinethylsulfat uncl Alkali oder mit Methyljodid und Siberoxyd gleichviel Methoxyl liefert wic die Cellulose und das Lichenin, d h. dass er nicht über $42 \%$ zunehmen kann, und dass die Methylierung beim Arbeiten mit

40 Journ. Cliem. Sic. res. 529 (1923).

41 J Lel. chini. act. $7 \cdot 3^{63}$ (1924). 
$30 \%$ iger Natronlauge und bei niedrigerer Temperatur leichter ist. Trincthylglukomannan muss einen Mcthoxylgehalt von 45.6\% haben. Durch K. Hess und W. Weztzien ${ }^{42}$, K. IIEss und H. I'ICHemarR ${ }^{43}$, auch di. Heuser und N. HiLmer ${ }^{14}$ gelang es, den Methoxylgehalt der Ccllulose soweit zu steigern. S. Mrrake ${ }^{25}$ beschrieb als Trimethyl-

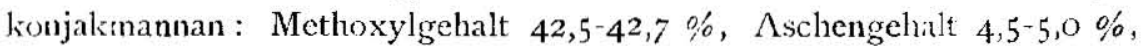
Wassergehalt I,IO-I,20 \%, entsprechend 45,3\% für asche- und wasserfreie Substanz. Fs ist uns nicht gelungen, den Methoxylgehalt auf $45 \%$ zu bringen.

Das Methylglukomannan $\left(\mathrm{OCH}_{3} 42,5 \%\right)$ ist in kaltem Wasser kolkeidal lösbar, in heissem Wasser dagegen tritt wieder Ausfkckung ein, wie der Methyläther der Cellulose, des I ichenins und der Stärke. Es löst sich in Chloroform, Bromoform, Alkohol, Aceton, Eisessig und Essigester, doch haben wir eine Molekulargewichtsbestimmung nicht ausgeführt.

Die Hydrolyse des Glukomannanäthers führt za methylierten Hexosen, und hat keine Abspaltung von Methylgruppen in Gefolge. $\mathrm{Zu}$ diesem Zweck wurden $29,8517 \mathrm{gr}$ methyljertes Glukomannan $\left(\mathrm{OCH}_{3}\right.$ 42,5\%) mit $1 \%$ iger methylalkoholischer Salzsäure in Bonbenröhren nach dem Verfahren, das J. C. IRviNE ${ }^{\circ \circ}$ zur Spaltung der Methylcellulose und KARRER und K. Nisind $A^{41}$ zur Hydrolyse des Methylolichenins benutzt hatten, zu den methylierten Methylglukosiden und -mamosiden aufgespalten. Das Spaltungsprodukt wurcle mit Silberkarbonat neutralisiert und es wurden nach dem Trocknen im Hoclwakuum bei der fraktionierten Destillation folgende fünf Fraktionen aufgefangen:

I. Fraktion Sdp. $124-125^{\circ} \mathrm{C}$. 0,8960 gr:

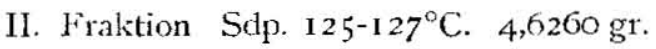

III. Fraktion Sulp. $127-\mathrm{I} 29^{\circ} \mathrm{C}$. $5,7658 \mathrm{gr}$.

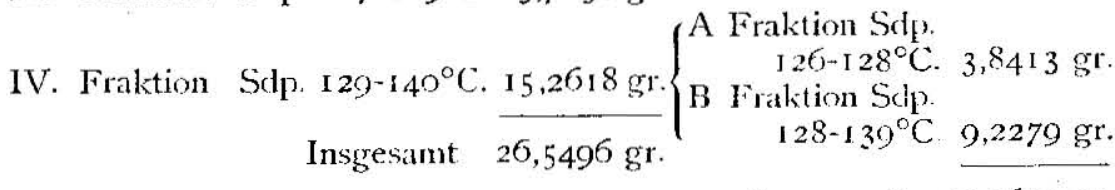
Insgresant $13,0692 \mathrm{gr}$.

\footnotetext{
42 Ann. 1. Chem. $442.46(1925)$.

47 Ebenda 450.37 (1926).

44 Cell. 6. 120 (1925).

25 1. cit.

40 1. cit.

43 1. cit.
} 
Die ersten drei Fraktionen zeigten cin fast farbloses, die späteren ein schwach gelbliches Ausschen, und alle färbten beim Stehen in Ianger Zeit nach.

Die Analysen ergaben:

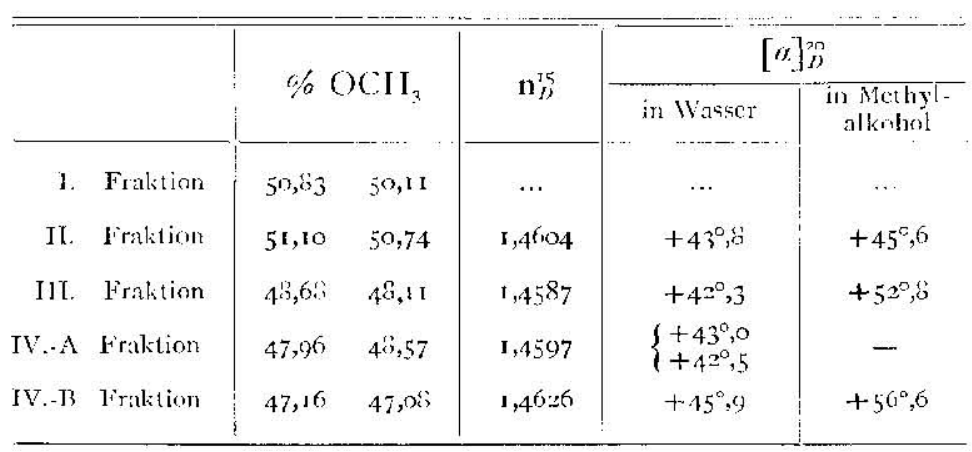

Die für die Baumwolle und das Lichenin crhaltenen Zahlen waren:

Aus methylierter Baumwolle:

\begin{tabular}{|c|c|c|c|}
\hline & $\% \mathrm{OCH}_{3}$ & $\mathbf{n}_{D}$ & {$[\mu]_{j}^{\infty}$} \\
\hline Sdp. $45^{\circ}$ & 52,3 & $\mathrm{I}, 4 \ldots 9 \mathrm{r}$ & $\left\{\begin{array}{l}+6,3,5 \text { in Waser } \\
+660^{\circ}, 5 \text { in Melhylatlionut }\end{array}\right.$ \\
\hline 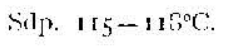 & $5^{2,5}$ & $1,45,0$ & \\
\hline $\begin{array}{l}\text { Selp. } 120-130^{\circ} \mathrm{C} . \\
\text { lïickstancl }\end{array}$ & 47,0 & 1,4665 & \\
\hline
\end{tabular}

Aus Methylolichenin :

\begin{tabular}{|c|c|c|c|}
\hline & \% $\mathrm{OCH}_{3}$ & $\mathrm{n}_{j}^{1}$ & {$[\lambda]^{20}$} \\
\hline Silp. II $y-I^{\prime} \mathrm{I}^{\circ} \mathrm{C}$ & $5^{2,4}$ & $\mathrm{~T}, 4590$ & $\left\{\begin{array}{l}+64^{\circ}, 5 \text { in Wasset } \\
+67^{\circ}, 5 \text { in Met liylatkonol }\end{array}\right.$ \\
\hline Selp $r \geq 1^{\circ} \mathrm{C}$. & 50,9 & & \\
\hline$S d_{\mathrm{p}} . \quad 121-\mathrm{J} 2 \mathrm{i}^{\circ} \mathrm{C}$ & $4 \delta, 5$ & & \\
\hline$-i d_{p} \cdot 127-129^{\circ} \mathrm{C}$ & $4,3,7$ & $J, 46=5$ & \\
\hline
\end{tabular}


Aus diesen Versuchen geht also hervor, dass die Konstanten der Fraktionen, die aus methylicrtem Glukomannan cinerseits, aus Mcthylcellulose und -lichenin anderseits durch Spaltung gewonnen worden sind, eine voreinander erheblich abweichende Zusammensetzung zu haben scheinen, da das Glukomannan aus 2 Mol Mannose und I Mol Glukose besteht und die Spaltprodukte müssen Trimethylmethylmannosid und -glukosid cuthalten.

Die I. und II. Fraktion stehen im Methoxylgehalt ca. I, s' nuter denjenigen, welche sich für ein Trimethylmethylmannosid ofer-glukosid aussprechen lassen wurden $(52,60 \%)$; es muss darin kleine Mengen Dimethylmethylmannosicl oder -glukosid $(4 \mathbf{I}, 8 \%$ \%), das in der III.-IV. Fraktionen überwiegt, enthalten scin. Bei cer Sieclepunktsdifferenz von $15^{\circ}$ wat eine bessere glatte lrennung und Charakteriticnng tes Trimetbylncthylmannosid und - gluksosicl in eimmaliger Destillation selr schwierig, dabci alle Fraktionen selbständige Mischungen waren. 1)er Methoxylgehalt der II. Fraktion war selu gleichmässig, aber Brechungstindex war etwas hoch, und dic spezifische Drehung war klein, verglichen nicht mit denjenigen, die bei Methylcellulose und -lichenin durch Abbau erhalten werden.

Die II. Fraktion wurde mit wässeriger Salzsäure verseift und dabei schied sich nicht dic kristallisierte 2,3,6-Trimethylgluknse $\left(41,89 \% 0 \mathrm{OCH}_{3}\right)$ nach langem Stelien wie diejenige, die aus der ersten Fraktion von Methylbaumwolle und Methylolichenin abgebaut wurde, ab. Dieser Sirup crwies:

$$
\begin{array}{ccc}
\% \mathrm{OCH}_{3} & {[a]^{20}} & \text { in Chloroform } \\
40,49 & 40,49 & +17^{\circ}, 8
\end{array}
$$

Es muss darin eine Spur Dimethylhexose $\left(29,81 \% \mathrm{OCI}_{3}\right)$ enthalten scin. Wir haben diesen Sirup mit Salpetersäure (spc\%. Cew. I,20), wie

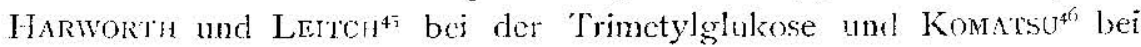
der Dimethylxylose mitgreteilt hatte, oxydiert, und erhielton Trimethylzuckersäurelakton oder -Inamozuckersäurclakton mit folgenden Figenschaften :

$\mathrm{OCII}_{3}$-Gehalt gef.

Berechnct für Trincthylzuckersäurelakton

,$\quad$, Jimethyl\%uckersäurelakton
, _. , Trimethylglukonsüurclakton

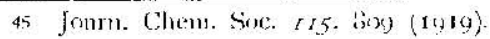

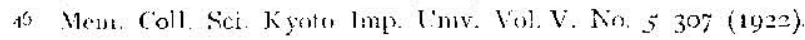

$$
\begin{gathered}
37, \mathrm{I} 5 ; \\
39,74 \% \\
28,18 \% \\
42,27 \%
\end{gathered}
$$




\begin{tabular}{|c|c|c|c|}
\hline $\begin{array}{l}\text { Verbrauch von } \\
\text { N/1o. Natromlauge: }\end{array}$ & $\begin{array}{l}\text { Berechnet für } \\
\text { Trimethylzucker- } \\
\text { sïurelaktons }\end{array}$ & $\begin{array}{l}\text { Borechut fiur } \\
\text { Dimelhylauch fr- } \\
\text { s:urelaktont }\end{array}$ & $\begin{array}{l}\text { Berechetel für } \\
\text { 'Irimclfylglukon- } \\
\text { siänrelaliton }\end{array}$ \\
\hline $\begin{array}{c}10,00 \mathrm{ccm} \\
(\text { Sulustanz } 0,116 \mathrm{gr})\end{array}$ & $9,91 \mathrm{ccm}$ & $\mathrm{I} 0,08 \mathrm{ccm}$ & $5,27 \mathrm{ccm}$ \\
\hline
\end{tabular}

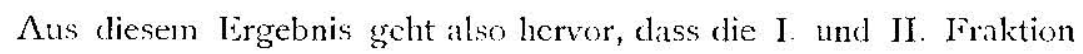
2,3,4-Trimethylmethylhexosid waren mit kleinen Mengen Dimethylhexosid und nicht 2,3,6-Trimethylmethylhexosid, und mit grosser Wahrscheinlichkeit hanclelte es sich un 2,3,4-Trimethylmethylglukosid und nicht Mannosicl. Dic IIl., IV.-A und -B Fralition wurken auch wic die erste fraktion mit Salzsäure verceff, dabei wir lrimethylhexose erhielten, die nach langen Stehen keine Kristalk abschied. Die Analyse ergab :

\begin{tabular}{|c|c|c|c|c|}
\hline \multicolumn{2}{|c|}{ Fraktion } & \multicolumn{2}{|c|}{$0,0 \mathrm{OCH}_{3}$} & {$[\alpha]_{0}^{\infty}$} \\
\hline III. & Fralition & $3^{3 i, \infty 4}$ & 38,01 & $+3^{6^{\circ}}$ in 11 asser \\
\hline IV. A & Fraktion & 3,73 & $3 \%, 46$ & $+18^{\circ}, 5$ in Chloroform \\
\hline IV.-B & Fraktion & $3^{6,26}$ & $3^{6,38}$ & $+11^{\circ}, 6$ in Chloroform \\
\hline
\end{tabular}

In Methoxylgehalt stehen diese Fraktionen ca. 3.3-5.6\% unter der Trimetlylliexose; es muss darin bereits geringe Mengen Dinetlyylhexose enthalten sein. Diese Fraktionen wurdon wic oben mit Salpetersäure oxydiert, und dabci wurden Mono- und Dikarbonsäurelakton mit folgenden Eigenscliaften gewonnen.

Aus der Ill. Jraktion OCII,-Gehalt gef. 36, I2; 35,78 .

Aus der IV.-A linktion $\mathrm{OCH}_{3}$-Gehalt gef. 35,$18 ; 35,28$.

Aus der IV.-B Fraktion $\mathrm{OCH}_{3}$-Gichalt gef. 33,$89 ; \quad 33,76$.

\begin{tabular}{|c|c|c|c|c|c|c|}
\hline Fraktion & Suldstanz' & 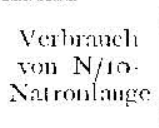 & 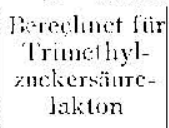 & $\begin{array}{c}\text { Rerechnet fijr } \\
\text { Pimellyyl- } \\
\text { atckersiute } \\
\text { lakton }\end{array}$ & $\begin{array}{l}\text { Pereclinet ritr } \\
\text { l'rimethyl- } \\
\text { blukmsianre- } \\
\text { atkion }\end{array}$ & 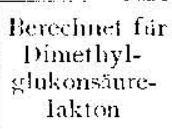 \\
\hline I11. Fraktion & $\begin{array}{c}g^{r} \\
0,1071\end{array}$ & $\begin{array}{l}c \operatorname{con} \\
7,52\end{array}$ & 9,15 & $\begin{array}{l}9,74 \\
9,74\end{array}$ & $\begin{array}{l}\mathrm{cm} \\
4.97\end{array}$ & $\begin{array}{l}\mathrm{ccm} \\
5,20\end{array}$ \\
\hline$I Y \cdot A$ Fraktion & 0,1762 & 9,$9 ;$ & 15,06 & 16,02 & $\$, 0 I$ & 3,55 \\
\hline IV.-I Fralstion & 0,1130 & 9,10 & $10, \infty$ & 10,73 & $5,3^{6}$ & 5,73 \\
\hline IV.-1) Frakticus & $0,26,3 \mathrm{t}$ & 19,33 & 22,44 & 23,42 & 11,06 & 12,77 \\
\hline
\end{tabular}


Aus hier nalım in der IlI. und der IV.-B Fraktion dic Aciclität zu, während der Sämregehait in der IV.-A Fraktion zur Halfte zuriclsging. Bei all diesen Saurclaliton handelte es sich eelbstverständlich um Mischungen, aus denen dic erste (atus der III. Fraktion) eine Lösung von Trimethylzuckersäurelakton mit kleinen Mengen Trimcthylmannonsänrelakton, die zweite (aus der IV.-A liralition) ein Sirup von Trimetlylmannumäurelakton nit einer Spur Tri-und Dimethylmannozuckersäurelakton, die dritte (aus der IV,-B Fraktion) cine Mischuns von Tri-und Dincthylmannozuckersäurclakton mit kleinen Mengen Tri- und Dimethylmannonsïurelakton waren. Bei 2,3,6-limelhyimethylghlukosid Fraktion finclen sich nach Verseifung mit Silzäure bekantlich Kristalle von 2,3,6-Trinethylglukose, die mit Salpetersaure zu 2,3,6-Trimethylglukmaurelaton (Monokabonsüurdakton) oxydieren müssen. Der grösscte Teil aus der IV.-A Fraktion war 2,3,6-Trimethylmethylhexosid, aber sein: Figenschaften und das Frgebuis ihrer Analyse zeigte nicht so grossic Aehnlichkeit, dass es sich licer um 2,3,6-Trimethylmethylglukosid handeln konnte; der Versuch, in welchem aus methyliertem Glukomaman durch Spaltung keine Kristalle gewonnen wurden, bildcte also auch eine Stütze für die Abwesenheit cler 2,3,6-Trimethylgrlukuse. Da die Trinethylglıkose und -mannose mit Phenylhydrazin kein Phenylosazon liefert, so muss an Kohlenstoffaton 2 eine Mcthoxylgruppe sitzen. Als Gesantergebnis der im vorstehenden skizzicrtell Untersuchungen auf dem Gubiete des Methylglukomannans folgt, dass das Spaltprodukt auf die Weise gewonnen wurde, wic sic das nachstehende Schema zeigt :

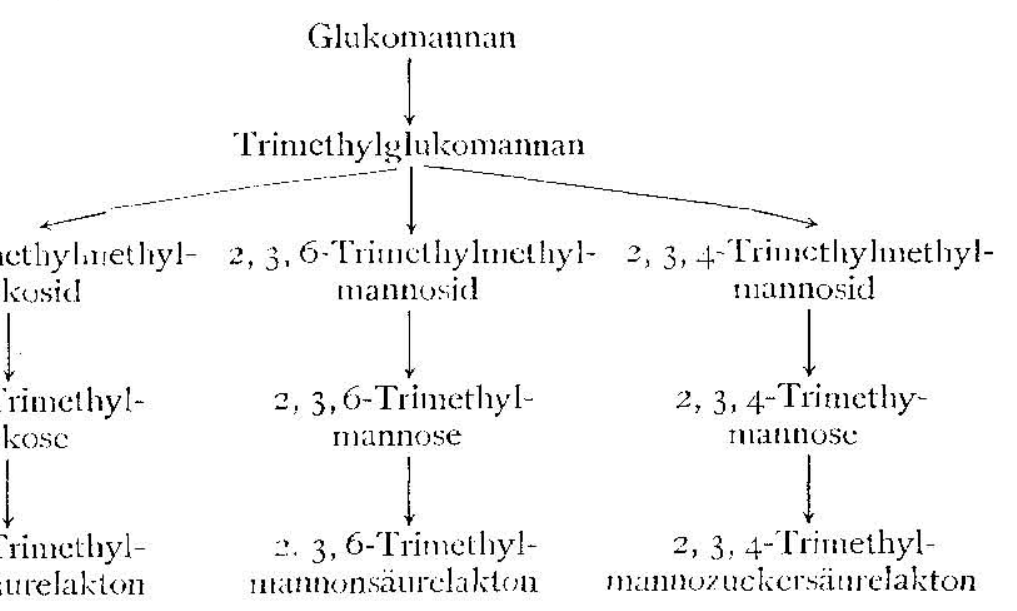

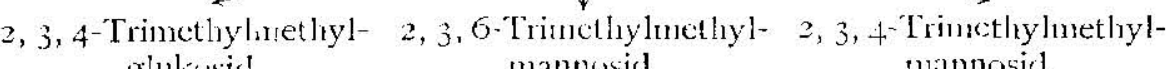

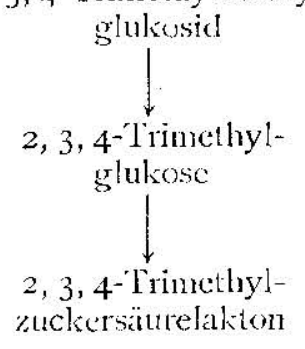

$\therefore$ 3, 6-Trimethylmannoruckersäurelakton 


\section{EXPERIMENTELLES}

\section{Methylietruig DES GLUKOMANNaNS}

(1) $5 \mathrm{gr}$ pulverisiertes Glukomannan wurden mit $100 \mathrm{ccm} 15 \%$ iger Natronlauge übergossen, in denen sie sich nach gründlicher Durchmischung unter Rühren kolloidal lösten. Dann wurden unter kräftigem lurbinieren $4^{8} \mathrm{gr}$ Dimethylsulfat cingetropft, wobei Erwärmung sich bemerkbar machte. Ein Teil des methylierten Glukomannans flocktc während des Verfahrens aus. Nach Beendigung der Reaktion fand die gleiche Methylierung wie vorher statt. Jie Lösung zeigte sich alkalisch. Darauf wurde noch etwas Dimethylsulfat zugesetzt, dabei die İösung gerade neutral war. Zur Isolierung des Methylierungsproduktes wurde es zum Sieden erhitzen, dabei wurde das Methylglukomannan nicht ausgefallt.

(2) $10 \mathrm{gr}$ Glukomannanpulver wurden mit $200 \mathrm{ccm} \quad$ I $5 \%$ iger Natronlauge übergossen und unter Unrühren gelöst. Darauf liessen wir langsam unter stetem Rülren $96 \mathrm{gr}$ Dimcthylsulfat cintropfen; durch besondere Kühlung hielten wir die Temperatur auf $o^{\circ} \mathrm{C}$. Darauf wurden nochmals $200 \mathrm{ccm}$ Natronlauge hinzugesetzt und tropenweisc sovicl Dinethylsulfat hinzugefügt, dass die Flüssigkeit schliesslich gerude neutral war. Nunmehr wurde sie zum Sicden erhitzt, und das ausfallende Methylierungsprodukt auf vorberciteter warmer Nutsche abfiltriert und gründlich mit kochendem Wasser gewaschen. Dann musste das gewaschene Methylglukomannan schnell von der Nutsche entfernt werden, da es andernfalls beim Erkalten infolge des anhaftenden Wassers schmierig wurde. Das so isolierte Prodult wurde wiecter in wenigem Wasser gelöst und weiter die Methylierung, wic oben beschrieben, öfter's wicderholt.

Zur Reinigung des Methylierungsproduktes wurde es in kaltem Warser gelöst und beim Erhitzen ein weisses, fluckiges, Reaktionsprodukt ausegefallt. Nach mehrmaligem Umbösen wurie die wässcrige Lösung auf cinem Uhrglas auf dem Wasserbarle verdunstet, dabei liess das Präparat sich in Fiorm einer (lünnen Masse pulverisieren und wurde über Phosphorsäureanllydrid im Vakuum gretrocknet. Der Muthoxylgehalt wurde nach der Mikromethode von Zeistir, bestimmt und gab folgende Analysenwerte.

Nach 3-maliger Methylierung

$5,412 \mathrm{mg}$ Substanz gaben $12,87 \mathrm{Img} \mathrm{AgJ}$, entsprechend $3 \mathrm{I}, 42 \% \mathrm{OCI}_{3}$. 
4,896 $\mathrm{mg}$ Substanz gaben I I,702 $\mathrm{mg} \mathrm{AgJ}$, entsprechend $3 \mathrm{I}, 57 \% \mathrm{OCH}_{3}$. Nach 6-maliger Methylierung.

5,280 $\mathrm{mg}$ Substanz gaben I 3,598 mg AgJ, ent sprechend 34,02\% \% $\mathrm{OCH}_{3}$. $6,3 \mathrm{Cg}$ ms Substanz gaben $16,348 \mathrm{ng} \mathrm{AgJ}$, entsprechend 34,23 ó $\mathrm{OCH}_{3}$.

(3) $20 \mathrm{gr}$ pulverisiertes Glukomannan wurden mit $300 \mathrm{ccm} 30 \%$ iger Natriumhydroxydlosung und $288 \mathrm{gr}$ Dimethylsulfat, wie bei (z) beschrieben, methyliert.

Nach 2-maliger Methylierung.

$8,881 \mathrm{mg}$ Substanz gaben $16,221 \mathrm{mg} \mathrm{AgJ}$, entsprechend 24, $3 \% \mathrm{OCH}_{3}$. $8,885 \mathrm{mg}$ Substanz gaben $\mathrm{I} 6,900 \mathrm{mg} \mathrm{Ag}$, entsprechend 25,12 \% $\mathrm{OCH}_{3}$. Nach 6-maliger Methylicrung.

5,177 $\mathrm{mg}$ Substan $z$ gaben ${ }_{5}, 207 \mathrm{mg} \mathrm{AgJ}$, entsprechend $38,80 \%$ OCl1 $5,565 \mathrm{mg}$ Substanz gaben $16,290 \mathrm{mg} \mathrm{AgJ}$, entsprechend $38,67 \% 0 \mathrm{OCI}_{3}$. Nach Io-maliger Methylierung.

5,41 I $\mathrm{mg}$ Substanz gaben I6,699 $\mathrm{mg} \mathrm{AgJ}$, entsprechend 40,77\% OCH 5,397 mg Substanz gaben $16,5 \mathrm{romg} \Lambda \mathrm{gJ}$, entsprechend 40,41\% OCH ${ }_{3}$. Nach 12-maliger Methylierung.

4, I50 mg Substanz gaben 12,997 m $\mathrm{AgJ}$, cntsprechend $4 \mathrm{I}, 37 \% \mathrm{OCH}_{3}$. $5,439 \mathrm{mg}$ Substanz gaben $16,892 \mathrm{mg}$ AgJ, cntsprechend 4 r,03\% $\% \mathrm{OCH}_{3}$. Nach 14-maliger Methylierung.

5,172 $\mathrm{mg}$ Substanz gaben $16,316 \mathrm{mg} \mathrm{AgJ}$, entsprechend 41,67\% $\mathrm{OCH}_{3}$. 6 , I $49 \mathrm{mg}$ Substanz gaben $19,340 \mathrm{mg}$ AgJ, entsprechend $4 \mathrm{I}, 55 \% \mathrm{OCH}_{3}$.

(4) $2 \mathrm{gr}$ 14-mal methyliertes Glukomannan mit 4I,55-4I,67\% $\mathrm{OCH}_{3}$ wurden mit $50 \mathrm{ccm}$ Methyljodid, in denen sic sich klar aufgelöst hatten, gemischt und dann $36 \mathrm{gr}$ Silberoxyd hinzugefügt und 8 Stunden unter dem Rücklusskühler gekocht. Nach einer neuen Zugabe von $6,5 \mathrm{gr}$ Methyljodid und $2 \mathrm{gr}$ Silberoxyd wurde 8 Stunden lang erhitet. Danacl wurde das unverbratuchte Methyljodirl abclestilliert und der Rückstand mit Chloroform extrahiert. 1)as isolierte Präparat wurde wie vorher für die Methoxylbestimmung entnommen.

4,537 $\mathrm{mg}$ Substan\% gaben $14,277 \mathrm{mg} \Lambda \mathrm{gJ}$, entsprechend 41,57\% $\mathrm{OCH}_{3}$. 5,008 $\mathrm{mg}$ Substanz gaben I $5,630 \mathrm{mg}$ AgJ, entsprechend 4I, $23 \%$ OCH 3 . 


\section{Spaltung des Metilylgllkomannans}

29,8517 gr Methylglukomannan mit 41,5\% Methoxylgehalt wurden 50 Stunden mit $400 \mathrm{ccm}$ I \% iger absoluter methylalkoholischer Salzsäure in sicben Bombenröhren auf $100^{\circ} \mathrm{C}$., hierauf weitere 50 Stunden auf $130^{\circ} \mathrm{C}$. erlitzt. Man neutralisierte das $A$ bbauprodukt mit Silberkarbonat, entfäıbte mit Tierkohle, verdampfte das lïltrat unter vermindertem Druck auf $35-40^{\circ} \mathrm{C}$. und trockncte den Rückstand in Vakuum über Phosphorsäureanhydrid 20 Stuncen auf $100^{\circ} \mathrm{C}$. Dann wurde es im Hochvakuum von Langmulr-Jayez-Pumpe destilliert und die folgenden Fraktionen aufgefangen :

\begin{tabular}{|c|c|c|c|}
\hline Fraktion & 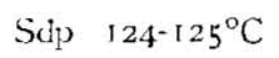 & Ausbeute & $0,8960 \mathrm{gr}$. \\
\hline Fraktion & Silp. $125-127^{\circ} \mathrm{C}$. & Austeute & $4,6260 \mathrm{gr}$. \\
\hline Fraktion & Sdp. $\quad 127-129^{\circ} \mathrm{C}$ & Ausbeute & $5,7658 \mathrm{gr}$. \\
\hline Fraktion & Sdp. $129-140^{\circ} \mathrm{C}$. & Ausbeutc & $15,2618 \mathrm{gr}$. \\
\hline & & sgesamt & 26 \\
\hline
\end{tabular}

Dje ersten drei Fraktionen waren farblos, die letzte sehr schwach gelblich. Dic IV. Fraktion wurde dann wieder in Hochvakuum destilliert und die zwci folgenden Fraktionen aufgefangen.

$$
\begin{aligned}
& \text { IV.-A Fraktion Sdp } 126-128^{\circ} \mathrm{C} \text {. Ausbcute } 3,8413 \mathrm{gr} \text {. } \\
& \text { IV.-B Fraktion Sdp. } 128-140^{\circ} \mathrm{C} \text {. Ausbeute } 9,2279 \mathrm{gr} \text {. } \\
& \text { Insgesamt } 13,0602 \mathrm{gr} \text {, }
\end{aligned}
$$

Dic beiden Fraktionen waren sehr schwach gelblich. Der Methoxylgehalt wurde nach der Mikroncthode ausgeführt.

I. Fraktion

$5.270 \mathrm{mg}$ Substanz gaben $20,280 \mathrm{mg} \mathrm{AgJ}$, entsprechend $50,83 \% \mathrm{OCH}_{3}$. $5,753 \mathrm{mg}$ Substanz gaben $21,822 \mathrm{mg} A g J$, entsprechend 50,1 I $\% \mathrm{OCH}_{3}$.

II. Fraktion

4,309 $\mathrm{mg}$ Substanz gaben $16,710 \mathrm{mg}$ AgJ, entsprechend $5 \mathrm{I}, 10 \% \mathrm{OCH}_{3}$. $4,375 \mathrm{mg}$ Substanz gaben $16,803 \mathrm{mg} \mathrm{AgJ}$, entsprechend $50,74 \% \mathrm{OCH}_{3}$.

III. Fraktion

$4,730 \mathrm{mg}$ Substanz saben $17,429 \mathrm{mg} \mathrm{AgJ}$, entsprechend $48,68 \% \mathrm{OCH}_{3}$. $5,936 \mathrm{mg}$ Substan $z$ gaben $21,618 \mathrm{mg} \mathrm{AgJ}$, entsprechend 48, г \% $\% \mathrm{OCH}_{3}$. 


\section{IV.-A Fraktion}

$5,248 \mathrm{mg}$ Substanz gaben I9,057 mg AgJ, entsprechend 47,96\% OCH $\mathrm{CH}_{3}$. $3,867 \mathrm{mg}$ Substanz gaben $14,2 \mathrm{IO} \mathrm{mg}$ AgJ, entsprechend $48,57 \% \mathrm{OCH}_{3}$.

IV.-B Fraktion

4,170 mg Substanz gaben 15,000 mg AgJ, entsprechend 47, $6 \%$ OCII, 4,290 mg Substanz gaben I 5,290 mg AgJ, entsprechend 47,08\% $\mathrm{OCH}_{3}$.

Die Brechungsindices wurden durch Refraktometer nach PuLrkicı ermittelt.

\section{Fraktion}

$$
43^{\circ} 6^{\prime} \text { bei } 15^{\circ} \mathrm{C} . \quad \mathrm{n}_{D}^{\mathrm{1c}}=1,4604
$$

III. Fraktion

$$
43^{\circ} 23^{\prime} \text { bei } 15^{\circ} \mathrm{C} . \quad \mathrm{n}_{D}^{\mathrm{TH}}=\mathrm{I}, 4587
$$

\section{IV.-A Fraktion}

$$
43^{\circ} 13^{\prime} \text { bei } 15^{\circ} \mathrm{C} . \quad \mathrm{n}_{D}^{15}=1,4597
$$

IV.-B Fraktion

$$
42^{\circ} 43^{\prime} \text { bei } 15^{\circ} \mathrm{C} . \quad n_{D}^{15}=1,4626
$$

Die spezifischen Drehungen wurden in wässeriger oder methylalkoholischer Lösung mit dem LandoL-L_LPICn'schen Polarimeter bestimmt :

\section{Fraktion}

$$
\left.[\alpha]_{i}^{\infty}\right) \text { in Wasser }=\frac{(+0,87) \times 3}{0,25 \times 0,23^{84}}=+43^{\circ}, 8
$$

$$
[\alpha]_{D}^{20} \text { in Methylalkohol }=\frac{(+0,75) \times 3}{0,25 \times 0,1972}=+45^{\circ}, 5
$$

III. Fraktion

$$
\begin{aligned}
& {[\alpha]_{D}^{20} \text { in Wasser }=\frac{(+\mathrm{r}, 70) \times 2}{0,25 \times 0,3213}=+42^{\circ}, 3} \\
& {[\alpha]_{D}^{20} \text { in Methylalkohol }=\frac{(+\mathrm{r}, \mathrm{I} \mathrm{I}) \times 2,5}{0,25 \times 0,2 \mathrm{IOI}}=+52^{\circ}, 8}
\end{aligned}
$$

IV.-A Fraktion

$$
[\%]_{D}^{20} \text { in Wasser }=\frac{(+\mathrm{I}, 02) \times 3}{0,25 \times 0,2846}=+43^{\circ}, 0
$$


$[\alpha]_{m}^{20}$ in Wasser $=\frac{(+0,93) \times 5}{0,25 \times 0,437^{6}}=+42^{\circ}, 5$

IV.-B Fraktion

$[\%]_{D}^{20}$ in Wasser $=\frac{(+2,40) \times 10}{0,5 \times 1,0464}=+45^{\circ}, 9$

$[a]_{D}^{2: 2}$ in Methylalkohol $=\frac{(+0,95) \times 5}{0,25 \times 0,3354}=+56^{\circ}, 6$

\section{Verseifung der II. Fraktion}

I,9834 gr des Trimethylmethylglukosids der II. Fraktion wurden in $5 \%$ iger wässeriger Salzsäure 4 Stunclen auf dem Wasserbade erhitzt, dann mit Bariunkarbonat neutralisiert, im Vakuum zur Trocken eingedampft. I)er Rückstand wurde mit trockenem Aether mchrmals ausgezogen und nach dem Verdampfen ein Sirup gewonnen, der nach längerem Aufbewahren in Exsiccator keine Kristalle gaben. Der Sirup war schr schwach gelblich.

4,108 $\mathrm{mg}$ Substanz gaben 12,593 $\mathrm{mg} \mathrm{AgJ}$, entsprechend 40,49\% $\% \mathrm{OCH}_{3}$. $3,986 \mathrm{mg}$ Substanz gaben I2,I97 mg AgJ, entsprechend 40,49\% $\mathrm{OCH}_{3}$.

Spezifische Drehung

$$
[a]^{20} \text { in Chloroform }=\frac{8,2515 \times(+2,30)}{0,5 \times 1,4452 \times 1,4476}=+17^{\circ}, 8
$$

\section{Oxydation der Trimethylglukose aus der II. Fraktion}

I,5 gr des Sirups wurden mit $20 \mathrm{ccm}$ Salpetersäure vom spez. Gew. $\mathfrak{I}, 20$ in einem Kolben auf dcm Wasserbade erhitzt. Die Tenmeratur wurde zunächst während einiger Minuten auf $80^{\circ} \mathrm{C}$. und dann während 4 Stunden auf $68^{\circ} \mathrm{C}$. gehalten, um eine heftige Reaktion zu verhindern. Schliesslich färbte sich die Masse braun. Wir verdünnten dann mit etwas Wasser und verdampften abcrmals, um clie Salpetersäure möglicht vollständig zu cntfernen. In gleicher Weise wurde mit Alkohol vielmals, bis ein dünner Sirup erhalten wurde, im Vakuum eingedampft. Schliesslich wurde ein dicker sehr schwach grünlich-gelber Sirup erhaIten. Die Kristalle wurden auch nach längerer Aufbewahrung im Exsiccator nicht gebildet. 
$4,377 \mathrm{mg}$ Substanz gaben $12,308 \mathrm{mg} \mathrm{AgJ}$, entsprechend $37, \mathrm{I} 5 \% \mathrm{OCH}_{3}$. 7, $49 \mathrm{mg}$ Sub tanz gaben $19,954 \mathrm{mg} \mathrm{AgJ}$, entsprechend 35,89\% OCII

$0,1160 \mathrm{gr}$ Substanz wurden in verdünntem Alkohol gelost und mit $\mathrm{N} / 10-N a t r o n l a u g e$ titriert (Phenolphthalein als Indikator). Nach $6,2 \mathrm{ccm}$ Zusat\% wurde der Indikatcr rot und war in einigen Minuten verschwunden. Wir bcobachteten das gleiche Phänomen, bis $9,12 \mathrm{ccm}$ Lauge hinzugefugt worden waren. Dic I ösung wurde danu in 1 I, $00 \mathrm{ccm}$ N/10-Natronlange cingelegt und auf dem Wasserbace erhitzt. Nach der Einwirkung wurde der Ueberschuss titrimetrisch mit $\mathrm{N} / 5$-Schwefelsäure crmittelt. I0,00 ccm N/IO-Natronlauge waren zum Neutralisicren von $0,1160 \mathrm{gr}$ Trimethylzuckersurelakton nötig.

\section{Tinseifung der III. Fraktion}

$0,9 \mathrm{gr}$ wurden mit $50 \mathrm{ccm} 5 \%$ iger Salzsäure wie vorher verseift. Der Spaltsirup (schwach gelb) wurde in Exsiccator über Schwefelsäure während langer Zeit aufbcwahrt, dabei keine Kristalle ausgeschicden wurden.

$4.719 \mathrm{mg}$ Substanz gaben $13,59 \mathrm{Img} \Lambda \mathrm{gI}$, entsprechend $38,04 \% \mathrm{OCH}_{3}$. $5,972 \mathrm{mg}$ Substanz gaben 17,183 $\mathrm{mg} \mathrm{AgJ}$, entsprechend 38,01 0;6 $\mathrm{OCH}_{3}$. Spezifische Drehung

$$
[\alpha]_{j,}^{20} \text { in Wasser }=\frac{(+0,65) \times 3,0}{0,25 \times 0,2182}=+36^{\circ} .
$$

\section{Oxydation der Trinctiylmamose aus der III. Fraktion}

$0,2354 \mathrm{gr}$ des Sirups wurden mit Io ccm Salpetersäure vom spez. Gew. I,20 wie vorher oxydiert. Es wurden auch nach Jängercm Aufbewahren im Exsiccator keine Kristalle ausgeschieden.

$5,374 \mathrm{mg}$ Substany gaben $14,694 \mathrm{mg} \mathrm{AgJ}$, entsprechend 36, r $2 \% \mathrm{OCH}_{2}$. 6,2 I $3 \mathrm{mg}$ Substanz gaben $16,834 \mathrm{mg} \mathrm{AgJ}$, entsprechend $35,78 \% \mathrm{OCH}_{3}$.

0,107 I gr Sirup wurden mit N/10-Natronlauge titriert. Zum Neutralisieren wurden $7,52 \mathrm{ccm}$ Lauge verbraucht.

\section{Verseifung der $I V .-1$ Iraction}

I,5590 gr der IV.B Fraktion wurden wie vorher verseift. Der so gewonnene Sirup war sehr schwach gelblich mit folgendem Methoxyl- 
gehalt. Es wurden licine Kristalle ausgeschieden, wenn auch dieses Produkt längere Tage im Exsiccator stehen lassen wurde.

4,108 $\mathrm{mg}$ Substanz gaben $12,044 \mathrm{mg} \mathrm{Ag}$, entsprechend $38,73 \%$ \% $\mathrm{OCH}_{3}$. $5,583 \mathrm{mg}$ Substan\% gaben $16,256 \mathrm{mg} \mathrm{AgJ}$, cntsprechend $38,46 \% \mathrm{OCH}_{3}$.

Spezifische Drehung

$$
[\alpha]_{D}^{20} \text { in Chloroform }=\frac{10,2730 \times(+\mathrm{I}, 19)}{0,5 \times 1,4653 \times 0,8999}=+18^{\circ}, 5
$$

\section{Oxydation der Trimethylmannose aus der IV.A Fraktion}

$0,8 \mathrm{gr}$ der Trimethylmannose wurden wie vorher oxydiert. Es wurde nunmehr ein viel dickerer grünlich-gelber Sirup gewonnen als bei der II. und III. Fraktion, auch hicr wurden keine Kristalle gebildet.

5, I $82 \mathrm{mg}$ Substanz gaben I3, Sot $\mathrm{mg} \mathrm{AgJ}$, entsprechend 35, $8 \% \mathrm{OCH}_{3}$. $3,260 \mathrm{mg}$ Substan? gaben $8,707 \mathrm{mg}$ AgJ, entsprechend $35,28 \% \mathrm{OCH}_{3}$.

Es wurden zum Neutralisieren von 0,1762 gy. Trimetlylmannonsäurclakton* 9,98 ccm N/ro-Natronlauge verbraucht.

\section{Verseifuns der $I V$-B Fraktion}

2,549 gr der IV.-B Fraktion wurden mit $100 \mathrm{ccm} 5 \%$ iger Salzäure wie vorher verseift. In dem sirupartigen Spaltprodulkt wurden keine Kristalle ausgeschieden.

$3,024 \mathrm{hig}$ Substaiz gaven $8,30 \mathrm{img} \mathrm{AgJ}$, enitsprechend $36,26 \% \mathrm{OCH}_{3}$. 4, $56 \mathrm{mg}$ Substanz gaben I 1,$44 ; \mathrm{mg} \mathrm{AgJ}$, entsprechend $36,38 \% \mathrm{OCH}_{3}$.

Spezifische Drehung

$$
[\omega]_{11}^{20} \text { in Chloroform }=\frac{(+0,25) \times 3}{0,25 \times 0,2584}=+11^{\circ}, 6
$$

\section{Oxydation der Trimethylnamnose** aus der IV.-B Fraktion}

$1,6679 \mathrm{gr}$ des Sirups wurden mit $20 \mathrm{ccm}$ Salpetersäure vom spez. Gew. I,20 wie vorher oxydiert. Es wurde auch hier ein grünlich-gelbes, sirupöses Produkt erhalten.

4,724 $\mathrm{mg}$ Substanz gaben 12,121 mg AgJ, entsprechend 33,89\% $\mathrm{OCH}_{3}$. $6,852 \mathrm{mg}$ Substanz gaben $17,514 \mathrm{mg} \mathrm{AgJ}$, entsprechend $33,76 \% \mathrm{OCH}_{3}$.

\footnotetext{
* in denen Trimethylmannozuckersäure vorhanden war.

** in der eine Spur Dimethylmannose vorlanden war.
} 
$0,1180 \mathrm{gr}$ und $0,263 \mathrm{r} \mathrm{gr}$ Sirup wurden mit N/10-Natronlauge titriert. Sie verbrauchten zu ihrer Neutralisierung $9,16 \mathrm{ccm}$ und 19,33 ccm Lauge.

\section{KAPITEL}

\section{Konstitumon bes Giukomannans}

Bei allen Diskussionen über Konstitutionsfragen der Cellulose und ancleren polymoren Kohlenhydraten, z. B. Stärke, Lichenin, Inulin, u. a. $\mathrm{m}$, begegnet man verschiedencn Ueberlegungen. Als Grundkörper der Cellulose stellte $\mathrm{K}$. Iless dic Formel $\left[\mathrm{C}_{5} / \mathrm{I}_{4} \mathrm{O}_{5}\right]$ auf, so dass also die Konstitution der Cellulose durch monomolekulare Glukosan-Moleküle ausgedrüclit wird. In Gegensatz zur Glukusan-Anschauung, gewann die Auffassung festere Form, danach der Grundkörper der Cellulose eine Cellobiose ist (KAKRLR, FREUDEn Konstitution der Cellulose die formel $\left[\mathrm{C}_{12} \mathrm{H}_{20} \mathrm{O}_{10}-\mathrm{H}_{2} \mathrm{O}\right]_{x}$ zukommt.

Nehmen wir also die von K. HEss aufgestellte monomolekulare Glukosantheorie für die Cellulosekonstitution als richtig an, so ergeben sich 4 Arten Trihexoien ofler Friohexsanc und daun 3 Arten Biosen oder Biosane aus Glukomaman durch Acetolye oder andere Abbauprozesse, z. B. durch Erhitzung in Bumbenröhc, durch enzymatische Wirkung, nach folgendem Schema; wemn das Glukomanan aus 2 Mol Mannose und I Mol Glukose bestelit, dann ist:

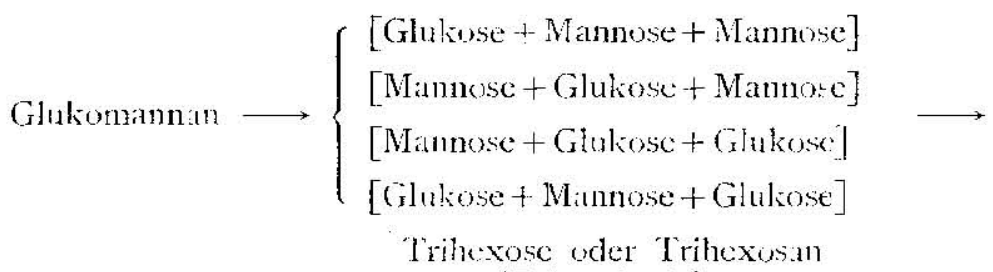

(Trisiccharid)

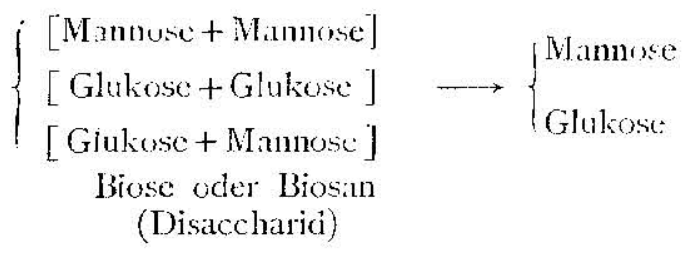

Durch Acetolyse, durch enzymatische Wirkung und durch Iir- 
hitzung mit Glyzerin in Bombenröhe auf $200^{\circ} \mathrm{C}$. wurde nur eine artige Glukomannotrihexose of cin Glukomannotriosan (Laevidulinose oder Lacviciulin) aus Glukomunnan abgespalten. Betrachtet man nun diese Tatsache, so scheint es, diss min das monomolekulare Glukosanund Mannosan-Molekül mit gleicher Stellung des Raumes als Grundkörper des Glukomannans nicht fassen kann, aber dass 2 Mol Mannose und I Mol Glukose sich in ihrem eigentlichen Raume als IBaustein zum Trisacclaricl d. h. zur Glukomannotrilhexose, vereinigen. In welcher Weise dic in Betracht kommenden Mannose- und Glukosegruppen miteinander verknüpft sind, kann man aus folgendem Schema entnehmen:

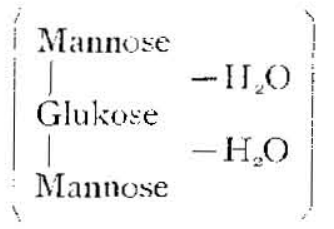

(I)

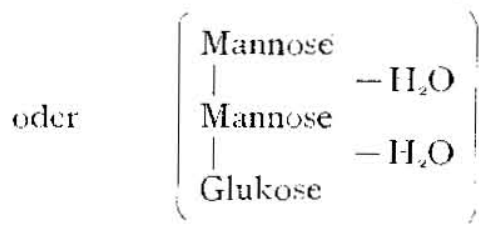

(1I)

Bei der Methylicrung des Glukomannans entsteht unter Eintreten von drei Methylgruppen das Trimethylglukomannan, das wurde bei der Hydrolyse mit methylalkohulischer Salzsäure in 2,3,4-Trimethylmannose, 2,3,6-Trimcthylmamose und 2,3,4-Trimethylglukose zerspalten. Nehmen wir clie von dem füngliedrigren Ring ausgeführte Glukose- und Mamnosekonstitution als richtig an, ergibt sich für clic Glukomannotrihexose die folgende Konstitution aus dem obigen Schemit.

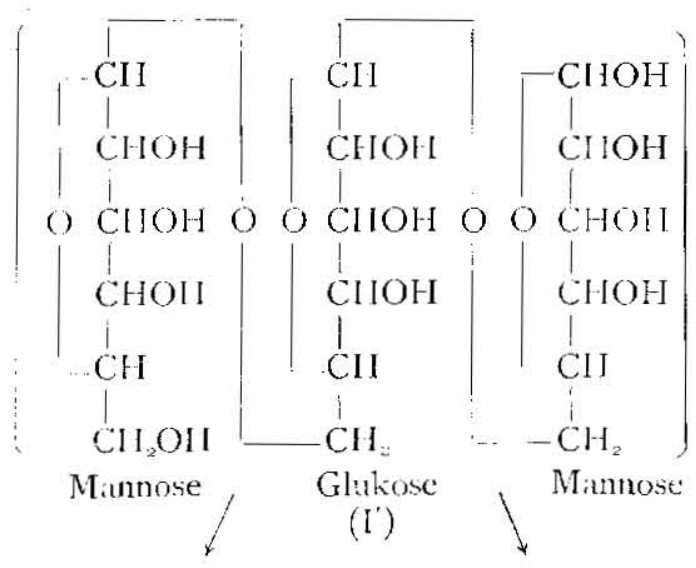




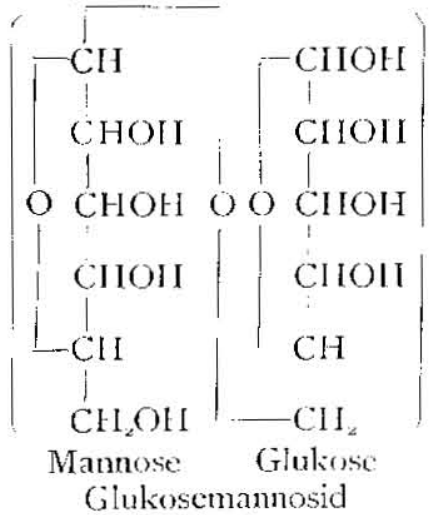

(III)

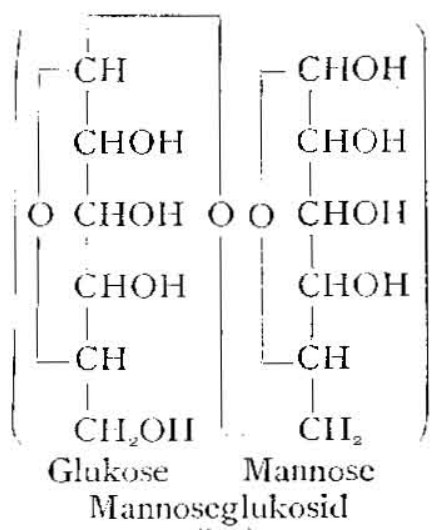

(IV)

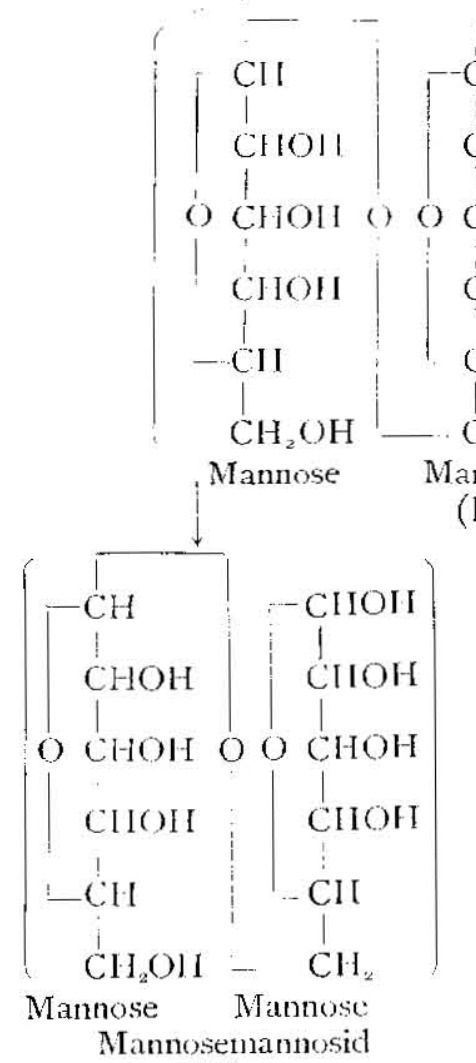

(V)

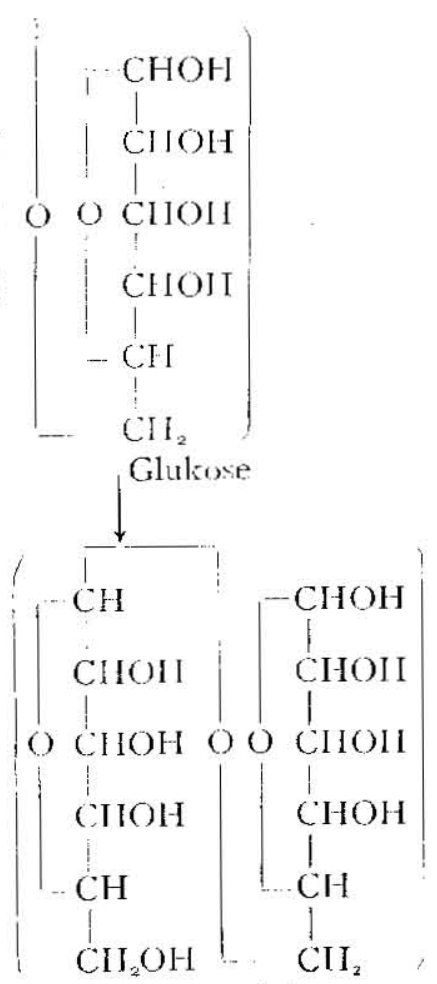

Mannose Glukose Glukosemannosie!

(VI) 
Die Acetolyste des Glukomannans ist schon über den fü Hendecaacetylglukomannotrihexose charakteristischen Zustand hinausgegangen und darüber $z u$ sehr viel weiter abgebauten Stoffen (Disacchariden) von kleineren Molekulargewicht mit höherem Acetylgehalt abgespalten worden, von deren cines (Mannosemannosid) nur die Mannose und das andere (Glukoscmannosid) I Mol Mammose und I Mol Glukose hydrolysierbar ist. Darauf erfolgt die Konstitution der Glukomannotrihexose nach den II' Schema.

Die Stellung der Mannose und der Glukose in der Glukomannotrihexose (I' oder II') ist auch noch durch weitere Versuche angefüht worden, dafür IIendekancetylglukomannotrihexose mit I vo iger Salzsäure zu Hexusedcetate gespalten warke. Man kanin die so gewonnenen I Iexoseacetate wit Methyljolid und Silberoxyd methylieren, dataus mit methylılkoholischem Ammsnik verseifen. Dabei Methylmannosid, 6Methylmethylmannosid und 6-Methylglukose nach folrondem Schema erhalten wurden.

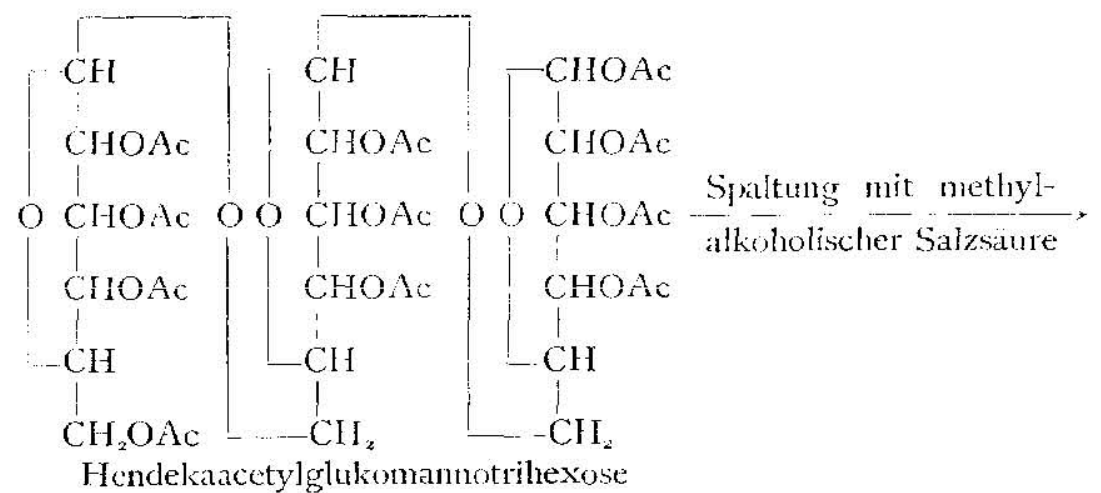

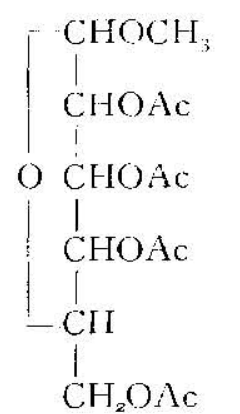

Tetraacetylmethylmannosid

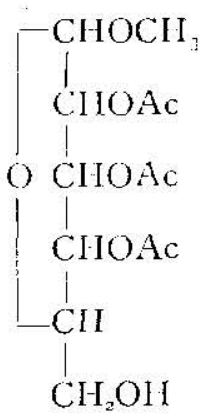

Triacetylmethylmannosid

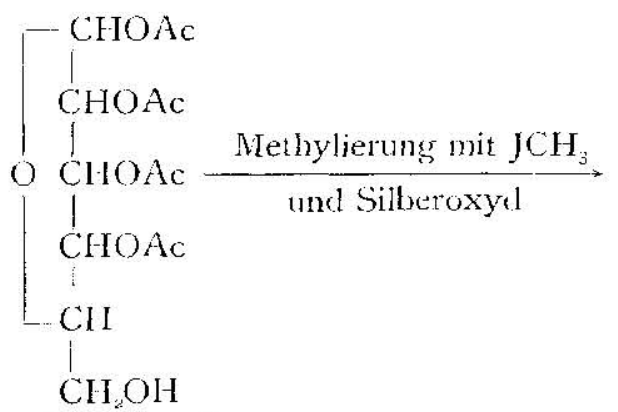

Tetracetylglukuse. 


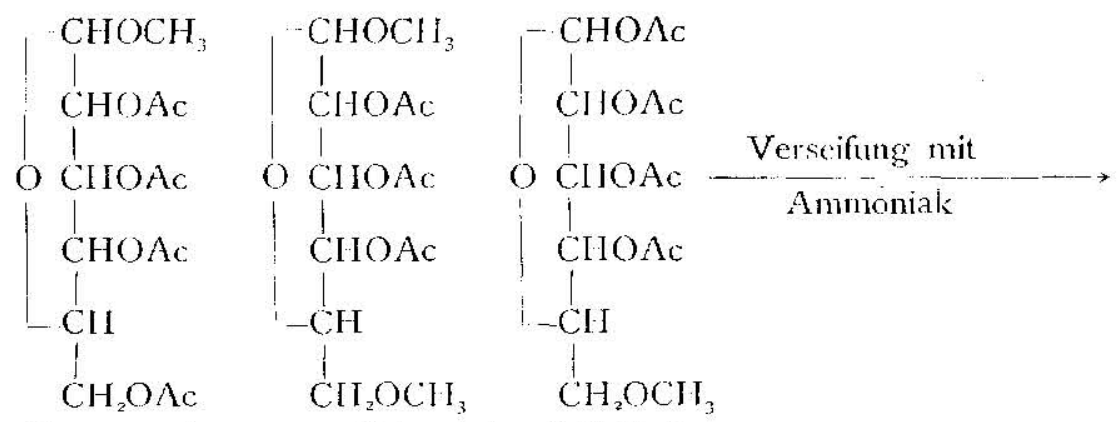

Tetraacetyl- 2, 3,4-Triactyl- 6-Methyltetramethylmannosid 6-nethyl- acetylglukose

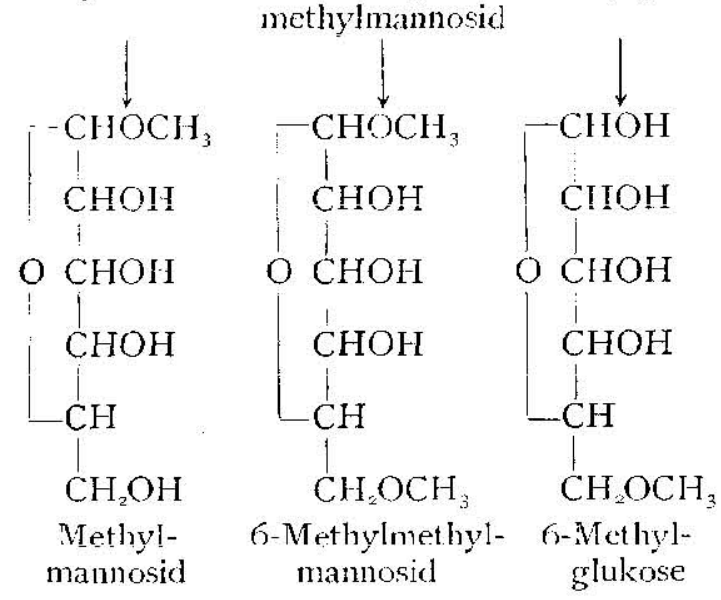

Dic Konstanten aus diesen Versuchen ergaben :

\begin{tabular}{|c|c|c|}
\hline Kristall & Sirup-1! & Sirup- $\Lambda$ \\
\hline Snup. $173^{\circ} \mathrm{C}$ & OCH, Gehall get 37,$61 ; 30,3^{i}$ & $O\left(\mathrm{H}_{3}\right.$-Gehalt gref. 21,$75 ; 21,45$. \\
\hline \multirow{5}{*}{$\left(\begin{array}{l}\text { Ausbule war shr gering, } \\
\text { kristallisierte nur eimmal. }\end{array}\right)$} & octi, Gelralt herechnef fir & 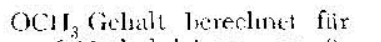 \\
\hline & 6. Wethylnctlylmamnsid 30,77 . & 6-Hethylgluliose $\quad 15$, is. \\
\hline & {$\left[{ }^{\prime}\right]_{0}^{2,}$ in Alkohol $+70^{\circ}, 0$} & {$[u]^{20}$ is All is ${ }^{\circ}$} \\
\hline & {$\left[13.1 \%\right.$ in Alkohol $+54^{3}, \mathrm{n}^{*}$} & 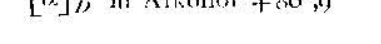 \\
\hline & 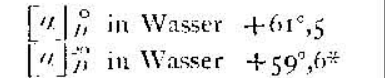 & {$[\%]_{j 1}^{20}$ in Walsser $+75^{\circ}, 5$} \\
\hline
\end{tabular}

* Endwert

Für dieses Ergebnis gibt es nur wenig stichhaltige Argumente, wir konnten daher nicht näher darauf eingehen. Aber aus der oben 
beschriebenen Acetolyse und Methylierung bestehen für die Konstitution des Glukomannans die folgenden beiden Möglichkeiten (VII und VIII).<smiles>CCC(I)C(O)C(O)C(O)C(O)CO</smiles>

Mannose<smiles>CC(C)C(O)C(O)C(O)O</smiles>

Mannose<smiles>OC(O)C(O)C(I)C(I)I</smiles>

Glukose

(VII)

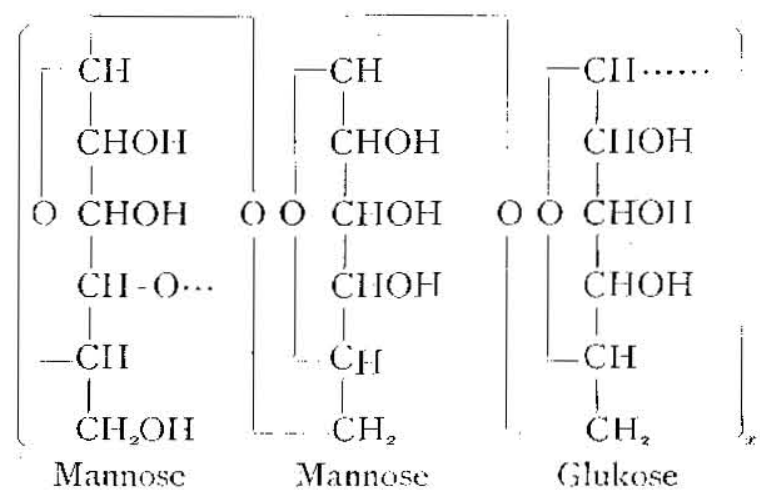

(VIII)

Gemäss der neuen Formulierung für Cellubiose und Maltose traten cliese als (VIII) Formel ein.

\section{EXPERIMENTELLLS}

\section{Sraltung der Hindekancetylglikomannotrufexose}

I 5 gr Hendekaacetylglukomannotrihexose wurden mit $180 \mathrm{gr} 1 \%$ iger absoluter methylalkoholischer Salzsäure in vier Bombenröhren 50 Stunden auf $100^{\circ} \mathrm{C}$. gespalten, hierauf weitere 50 Stunden auf $130^{\circ} \mathrm{C}$. 1)as Spaltprodukt wurcle mit Silberkarbonat noutralisicrt, mit Tierkohle 
entfärbt, dann im Vakuum eingedampft. Es ergab weder Kristalle nach Stehen im Exsiccator, noch war es im Iochvakuum destillierbar.

\section{Methyleierung der Hexosencetate}

$6,6 \mathrm{gr}$ dieses Spaltproduktes wurden in $15 \mathrm{ccm}$ Methyljodid aufgelöst, dann I $2 \mathrm{gr}$ Silberoxyd hinzugefügt uncl am Rückflusskübler ausgekocht. Nach viclmaliger Methylierung wurcle das überllüssige Methyljodid abdestilliert, und der Rückstand mit Methylalkolol ausgezogen. Man gewann cinen hellbraunen kicberigen Sirup; Ausbeute $=7,2 \mathrm{gr}$.

\section{Verseitung DEs Siruts}

Dieses methylierte Hexoseacetat wurde in Methylalkohol aufgelöst, dann mit drei fachem methylalkoholischem Ammoniak in Eisschrank 18 Stunden aufbewahrt. Das Reaktionsprodukt wurde im Vakumm eingedickt, darauf entfäbt mit wenig Tierkohle, dann wieder eingedampft unter vermindertem Druck und der Rückstand im Vakuum über Phosphorsäureanhydrid getrocknet. Es wurde in absolutem Alkohol aufgelöst, dazu wasserfreicr Aether hinzugefügt, dabei liessen wir Methylmannosid als voluminöse Fällung isolieren. Die Fällung wurde nur cinmal mit Alkohol und Ligroin auskristallisicrt, Smp. $173^{\circ} \mathrm{C}$. Leider war die Ausbeute z.u gering, als class wir aus ihrem Auftreten Konstanten in bezug auf den Methoxylgehalt und die spezifische Drchung (les Methylmannosids ziehen durften. $\Lambda$ ber es war sicher Methylmannosid.

Die Mutterlauge war mit weiterem Aether in der Schale viskos geworden. Wir haben dicsen Teil von der klaren ätherischen Lösung getrennt und die beiclc Lösungen im Vakum über I'hosphorsäureanhyclrid getrocknet.

Sirup $A$, der aus klarer Lösung gewonnen wurde, ergab:

5,309 $\mathrm{mg}$ Substanz gaben 8,74I mg $\Lambda \mathrm{gJ}$, entsprechend $21,75 \% \mathrm{OCH}_{3}$.

$3,476 \mathrm{mg}$ Substanz gaben $5,646 \mathrm{mg} \mathrm{AgJ}$, entsprechend 21,45 \% $\mathrm{OCH}_{3}$.

Sperifische Drehung

$$
\begin{aligned}
& {\left[{ }^{\prime \prime 2}\right]_{n}^{20} \text { in Alkohol }=\begin{array}{l}
(+2,25) \times 6 \\
0,5 \times 0,3107
\end{array}=+86^{\circ}, 0} \\
& {[\alpha]_{3}^{* 0,} \text { in Wasser }=\frac{(+0,95) \times 6}{0,25 \times 0,3004}=+75^{\circ}, 8}
\end{aligned}
$$


Sirup B, der aus viskoser Lösung gewonnen wurke, ergab:

$5,405 \mathrm{mg}$ Substanz giben $12,523 \mathrm{mg} \mathrm{AgJ}$, entsprechend $30,6 \mathrm{t} \% \mathrm{OCII}_{3}$. 5,006 mg Substanz gaben $11,512 \mathrm{mgr} \Lambda \mathrm{gl}$, entsprechend $30,38 \%$ OCl $\mathrm{l}_{3}$.

Spezifische Drehung

$[\alpha]_{D}^{20}$ in Alkohol nach io Minuten $=\frac{(+1,75) \times 6}{0,5 \times 0,209^{8}}=+70^{\circ}, 0$

$[\alpha]_{z}^{20}$ in Alkohol mach 24-48 Stunclen $=\frac{(+1,60) \times 6}{0,5 \times 0,2998}=+54^{\circ}, 0$

$[x]^{20} ;$ in Wasser nach io Minuten $=\frac{(+1,55) \times 6}{0,5 \times 0,3022}=-61^{\circ}, 5$

$[a]_{D}^{20}$ in Wasser nach $244^{8}$ Stunden $=\frac{(+1,50) \times 6}{0,5 \times 0,3022}=+59^{\circ}, 6$ 